\title{
Application of aluminum triiodide in organic synthesis
}

\author{
Juan Tian and Dayong Sang* \\ Jingchu University of Technology, Jingmen, Hubei 448000, China \\ E-mail:sangdy@gmail.com
}

DOI: http://dx.doi.org/10.3998/ark.5550190.p009.309

\begin{abstract}
The multifaceted reactivity of aluminum triiodide $\left(\mathrm{AlI}_{3}\right)$ is reviewed. The oxophilic character of the Lewis acid enables the formation of coordination complexes with esters, ethers, oxiranes, diols, $N$ oxides, and sulfoxides that decompose spontaneously to afford acids, alcohols and olefins via ester and ether cleavage, deoxygenation of oxiranes, and deoxydehydration of diols, respectively. As an iodide ion source and hydrogen iodide precursor, the reagent allows iodination and reduction of $N$ oxides, sulfoxides and azides as well as hydroiodination of alkenes and alkynes. Aluminum enolates, generated by treatment of $\alpha$-haloketones with $\mathrm{AlI}_{3}$, provide accesses to $\beta$-hydroxy ketones, 1,5 diones, and $\beta$-iodo Morita-Baylis-Hillman esters.
\end{abstract}

Keywords: Aluminum triiodide, ester cleavage, ether cleavage, hydroiodination, deoxygenation, deoxydehydration, aluminum enolate

\section{Table of Contents}

1. Introduction

2. Ester Cleavage

2.1 Scope of substrates

2.2 Application in syntheses of pharmaceutical targets

2.3 Other applications

3. Ether Cleavage

3.1 Regioselectivity

3.2 Solvent effects

3.3 Deprotection of alkyl aryl ethers

3.4 Exhaustive demethylation

3.5 Partial demethylation

3.6 Removal of methoxymethyl, methoxyethyl and other phenolic protecting groups

3.7 Application of $\mathrm{AlI}_{3}$-TBAI in exhaustive demethylation

4. Deoxygenation and Deoxydehydration 
4.1 Deoxygenation of oxiranes

4.2 Deoxydehydration of diols

4.3 Deoxygenation of sulfoxides and sulfonyl chlorides

4.4 Deoxydehydration of oximes

4.5 Deoxygenation of $N$-arylnitrones, azoxyarenes, and $N$-heteroarene $N$-oxides

5. Iodination

5.1 Halide exchange reaction

5.2 Iodination of allylic, benzylic, and tertiary alcohols

5.3 Hydroiodination of alkenes and alkynes

5.4 Electrophilic iodination of secondary and tertiary alkanes

6. Deprotection of Ketals

7. Reduction of Quinones

8. Reduction of Azides

8.1 Reduction of azides to primary amines

8.2 Reduction of azides to secondary amines

9. Aluminum Enolate Mediated Reactions

9.1 Generation of aluminum enolates

9.2 Dehalogenation of $\alpha$-haloketones

9.3 Michael addition

9.4 Preparation of Morita-Baylis-Hillman esters

9.5 Acetonitrile adduction

10. Friedel-Crafts Acylation and Alkylation

11. Miscellaneous

11.1 Preparation of selenocarbonyl fluorides

11.2 Triene electrocyclization

11.3 Preparation of a perfluorophthalocyanine

11.4 Formation of frustrated Lewis pairs with hindered Lewis bases

12. Preparation of the Reagent

12.1 In situ preparation of $\mathrm{AlI}_{3}$

12.2 Preparation of crystalline $\mathrm{AlI}_{3}$

13. Conclusions

14. Acknowledgements

15. References

\section{Introduction}

Efficient transformations of organic functional groups using conveniently available and inexpensive reagents under mild reaction conditions represent a challenging demand of current organic syntheses. Aluminum triiodide $\left(\mathrm{AlI}_{3}\right)$, to this end, has emerged as a non-hazardous and easy to handle reagent toward a broad spectrum of functional groups. ${ }^{1}$ 
$\mathrm{AlI}_{3}$ exists as a dimer $\left(\mathrm{Al}_{2} \mathrm{I}_{6}\right)$ in the solid state and in aprotic apolar solvents, whereas planar monomer has also been observed in gas phase. ${ }^{2}$ The reagent serves as an oxophilic Lewis acid ${ }^{3,4}$ and coordinates with Lewis base ligands to form tetrahedral complexes. ${ }^{5}$ Due to the unique oxophilicity and Lewis acidity nature, $\mathrm{AlI}_{3}$ has been extensively applied in organic synthesis.

\section{Ester Cleavage}

The oxophilic character of $\mathrm{AlI}_{3}$ enables coordination with esters by the Lewis acidic center $\left(\mathrm{Al}^{3+}\right)$ through the formation of donor-acceptor complexes. The complexes undergo cleavage at ambient temperature, and their decomposition could be accelerated at elevated temperatures. ${ }^{6-8}$ The cleavages were complete within 0.5 hour and afforded corresponding acids in moderate to high yields. ${ }^{9}$ Such kind of non-hydrolytic cleavage of esters features the advantage of avoiding strong acidic or basic conditions and is suitable for substrates containing sensitive functional groups. The transformation can be accessed alternatively with trimethyltin hydroxide, ${ }^{10}$ lithium iodide, ${ }^{11}$ lithium 1-propanethiolate, ${ }^{12}$ lithium bromide, ${ }^{13}$ and trimethylsilyl iodide (TMSI). ${ }^{14}$

\subsection{Scope of substrates}

The ester cleavage method was applied to a variety of substrates (1) including aromatic ester (1a), $\alpha, \beta$-unsaturated esters (1b, 1c), halogen-containing ester (1d), and aliphatic ester (1) $)$, see scheme $1 \mathrm{~A}{ }^{9}$

When the method was applied to phenyl esters, however, ester cleavage was superceded by Fries rearrangement. For example, a mixture of benzophenols $(\mathrm{p} / \mathrm{o}=2)$ were obtained in moderate yields after treatment of phenyl benzoate with $\mathrm{AlI}_{3} .{ }^{9}$

\subsection{Application in syntheses of pharmaceutical targets}

The method has been applied in syntheses of pharmaceutical targets: (I) A class of potent cholecystokinin $\mathrm{B}(\mathrm{CCK}-\mathrm{B})$ receptor antagonists were accessed through $\mathrm{AlI}_{3}$ induced ester cleavage. The cleavages of $\mathbf{4 a}$ and $\mathbf{4 b}$ were complete after refluxing in acetonitrile for several hours with $\mathrm{AlI}_{3}$ and afforded 1,5-disubstituted benzodiazepines (6a and $6 \mathbf{b}$ ) in low yields (scheme 1B). ${ }^{15,16}$ Trace amount of meta-substituted phenol (7) was isolated, and was formed apparently through ether cleavage. ${ }^{17}$ (II) Hexahydropyrrolo[1,2-c] imidazolones (9a and 9b), a family of effective MDM2-p53 interaction inhibitors and useful drug candidates for treating cancer, were prepared by $\mathrm{AlI}_{3}$ induced cleavage of $\mathbf{8 a}$ and $\mathbf{8 b}$ in virtually quantitative yields. Microwave irradiation was used to assist the cleavage, and the conversions were complete efficiently in 15 30 minutes (scheme 1C). ${ }^{18}$

\subsection{Other applications}

An organic-inorganic hybrid material with free carboxylic groups over the surface was prepared by $\mathrm{AlI}_{3}$ induced ester cleavage of corresponding methyl carboxylate groups. Hydrosilylation of 11 with triethoxysilane (10) gave 12. Sol-gel co-condensation between 12 and tetraethoxysilane (TEOS) afforded nanohybrid material 13. The surface of 13 was modified by $\mathrm{AlI}_{3}$ to release terminal carboxylic groups (14) for uptake of lanthanide cations (Scheme 1D). ${ }^{19}$ 


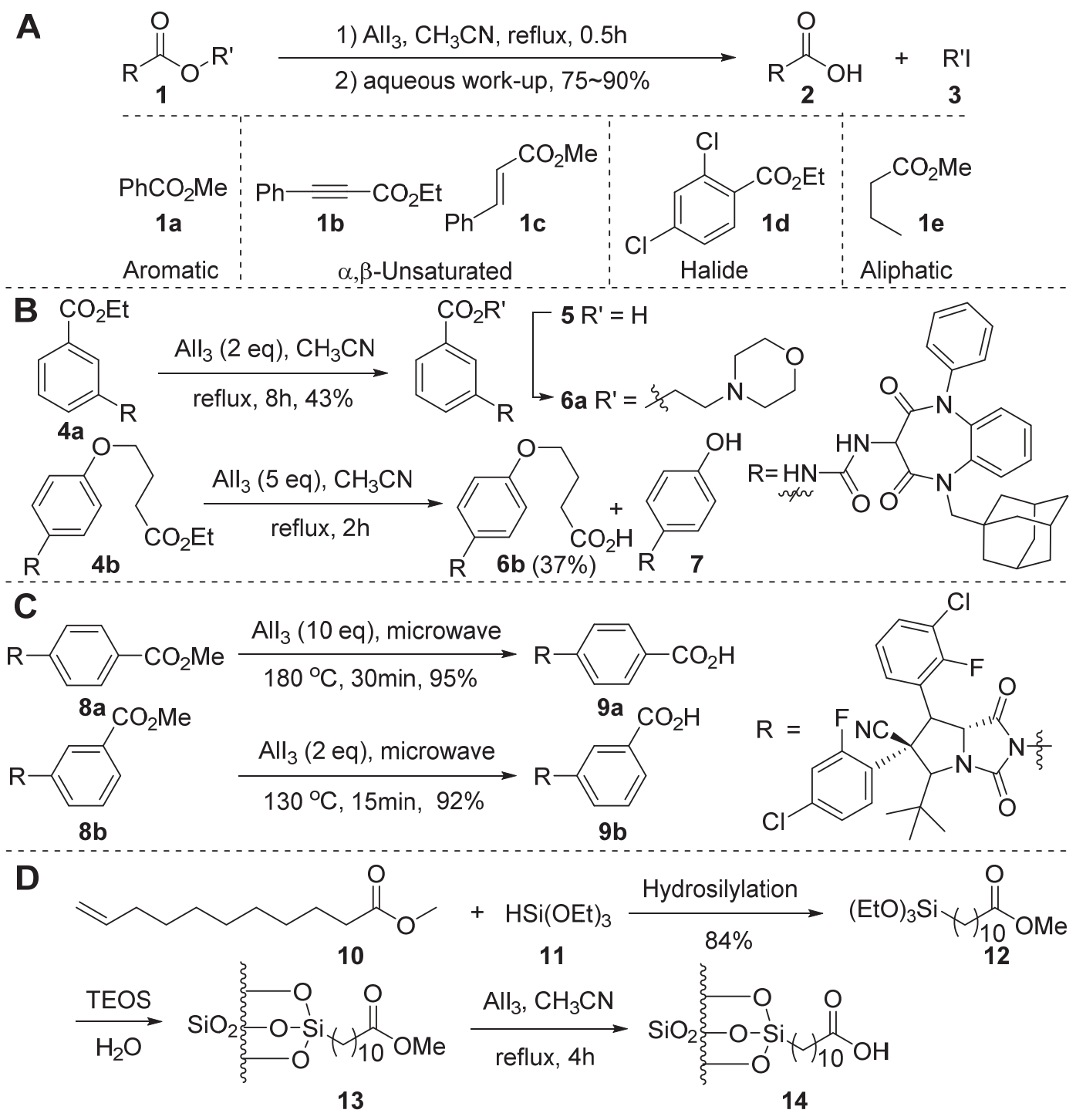

Scheme 1. $\mathrm{All}_{3}$ induced non-hydrolytic ester cleavage. A: Scope of substrates; B: syntheses of CCK-B receptor antagonists; C: syntheses of inhibitors for MDM2-p53 interactions; D: surface modification of an ester terminated silica nanohybrid.

\section{Ether Cleavage}

Ethers (15) tend to form ethereal-AlI 3 complexes (16) with $\mathrm{AlI}_{3}$ as a result of its unique oxophilicity. The complexes underwent noticeable ether cleavages (Figure 1A) that afforded alcohols (18) and alkyl iodides. For example, methyl iodide, ethyl iodide and 4-iodobutanol were observed during decomposition of anisole, ethyl ether ${ }^{20}$ and tetrahedronfuran complexes, respectively. ${ }^{6}$ Ether cleavage reaction was applied in deprotection of alkoxybenzene, 1,3-benzodioxole, and alkylthiophenyl alkyl ether to afford corresponding phenol, pyrocatechol and alkylthiophenol, respectively. ${ }^{21}$ 


\subsection{Regioselectivity}

Cleavage of ethers is commonly carried out with Brønsted acids (such as $\mathrm{HI}$-anhydride, ${ }^{22} \mathrm{HBr}$ $\mathrm{HOAc}^{23}$ or $\mathrm{HCl}$-pyridine ${ }^{24}$ ) or Lewis acids (boron, silicon and metal halides). $\mathrm{AlI}_{3}$ showed an inversed regioselectivity in ether cleavage compared to boron and silicon halides when a dialkyl ether group and an alkyl aryl ether group coexisted in a substrate. For example when 19 was cleaved by $\mathrm{AlI}_{3}$, phenol (20) was the exclusive product (Figure 1B). By contrast, boron chloride $\left(\mathrm{BCl}_{3}\right)$, boron bromide $\left(\mathrm{BBr}_{3}\right)$, TMSI and trichlorosilyl iodide preferentially cleaved the aliphatic ether bond and gave 2-phenoxy ethanol (21) in moderate yields. ${ }^{25}$

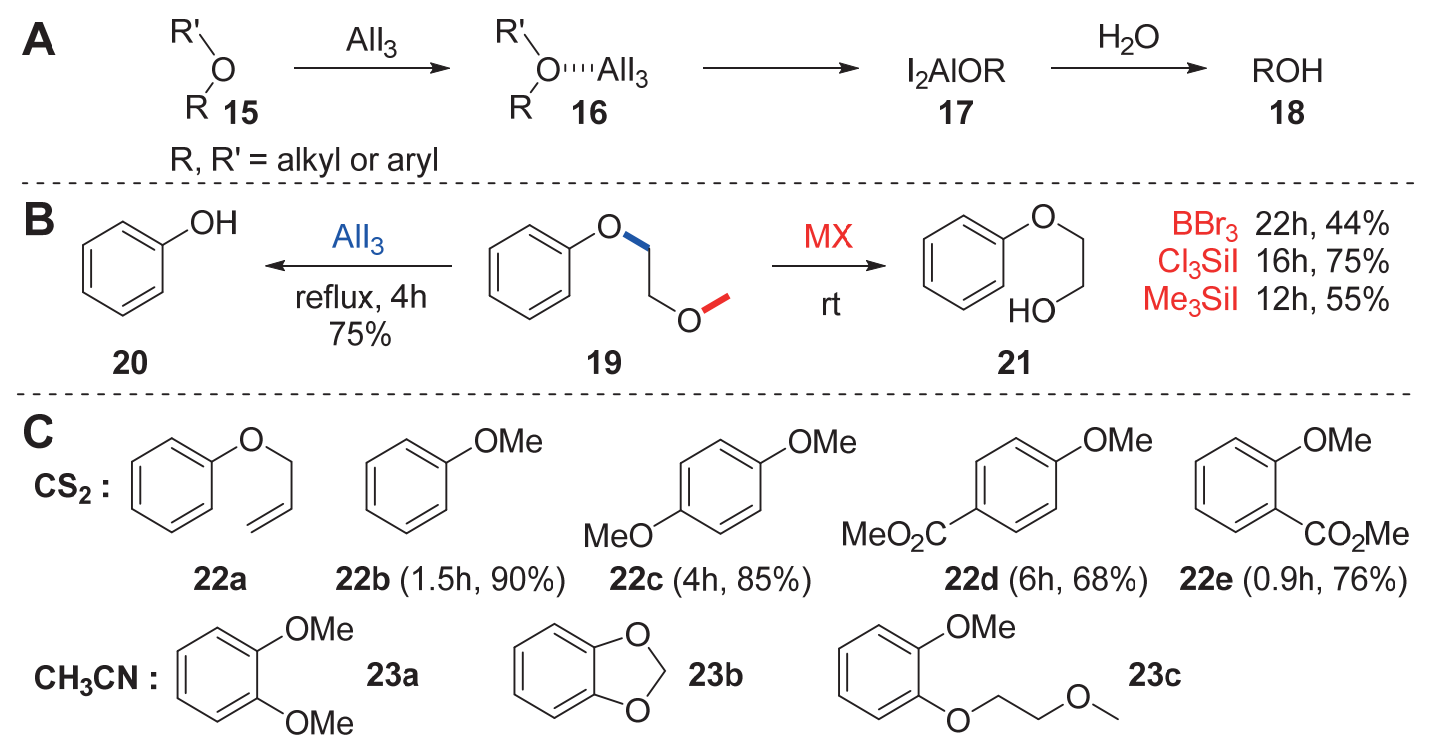

Figure 1. $\mathrm{AlI}_{3}$ catalyzed cleavage of ethers. A: formation and decomposition of ethereal- $\mathrm{AlI}_{3}$ complexes; B: regioselectivities induced by variant Lewis acids; C: solvent effects.

\subsection{Solvent effects}

Deprotection of alkyl aryl ethers (22a 22e) can be accessed more efficiently in carbon disulfide $\left(\mathrm{CS}_{2}\right)$ then in acetonitrile. Surprisingly, cleavage of pyrocatechol derived ethers (23a $\left.\sim 23 \mathrm{c}\right)$ turned faster in acetonitrile (Figure 1C). Meanwhile, it was noted that the ethereal cleavage of 22d was slower than its $o$-isomer (22e). The conversion proceeded possibly via chelation mechanism featuring neighboring group participation. Accordingly, demethylation of 22c occurred in a stepwise manner, and $p$-methoxyphenol was isolated. ${ }^{25,26}$

\subsection{Deprotection of alkyl aryl ethers}

$\mathrm{AlI}_{3}$ was applied in deprotection of phenolic ethers to afford several phenol intermediates, as depicted in scheme 2. Demethylation of $\mathbf{2 4}$ with $\mathrm{AlI}_{3}$ afforded 2-formyl-6-naphthol (25) in almost quantitative yield (Scheme 2A). ${ }^{27} \mathbf{2 8}$ is a useful performance enhancement additive for engineering thermoplastics such as polycarbonate. A convenient preparation of $\mathbf{2 8}$ was accomplished by $\mathrm{AlI}_{3}$ mediated demethylation of 27. Failed deprotection attempts include treatments of the ether with $\mathrm{BBr}_{3}$ and TMSI (Scheme 2B) ${ }^{28,29}$ Deprotection of 29 by $\mathrm{AlI}_{3}$ in refluxing $\mathrm{CS}_{2}$ furnished 5-allyl 
resorcinol (30). 30 was further transformed into an organoirridium catalyst loaded on silica (31) for converting low molecular weight alkanes into higher molecular weight fuel (Scheme 2C). ${ }^{30}$ As an inhibitor of $17 \alpha$-hydroxylase- $\mathrm{C}_{17,20}$-lyase and $5 \alpha$-reductase for treatment of hormone-dependent prostatic carcinoma, $\mathbf{3 3}$ was obtained as a mixture of stereoisomers $(E / Z=91: 9)$ by demethylation of 32 with $\mathrm{AlI}_{3}$ in $\mathrm{CS}_{2}$ (Scheme 2D). ${ }^{31}$ 1,5-Dialkyl-1,5-benzodiazepine (35), a potent CCK-B receptor antagonist, was synthesized by demethylation of ether $\mathbf{3 4}$ with $\mathrm{AlI}_{3}$ in reflux acetonitrile. Alhough the transformation was sluggish, a large excess of $\mathrm{AlI}_{3}$ furnished the deprotection in moderate yield (Scheme 2E). ${ }^{32}$ The method was applied in syntheses of four coumarin analogues (39 42) applicable to organic light emitting displays as fluorescent dyes. Key intermediate 3hydroxytriphenylamine (38) was prepared in a two-step procedure: Ulmann coupling of iodobenzene and $m$-anisidine (36) furnished anisole 37; demethylation of 37 with $\mathrm{AlI}_{3}$ afforded $\mathbf{3 8}$ in $93 \%$ yield (Scheme $2 \mathrm{~F}){ }^{33}$

\subsection{Exhaustive demethylation}

$\mathrm{AlI}_{3}$ was applied in syntheses of several naturally occurring phenols (Scheme 3). (I) Anacardic acids (44), a class of salicylic acids bearing a long alkyl chain, were achieved by demethylation of relevant ethers $(\mathbf{4 3}$ and $\mathbf{4 6})$. The substrates were refluxed with $\mathrm{All}_{3}$ in acetonitrile for 0.5 hour to complete the deprotection and afforded $\mathbf{4 4}$ in moderate to high yields (Scheme 3A). For two substrates with $(8 Z, 11 Z)$-aliphatic substituent, limonene was used as hydrogen iodide (HI) scavenger. ${ }^{34}$ (II) Plumbagic acid (48) was prepared in $77 \%$ yield by exhaustive demethylation of ether 47 with $\mathrm{AlI}_{3}$. The conversion was complete in 0.5 hour in refluxing acetonitrile. ${ }^{35}$ It is noteworthy that the generation of $\mathrm{I}_{2}$ complicated the work-up (Scheme 3B). ${ }^{36}$ (III) Elliptinone (51), a biaryl natural product, was achieved by exhaustive deprotection of a 2,2'-binaphthol (BNAP, 50) followed by air oxidation. The BNAP was synthesized by tin tetrachloride $\left(\mathrm{SnCl}_{4}\right)$ mediated oxidative coupling of $\alpha$-naphthol (49), see Scheme 3C. ${ }^{37}$ Deprotection of such 1,4dimethoxybenzene is typically achieved by cerium ammonium nitrate (CAN) mediated oxidation. ${ }^{38-}$ ${ }^{39}$ (IV) In a similar manner ( \pm )-plumbazeylanone (54), a trimer of naphthoquinone, was achieved by exhaustive demethylation of ether $\mathbf{5 3}$ followed by air oxidation in $65 \%$ yield (Scheme 3D). ${ }^{40}$ (V) Resveratrol (56b) and its derivatives such as oxyresveratrol (56c) and piceatannol (56d) were obtained by exhaustive deprotection of related phenolic methyl ethers (55). The transformations were complete after 3 hours of refluxing in acetonitrile, and afforded polyphenols (56a $\sim 56 \mathbf{d})$ in 68 83\% yields. ${ }^{41-43}$ Surprisingly, $E$-stilbenes were obtained after treatment of $Z$-stilbenes with $\mathrm{AlI}_{3}$ (Scheme 3E). ${ }^{44}$ Conjugation of $Z$-4-styrylphenolates, a reactive species derived from 4-methoxystilbenes, may account for the $E / Z$ stereoisomerization. 

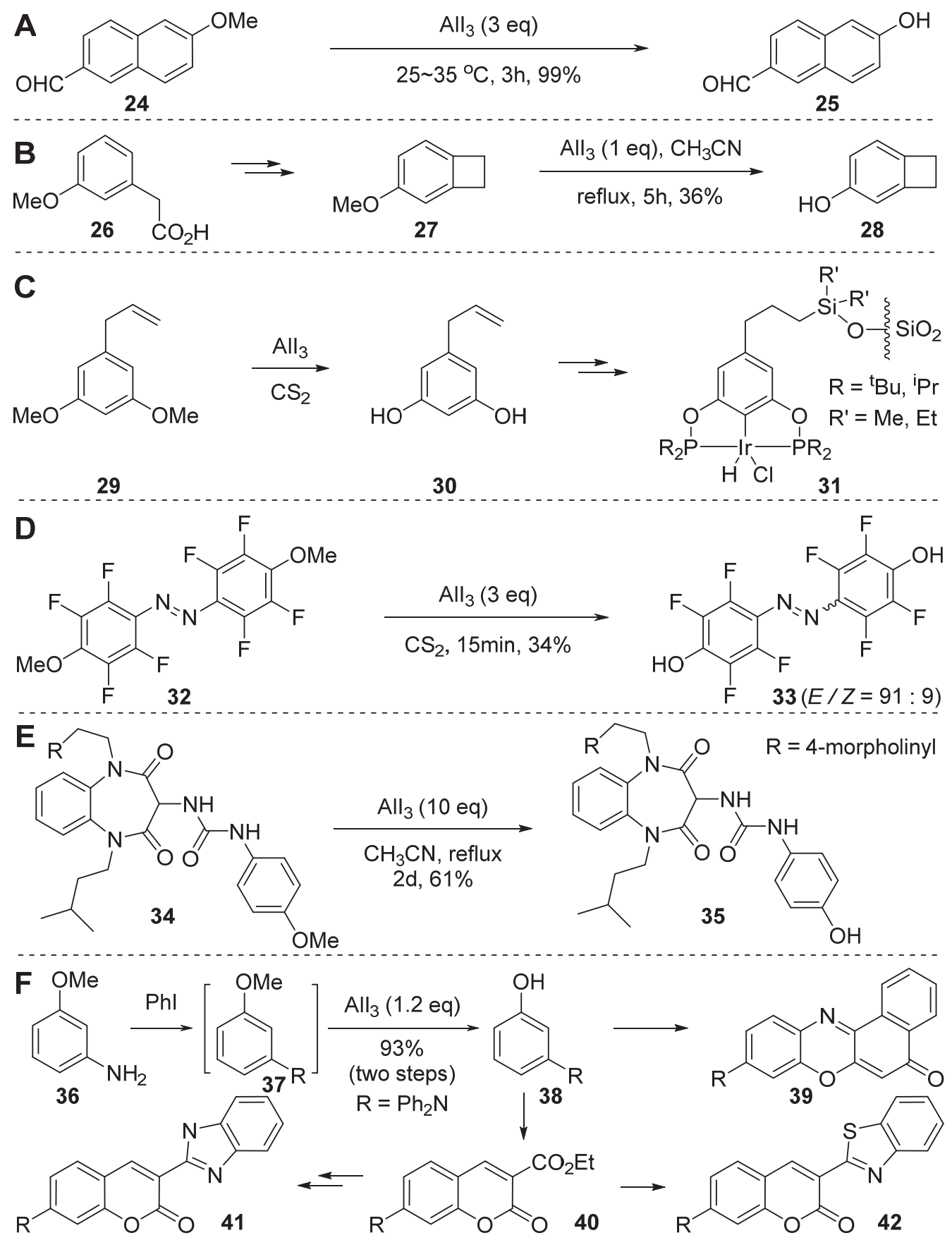

Scheme 2. Application of $\mathrm{AlI}_{3}$ in deprotection of phenolic ethers. A: 2-Formyl-6-naphthol; B: 4hydroxybenzocyclobutane; C: iridium catalyst intermediate; D: $17 \alpha$-hydroxylase-C17,20-lyase and $5 \alpha$-reductase inhibitor 4,4'-dihydroxyoxtafluoroazobenzene; E: CCK-B receptor antagonist 1,5dialkyl-1,5-benzodiazepine; F: OLED material intermediate. 


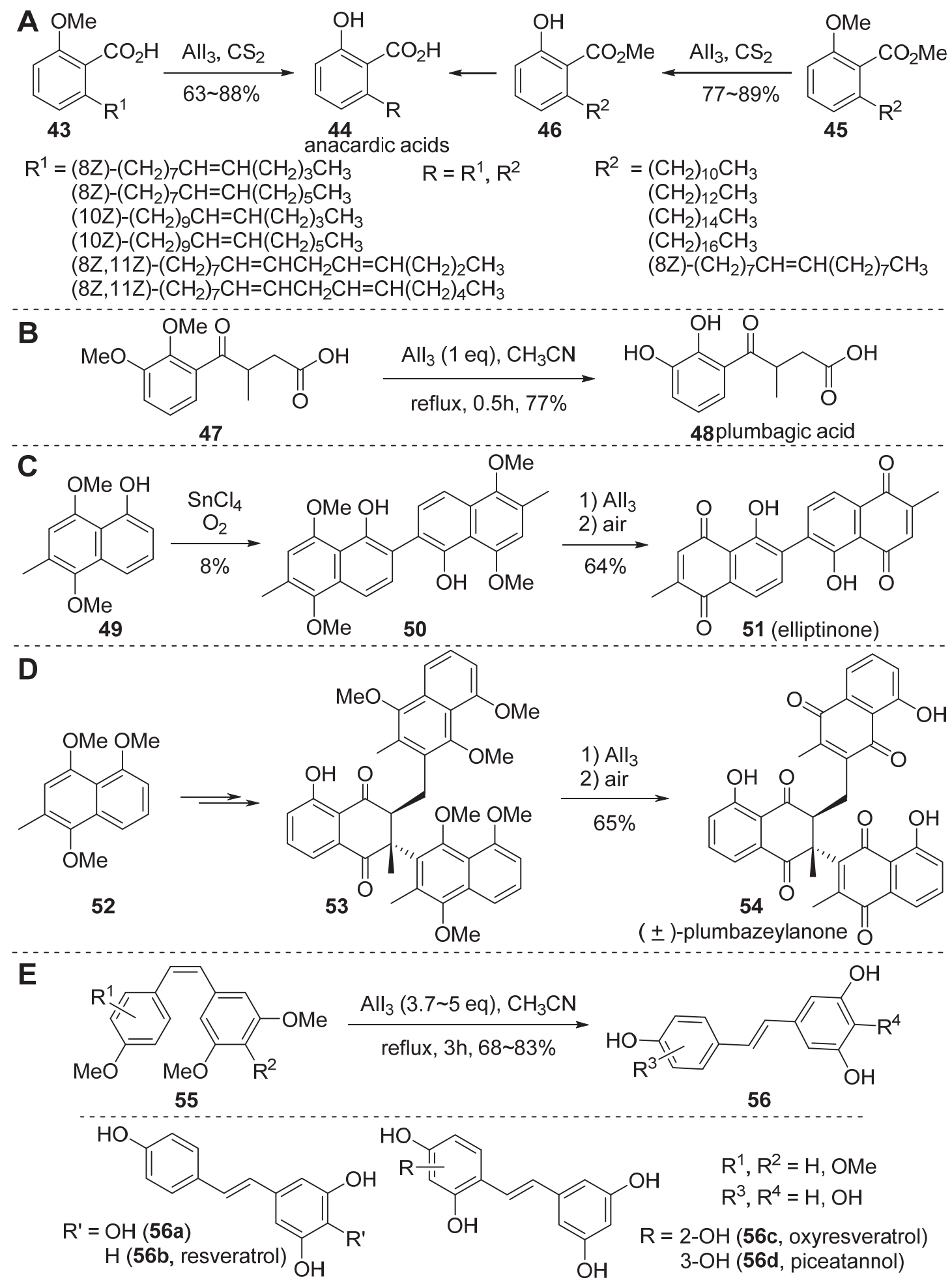

Scheme 3. Application of $\mathrm{AlI}_{3}$ in syntheses of phenolic natural products. A: Anacardic acids; B: plumbagic acid; C: elliptinone; D: ( \pm )-plumbazeylanone; E: resveratrol analogues.

It should be noted, however, that slight excess $\mathrm{AlI}_{3}$ is needed for successful exhaustive demethylation; otherwise partial demethylation may occur. For example deprotection of 3,4',5- 
trimethoxystilbene $(15 \mathrm{mmol})$ by $\mathrm{AlI}_{3}(36.9 \mathrm{mmol}, 2.46 \mathrm{eq})$ in refluxing acetonitrile afforded $\mathbf{5 6} \mathbf{b}$ in $15 \%$ yield. ${ }^{45-47}$ Apparently, failure to remove HI constitutes an factor for the low yield.

\subsection{Partial demethylation}

As mentioned above, insufficient $\mathrm{AlI}_{3}$ leads to partial demethylation. In the case of isolable intermediates, regioselective demethylation may be accessed. For example, after treating deoxyschizandrin (57) with $\mathrm{AlI}_{3}(0.3 \mathrm{eq})$ in acetonitrile for 2 hours under reflux, several intermediates (58) including schisanhenol were separated (in low yields) by preparative thin layer chromatography (Scheme 4A). ${ }^{48}$
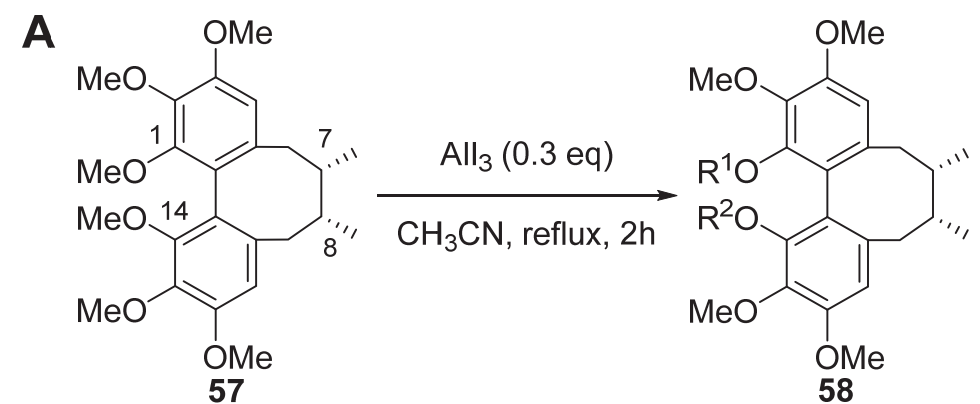

$$
\begin{aligned}
& R^{1}=H, R^{2}=M e \\
& R^{1}=M e, R^{2}=H \\
& R^{1}=R^{2}=H, \text { schisanhenol }
\end{aligned}
$$<smiles>[B-]c1ccc(Nc2ncnc3cc(OC)c(OC)cc23)cc1Cl</smiles>

59

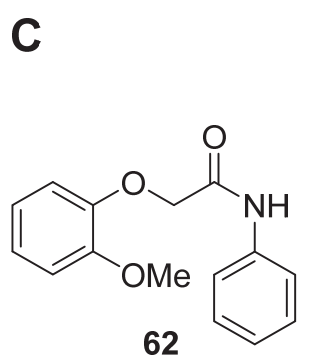

$\mathrm{All}_{3}(2.4 \mathrm{eq})$

$\mathrm{PhSH}(2 \mathrm{eq})$

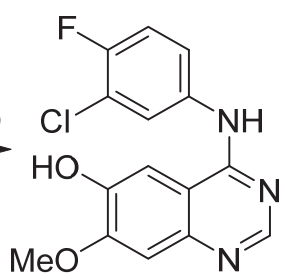

60<smiles>COc1cc2ncnc(Nc3ccc(F)c(Cl)c3)c2cc1OCCCN1CCOCC1</smiles>

61 gefitinib

(-.... -

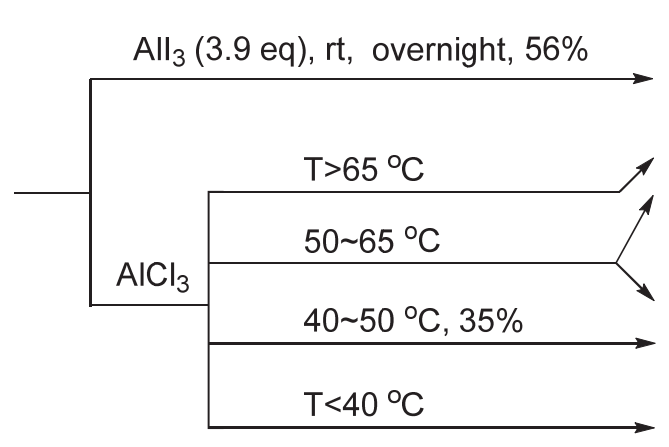

Scheme 4. Regioselective demethylation. A: Deprotection of deoxyschizandrin by $\mathrm{AlI}_{3} ; \mathrm{B}: \mathrm{PhSH}$ promoted demethylation of gefitinib intermediate; C: comparisons between $\mathrm{AlI}_{3}$ and $\mathrm{AlCl}_{3}$ in deprotection of 2-(2-methoxyphenoxy)- $N$-phenylacetamide.

The oxophilic character of $\mathrm{AlI}_{3}$ could be tuned by thiophenol ( $\left.\mathrm{PhSH}\right)$. Thiols and sulfides alone are effective for dealkylation of alkyl aryl ethers. ${ }^{49}$ Reagent combinations of aluminum halidesthiols are useful for demethylation of aliphatic and aromatic methyl ethers. ${ }^{50}$ In a concise route to gefitinib (61), 6,7-dimethoxyquinazoline (59) was regioselectively demethylated to give $\mathbf{6 0}$ by the 
action of $\mathrm{PhSH}$ and $\mathrm{AlI}_{3}$ in $84 \%$ yield (Scheme $\left.4 \mathrm{~B}\right){ }^{51}$ The method could not be extended to aldehydes due to the formation of hemithioacetals. ${ }^{52}$

Selectivive deprotection of $\mathbf{6 2}$ was accomplished with $\mathrm{AlI}_{3}$ (Scheme 4C). Complicated temperature effects were observed when aluminum trichloride $\left(\mathrm{AlCl}_{3}\right)$ was used. The desired phenol 64 was not obtained below $50{ }^{\circ} \mathrm{C}$. Above $65{ }^{\circ} \mathrm{C}$, demethylation proceeded in poor yields. The deprotection was improved by the use of $\mathrm{AlI}_{3}$ that afforded 64 in $56 \%$ yield after stirring overnight at room temperature. ${ }^{53}$

\subsection{Removal of methoxymethyl, methoxyethyl and other phenolic protecting groups}

$\mathrm{AlI}_{3}$ is suitable for removal of aliphatic protecting groups from ethers to release (phenolic) hydroxyl groups (Scheme 5). (I) A synthetic route to (-)-carbovir (68) involved the cleavage of methoxyethyl (MOE) group from 65 (Scheme 5A). Deprotection by Brønsted acids was unsuccessful. ${ }^{54}$ After treating 65 with $\mathrm{AlI}_{3}$ in acetonitrile for 2 hours under reflux, the deprotection was complete. The purification, however, was unsatisfactory due to aluminum salt contamination. Hence the intermediate was used directly in the next step, and the yield was $13 \%$ over two steps. (II) $1 \alpha, 25$ Dihydroxy-19-norvitamin $\mathrm{D}_{3}$ is a functional vitamin $\mathrm{D}$ metabolite. Syntheses of two analogues (72 and 73) of this metabolite involved the removal of a methoxymethyl (MOM) group from intermediate $\mathbf{7 0}$ (Scheme 5B). Attempts to furnish the deprotection using hydrogen chloride/isopropanol, trifluoroacetic acid/dichloromethane (DCM), lithium boron tetrafluoride/acetonitrile, trimethylsilyl bromide/DCM and trityl boron tetrafluoride/DCM had failed; butylthiol/magnesium bromide afforded $\mathbf{7 1}$ in low yield. The best reagent selected for the deprotection was $\mathrm{AlI}_{3}$. The reaction proceeded smoothly under a mild condition and afforded 71 in $71 \%$ yield. Biological activity of the analogues were 2 3 orders or magnitude lower in vitro then $1 \alpha, 25$-dihydroxy-19-norvitamin $\mathrm{D}_{3} \cdot{ }^{55-57}$ (III) MOE was attached to a diarylmethane scaffold (74) for additional coordinations to reactive lithium species and hence for improved enantiomeric excess (75) in asymmetric alkylation (Scheme 5C). The protecting group was removed by $\mathrm{AlI}_{3}$ to afford (R)-2-(1-phenylethyl)phenol (76) in 75\% yield. Products with other substituents (benzyl, ethyl, and trimethylsilyl) were prepared by the method in acceptable yields for determination of chiral configurations. ${ }^{58}$ (IV) $\mathrm{AlI}_{3}$ was applied in synthesis of carboxamide 78, a useful kinase inhibitor, by removal of $\mathrm{MOE}$ (Scheme 5D). ${ }^{59}$ The deprotection afforded 78 in 19\% yield after refluxing a mixture of 77 and $\mathrm{AlI}_{3}$ (2.5eq) in acetonitrile for 4 hours. (V) In a recent synthesis of 80, tetrafluorobenzodioxin (79a) was deprotected by $\mathrm{AlCl}_{3}$ to afford tetrafluorocatechol in $28 \%$ yield. $^{60}$ A markedly improved method consisted of treating dioxin $79 \mathrm{~b}$ with $\mathrm{AlI}_{3}$ to furnish the catechol in $79 \%$ yield (Scheme 5E). ${ }^{61}$ (VI) The regioselective preference of $\mathrm{AlI}_{3}$ for cleaving alkyl aryl ethers has been applied in evaluation of nonylphenol ethoxylates $\left(\mathrm{NPEO}_{\mathrm{n}}\right)$ and octylphenol ethoxylates $\left(\mathrm{OPEO}_{\mathrm{n}}\right)$ in textiles and leathers (Scheme 5F). These ethoxylates are non-ionic surfactants prohibited for domestic use. After cleaving the ethers (81), the resultant nonylphenol and octylphenol (82) could be quantitatively evaluated by GC-MS. ${ }^{62-67}$ 

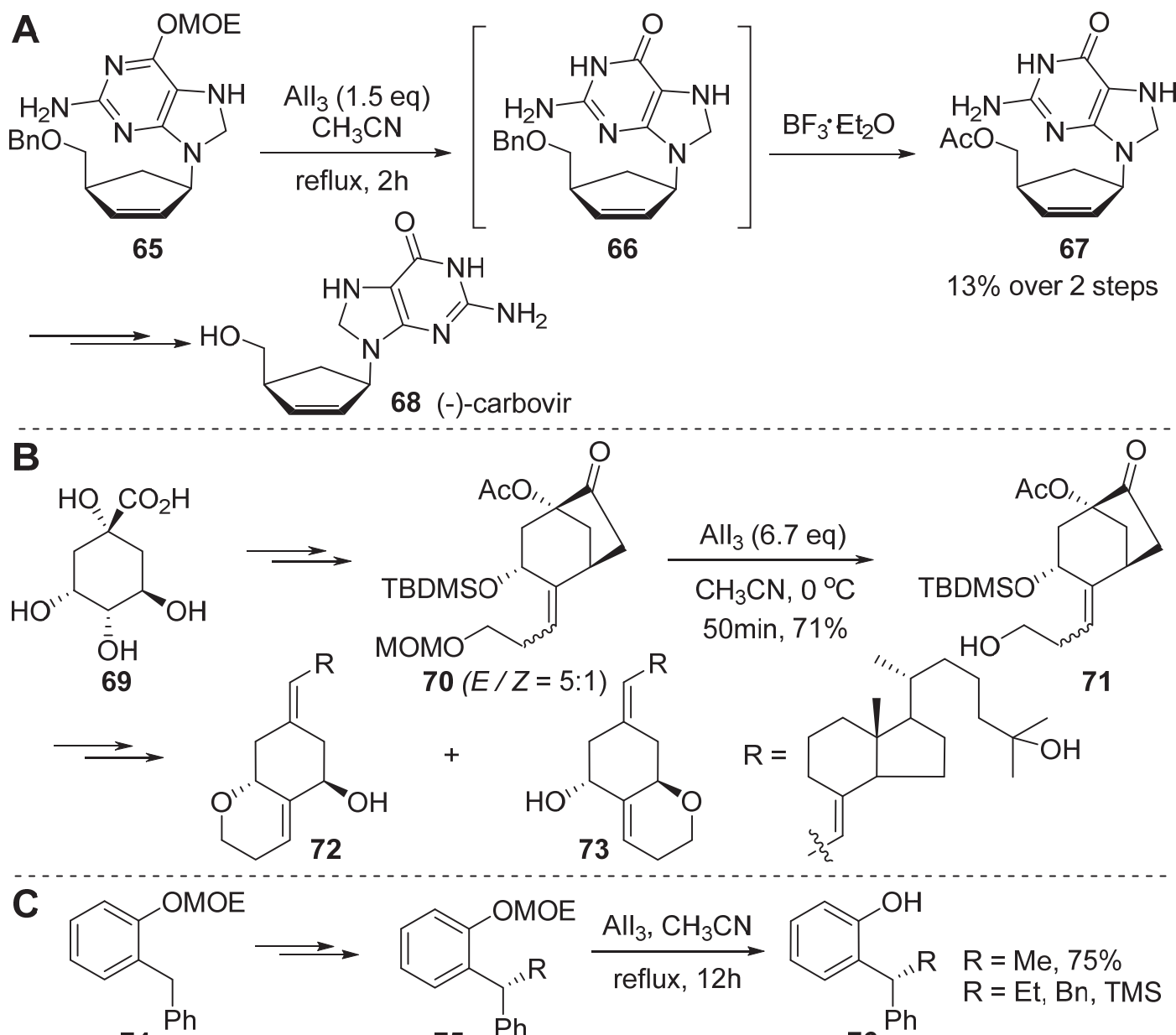

74

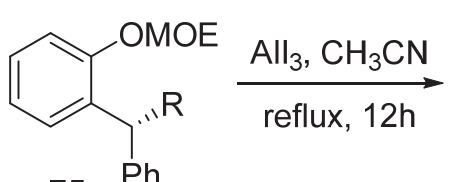

75

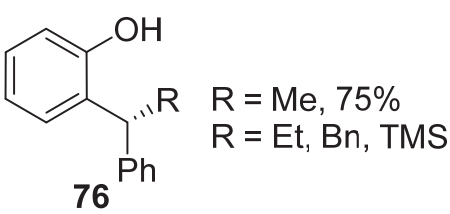

D $\mathrm{H}_{2} \mathrm{NOC}$

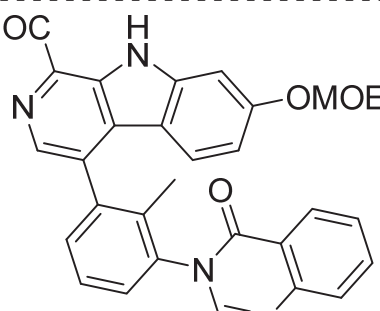

$77=\mathrm{N}$
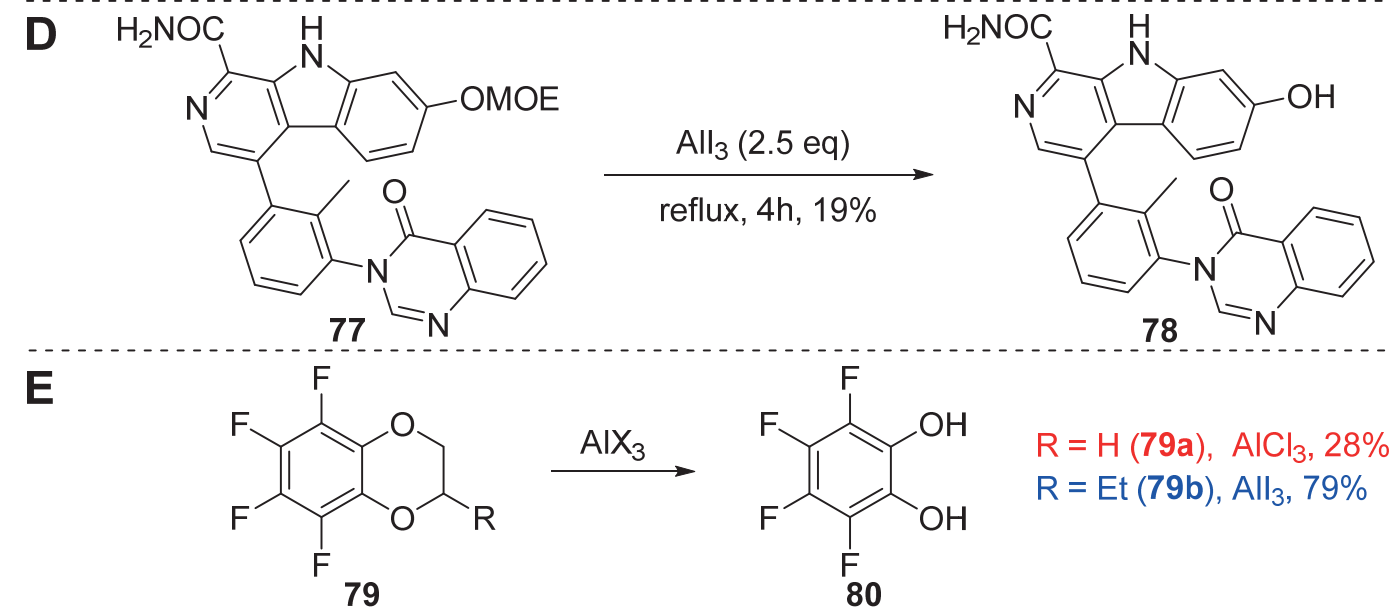

$\left.\mathrm{F}_{\mathrm{R}} \frac{r_{1}^{1}}{\mathrm{O}} \mathrm{P}_{81}^{\mathrm{H}} \stackrel{\mathrm{All}_{3}}{\longrightarrow} \mathrm{R} \frac{r_{1}^{1}}{\mathrm{OH}}+\mathrm{I}_{83}^{\mathrm{O}}\right)_{\mathrm{n}}^{\mathrm{H}} \mathrm{R}=\begin{gathered}\text { nonyl } \\ \text { octyl }\end{gathered}$

Scheme 5. Removal of phenolic protecting groups. A: (-)-Carbovir intermediate; B: 1 $\alpha, 25-$ dihydroxy-19-norvitamin $\mathrm{D}_{3}$ analogue intermediate; $\mathrm{C}$ : chiral benzylphenol; $\mathrm{D}$ : kinase inhibitor carboline carboxamide; E: 3,4,5,6-tetrafluorocatechol; F: nonylphenol and octylphenol. 


\subsection{Application of $\mathrm{AlI}_{3}-\mathrm{TBAI}$ in exhaustive demethylation}

Anderson independently developed an efficient method for deprotection of phenolic alkyl ethers (84) by using catalytic tetrabutylammonium iodide (TBAI) as a promoter (Scheme 6). By contrast, TBAI is commonly used in Finkelstein reaction ${ }^{68}$ for halide exchange, and the alkyl iodides generated therein can be used to accelerate etherification. The demethylation conversions were complete after stirring for 3 hours in benzene or cyclohexane and afforded phenols in moderate to high yields. ${ }^{69,70}$ Extension of the substrate to 3,4,5-trimethoxybenzaldehyde and isovanillin were less satisfactory for either low isolated yields or partial deprotection. Diphenyl ether remained intact under the condition.

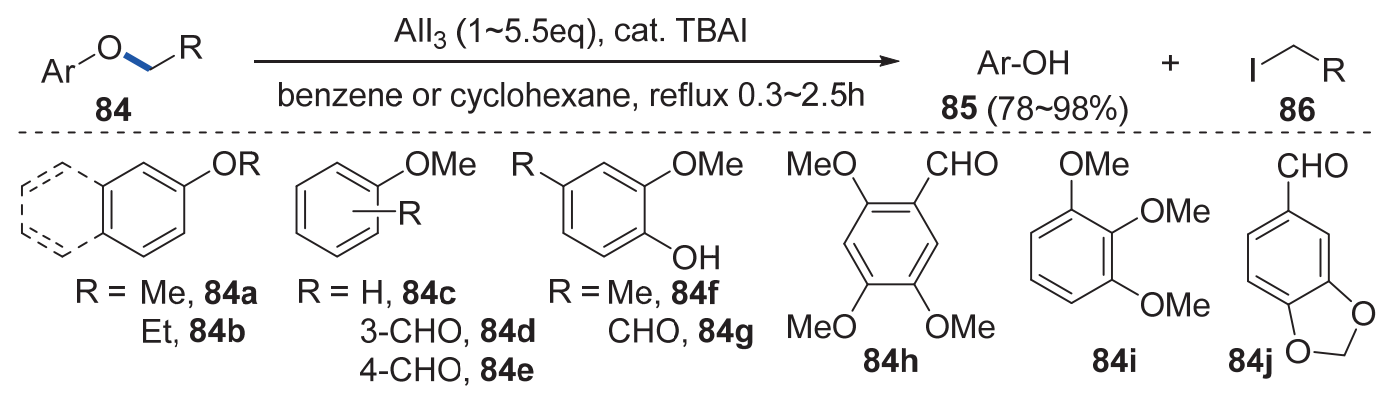

Scheme 6. AlI $_{3}$-TBAI induced cleavage of alkyl aryl ethers.
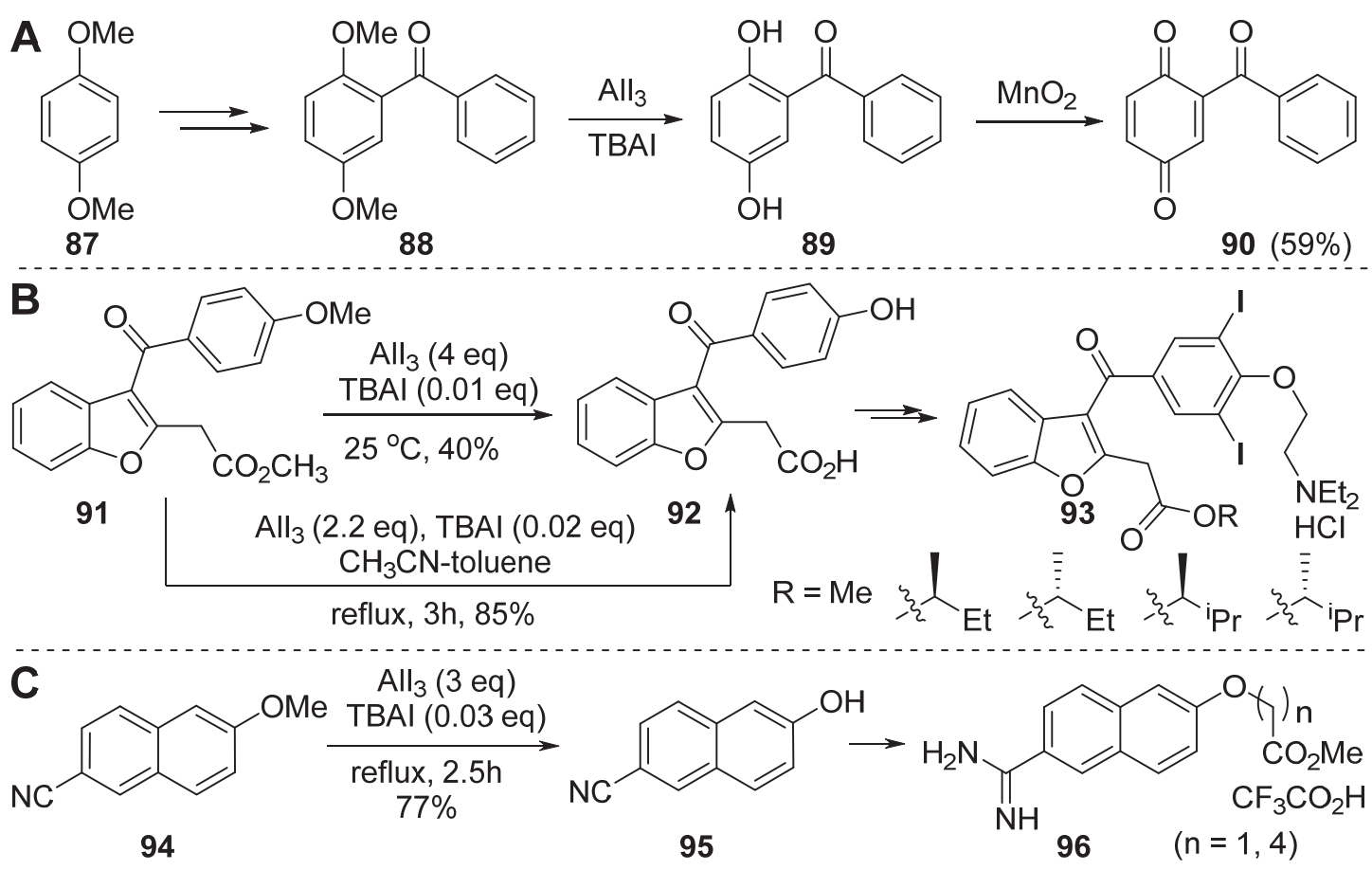

Scheme 7. Syntheses of several intermediates. A: 2-Benzoylhydroquinone; B: pharmaceutical intermediate; C: urokinase inhibitor intermediate 7-cyanon-2-naphthol. 
Anderson's method was used in syntheses of several intermediates such as $\mathbf{8 9},{ }^{71} \mathbf{9 2}^{72-74}$ and $\mathbf{9 5},{ }^{75}$ see Scheme 8. 89 can be oxidized to benzoquinone 90 by active manganese dioxide $\left(\mathrm{MnO}_{2}\right)$ (Scheme 7A). Benzofuran 92 is an intermediate to five pharmaceutical agents (93) useful in treating cardiac arrhythmia and congestive heart failure (Scheme 7B). Naphthol 95 is an intermediate to two urokinase inhibitors (96), see Scheme 7C.
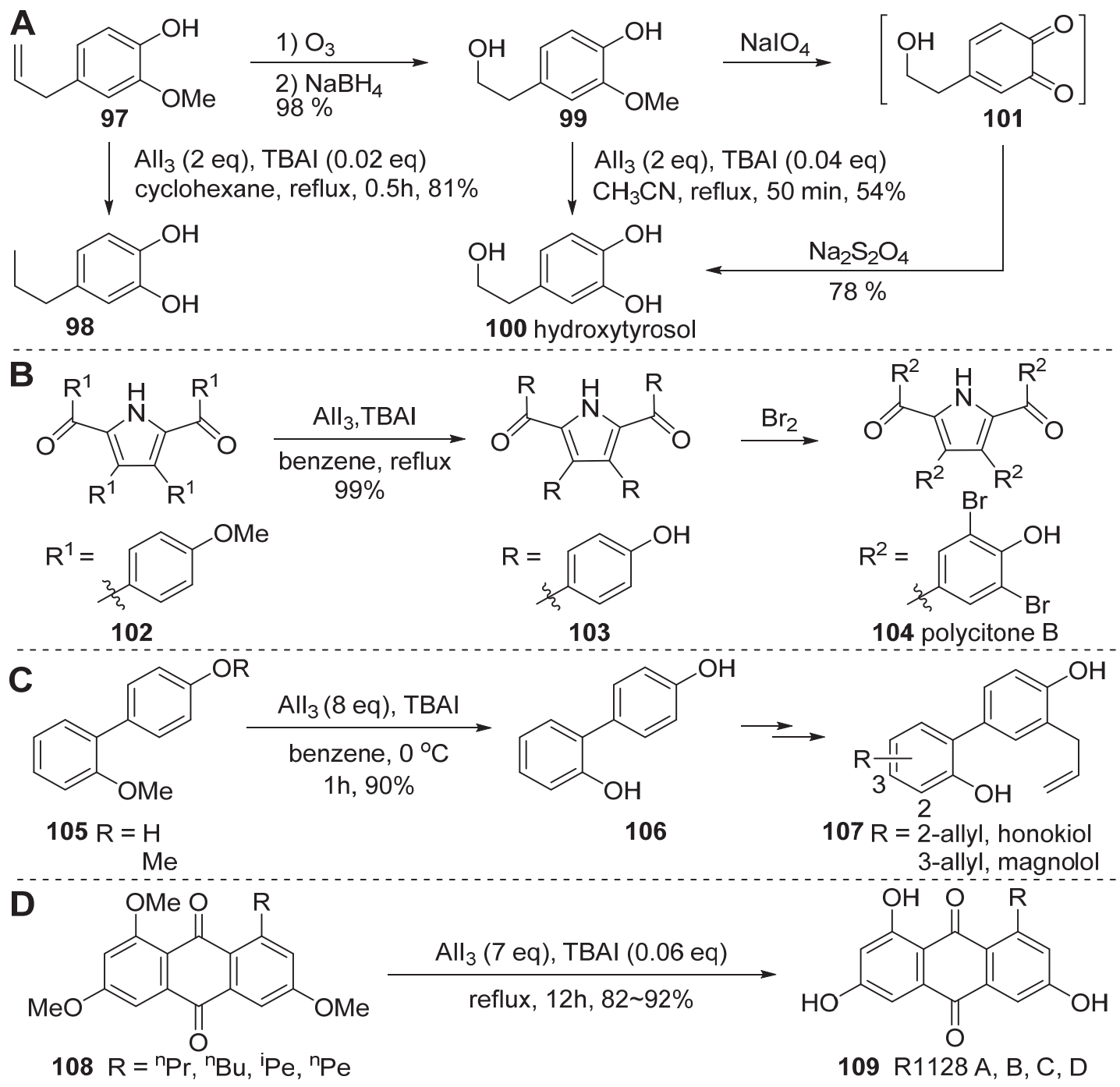

Scheme 8. Syntheses of natural products. A: Hydroxytyrosol; B: polycitone B intermediate; C: honokiol and magnolol intermediate; D: R1128A, B, C, and D.

The $\mathrm{AlI}_{3}$-TBAI reagent combination was applied in synthesis of several natural products (Scheme 8). Hydroxytyrosol (100), a natural antioxidant, was obtained by demethylation of 99 with $\mathrm{AlI}_{3}$-TBAI in 54\% yield, see Scheme 8A. Surprisingly, the allylic group para to phenolic hydroxyl group was reduced to propyl group when eugenol (97) was demethylated under the condition, and furnished 98 in $81 \%$ yield. $^{76}$ Polycitone B (104, see Scheme $\left.8 \mathrm{~B}\right),{ }^{77}$ biaryl plural neolignan honokiol and magnolol (107, see scheme 8C), ${ }^{78}$ and non-steroidal Estrogen receptor antagonists R1128 A D 
(109, see Scheme 8D $)^{79}$ were accomplished similarly in moderate to high yields. It is noteworthy that deprotection of 108 with $\mathrm{BBr}_{3}$ resulted in partially demethylated mixtures; besides, the 9,10anthraquinone skeleton was not affected by $\mathrm{AlI}_{3}$.

The $\mathrm{AlI}_{3}$-TBAI combination has also been applied in syntheses of other natural products including isocladosorpin (111a) ${ }^{80}$ sporostain (111b) ${ }^{81} 11-\alpha$-methoxycurvularin $(\mathbf{1 1 1 c})$ and 11- $\beta$ methoxycurvularin (111d) ${ }^{82,83}$ as well as xestodecalactone A (113), ${ }^{84} \mathrm{~B}$ and C (115) ${ }^{85}$ see Scheme 9 and Scheme 10. A deoxydehydration product (116) was obtained from 112 at ambient temperature in $94 \%$ yield during the synthesis of xestodecalactone $\mathrm{C} .{ }^{86}$ The naturally occurring sporostain (111b) is an inhibitor of cyclic adenosine 3',5'-monophosphate phosphodiesterase (cAMP-PDE).

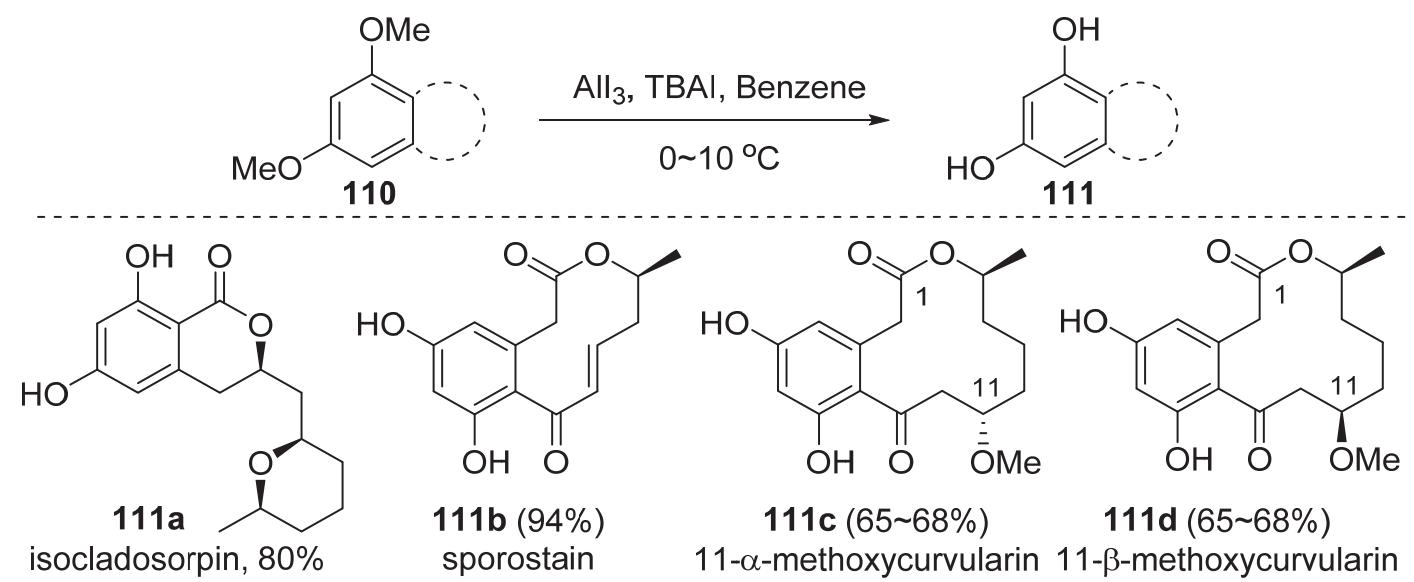

Scheme 9. Syntheses of naturally occurring isocladosorpin, sporostain, 11- $\alpha$-methoxycurvularin and $11-\beta$-methoxycurvularin via exhaustive demethylation.

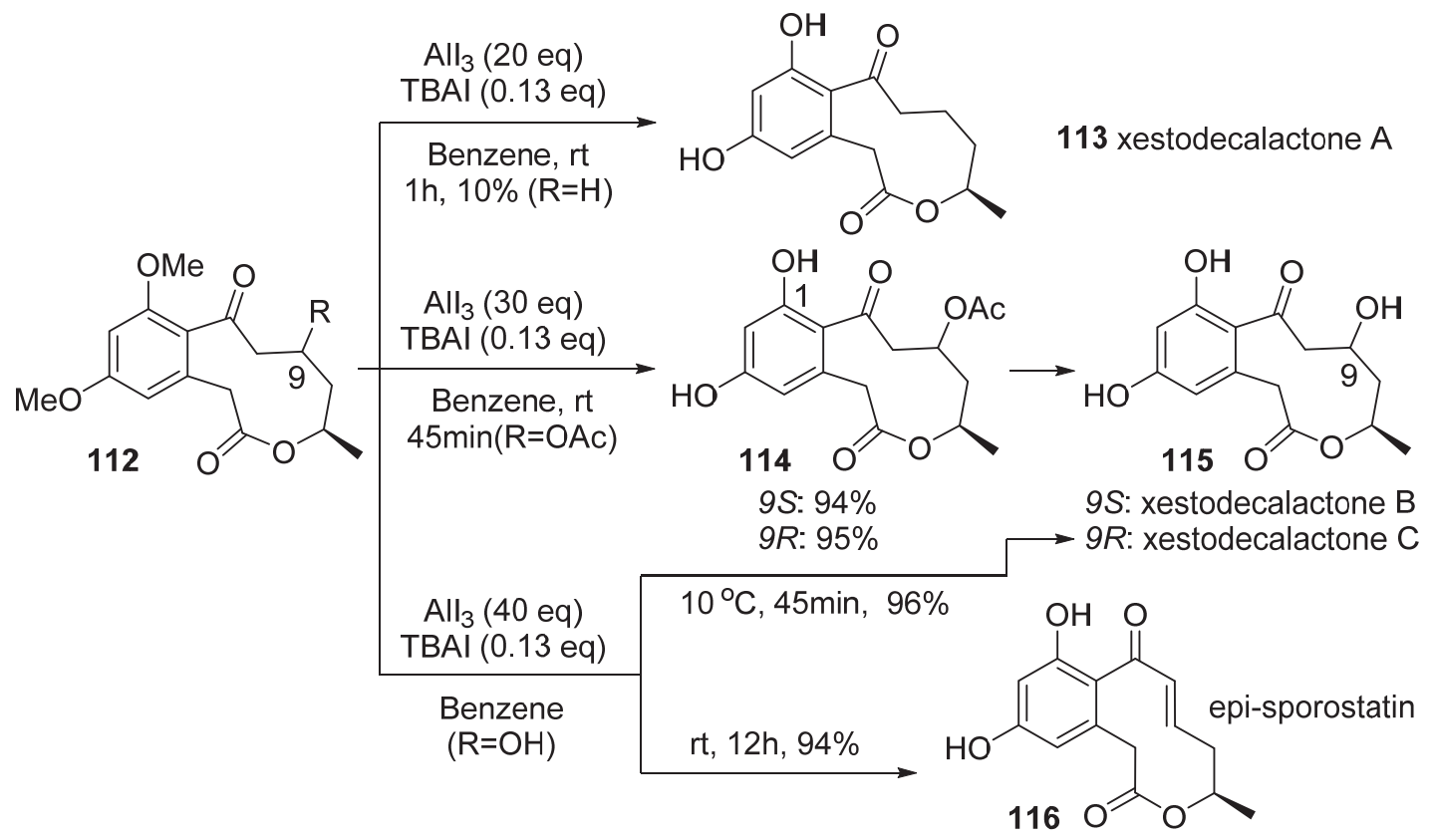

Scheme 10. Syntheses of xestodecalactone A, B, C and epi-sporostatin. 
Lipoxygenase inhibitor $(S)-(-)$-zearalenone $(\mathbf{1 1 8} \text {, Scheme } 11 \mathrm{~A})^{87}$, zeranol (120, Scheme 11B $)^{88,89}$ and several zearalenone analogues $(\mathbf{1 2 2}, 124$ and 126, scheme 11C) were prepared by exhaustive demethylation of corresponding resorcinol dimethyl ethers $(\mathbf{1 2 1}, \mathbf{1 2 3}, \mathbf{1 2 5})$. Regioselective cleavage of the $\mathrm{C}_{3}$-phenyl methyl ethers was achieved alternatively with $\mathrm{BBr}_{3}$ or $\mathrm{BCl}_{3}$ in high yields. Exhaustive deprotection of 121, 123 and 125 was accomplished by $\mathrm{BCl}_{3}-\mathrm{BBr}_{3}$ combination, ${ }^{90,91}$ and by $\mathrm{AlI}_{3}$-TBAI. ${ }^{92-94}$ Phloroglucinol, a widely used antioxidant, was sacrificed herein to scavenge $\mathrm{HI}$ in syntheses of $\mathbf{1 1 8}$ and $\mathbf{1 2 6}$.
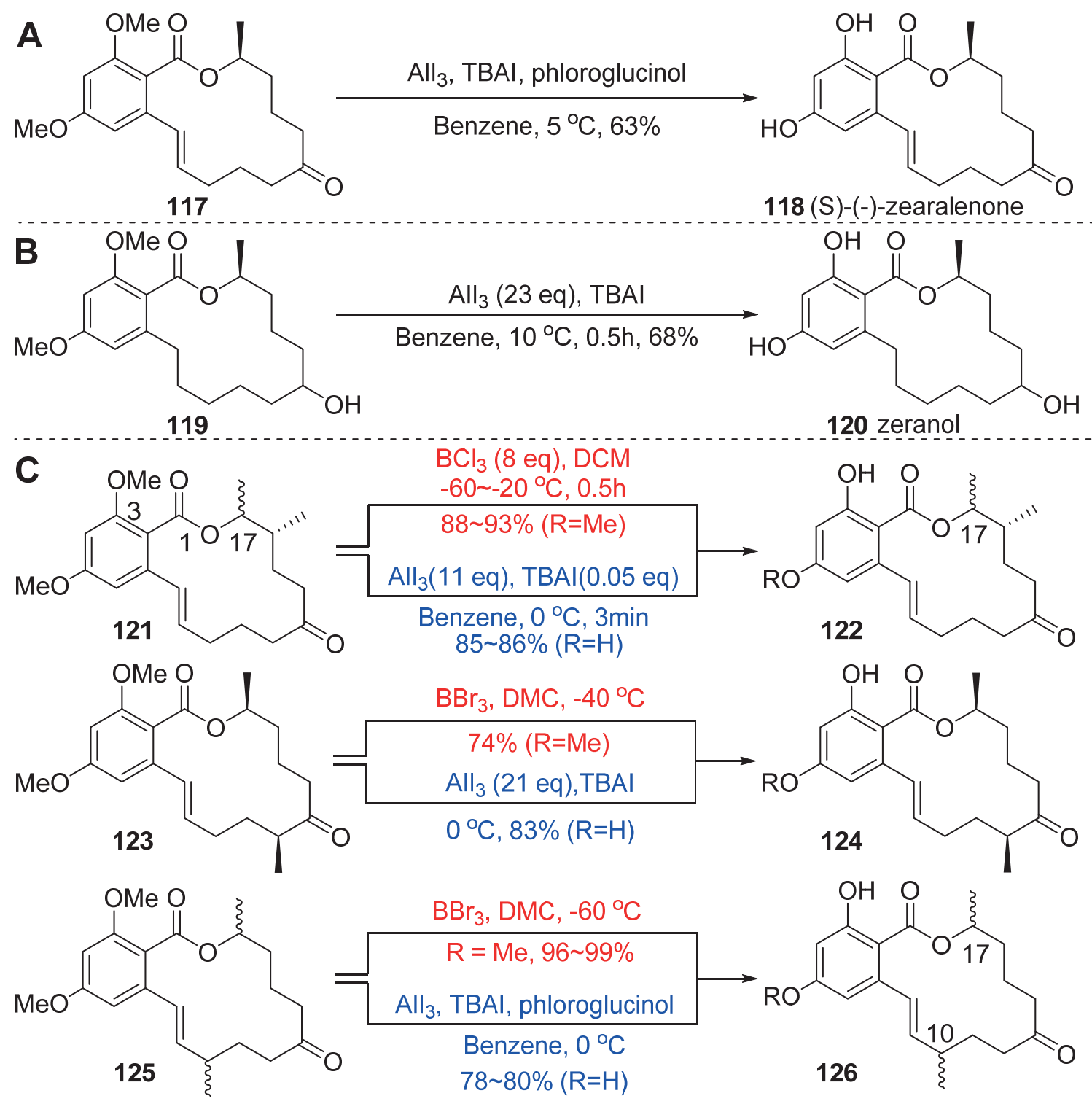

Scheme 11. Syntheses of zearalenone analogues. A: (S)-(-)-zearalenone; B: zeranol; C: zearalenone analogues. 


\section{Deoxygenation and Deoxydehydration}

\subsection{Deoxygenation of oxiranes}

A variety of reagents have been used in deoxygenation of oxiranes to prepare olefins in moderate to low yields and poor retention of stereochemistry. ${ }^{95}$ Inspired by the succes of $\mathrm{AlI}_{3}$ in ether cleavage, Barua and Sarmah extended the reagent to oxiranes $(\mathbf{1 2 7 a} \mathbf{1 2 7 g})$, see Figure 2. The conversions were complete within 1 hour in moderate to high yields depending on the substrate. ${ }^{96}$ For example, treatment of 129 with $\mathrm{AlI}_{3}$ afforded 130 in 70\% yield after refluxing in acetonitrile for 1 hour. Carvone (131) was accessed via deoxygenation of 130 with $\mathrm{AlI}_{3}$ in $90 \%$ yield after refluxing for 8 hours in acetonitrile. 131 was alternatively prepared by deoxygenation of the sterically less hindered 132 in $87 \%$ yield within 0.5 hour (Scheme 12). ${ }^{96}$
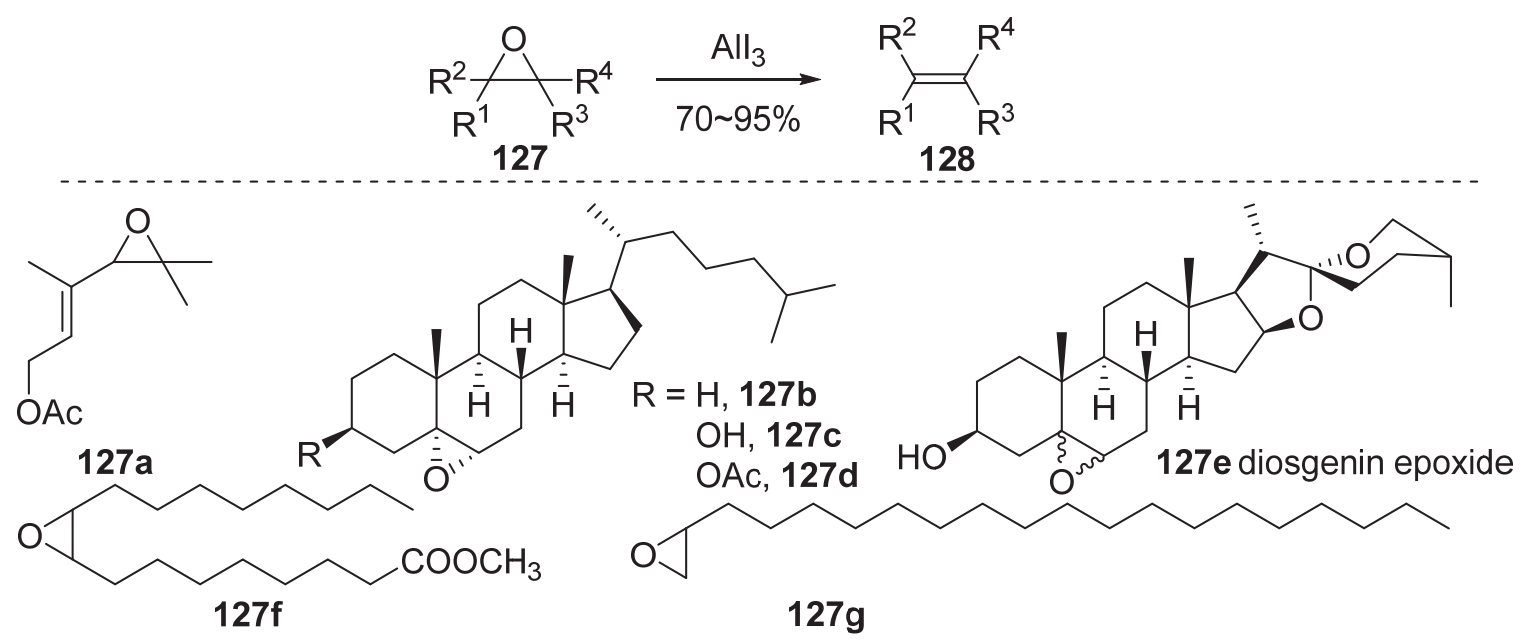

Figure 2. Deoxygenation of oxiranes.

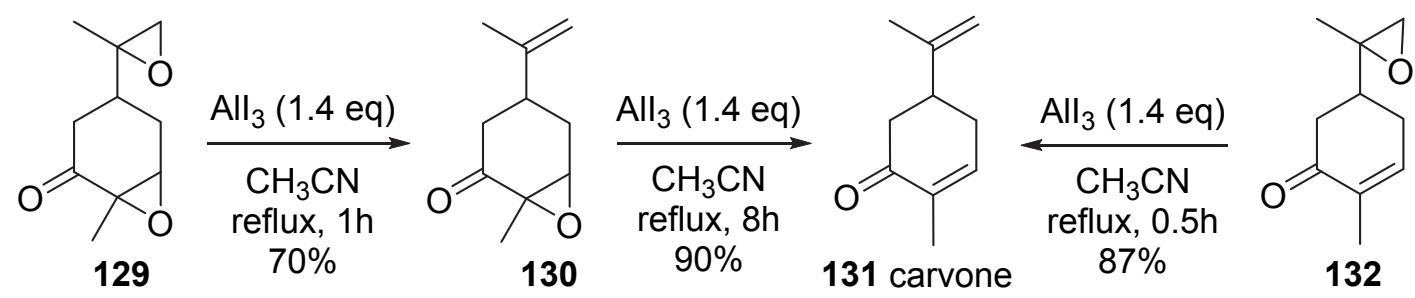

Scheme 12. Synthesis of carvone by deoxygenation.

The mechanism for $\mathrm{AlI}_{3}$ induced deoxygenation was well illustrated by the study of trichlorooxirane 133 (Figure 3A). ${ }^{97}$ Trichloroolefin 136 was obtained in 91\% yield after the reaction mixture of $\mathrm{AlI}_{3}$ and 133 (conducted at room temperature) was loaded on column in place of radial chromatography during workup at $30 \sim 32{ }^{\circ} \mathrm{C}$ for 20 hours, whereas cis-iodohydrin 138 was isolated in 50\% yield along with 136 (25\%) when the column was stored at $35^{\circ} \mathrm{C}$ for 24 hours. When the reaction was quenched 15 minutes after start, anti-iodohydrin 137 was isolated in 95\% yield as colorless needles. Apparently trans-iodohydrin 135 was involved in the reaction. At lower 
temperature, the reaction proceeded through path $\mathrm{b}$ with an iodide anion attacking the C-I bond leading to 136. Accordingly, 138 was accessed at higher temperature via path a. 137 was further converted to 133 in basic conditions in 74\% yield, and to 138 in $92 \%$ yield by treating with either I or $\mathrm{AlI}_{3}$. It is worth noting that deoxygenation of oxarine 139 afforded olefin 140 in $78 \%$ yield after stirring for 20 hours with $\mathrm{AlI}_{3}$; accordingly 140 was oxidized to 139 with 3-chloroperoxybenzoic acid ( $m$-CPBA) in high yield, see Figure 3B.

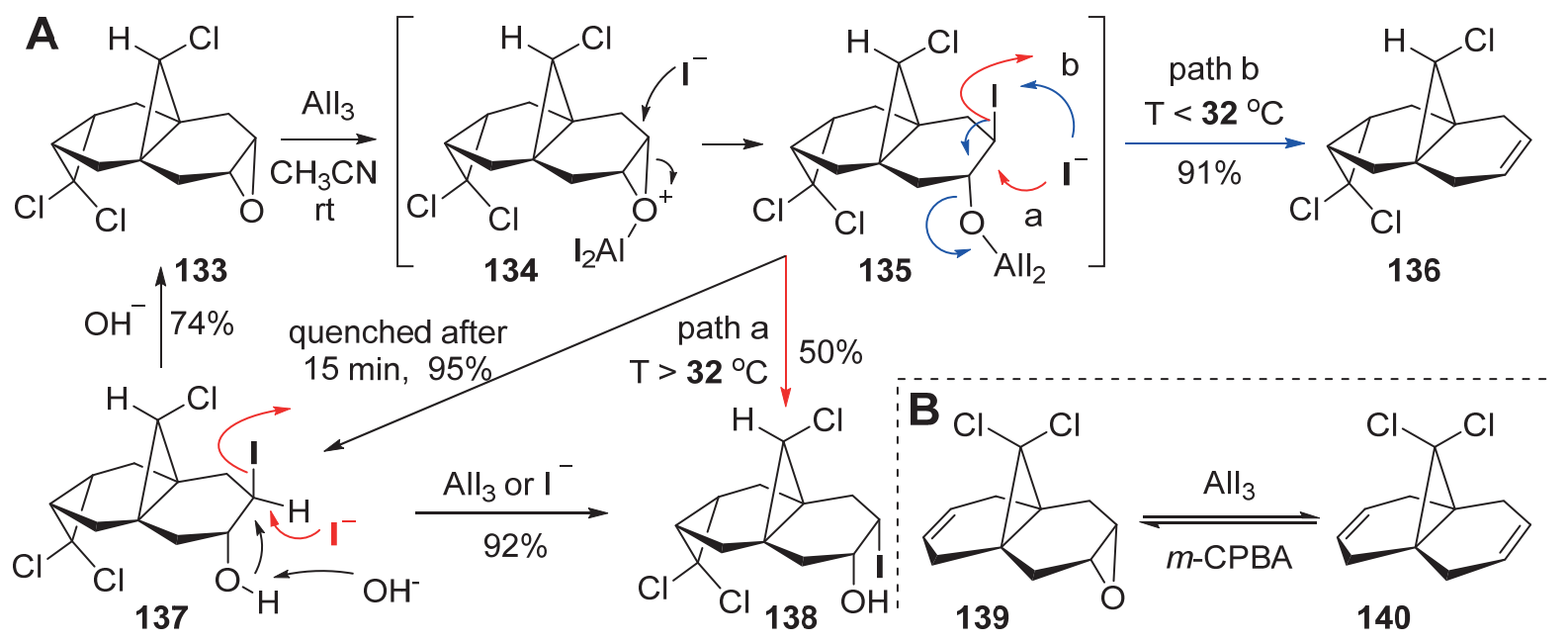

Figure 3. Deoxygenation of oxiranes. A: deoxygenation mechanism; B: reversible epoxidation and deoxygenation.

A class of 1,3-halohydrins (142) were prepared through aluminum halide induced ring opening of oxiranes. Treating a mixture of stereoisomers of 141 (exo/endo=15:1) with $\mathrm{AlX}_{3}(\mathrm{X}=\mathrm{Cl}, \mathrm{Br}, \mathrm{I})$ in DCM or $\mathrm{CS}_{2}$ (Figure 4), followed by carbocation rearrangements (143) and halide transfer (144) afforded 142 in 79 84\% yields. ${ }^{98}$

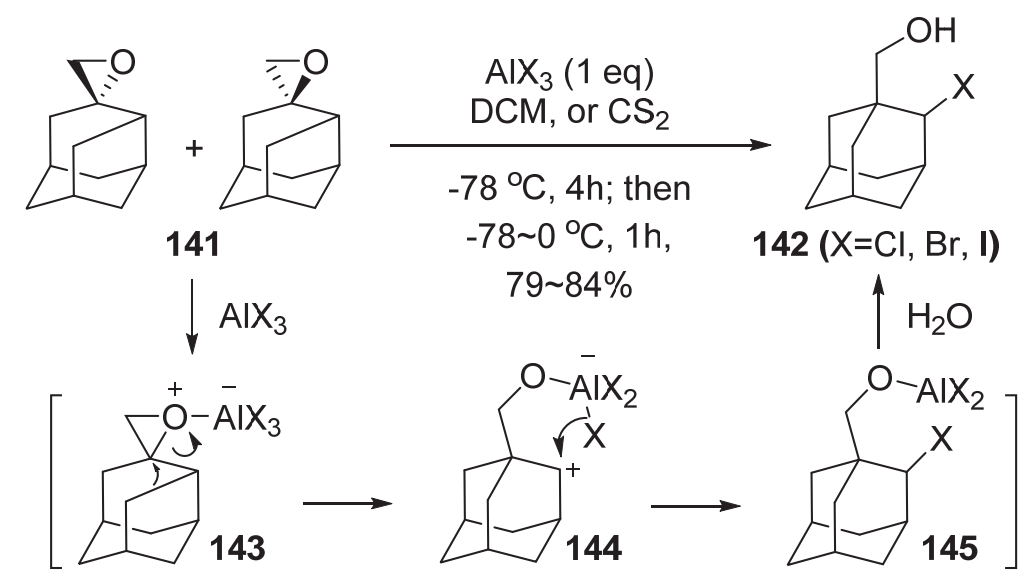

Figure 4. Synthesis of 2-halo-1-(hydroxymethyl)adamantine. 
Ring-opening of oxirane by $\mathrm{AlI}_{3}$ was regioselective in the case of 1,2-decane epoxide. The reaction was complete after stirring for 2 hours in heptane at room temperature, and afforded 1iodo-2-decanol exclusively. The high regioselectivity was attributed to the larger volume size and higher nucleophilicity of $\mathrm{I}^{-}$; thus $\mathrm{I}^{-}$attacked the oxirane from the sterically more accessible terminal site (148). ${ }^{99}$ Though depicted in stepwise sequences, the reaction may proceed in a concerted manner via a four-membered transition state (Figure 5).

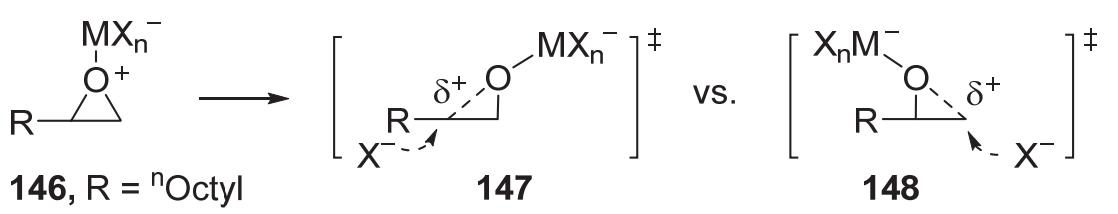

Figure 5. Regioselectivity analysis.

Several natural products were prepared by $\mathrm{AlI}_{3}$ induced deoxygenation of oxiranes (Scheme 13). An epoxidation-deoxygenation protocol had been applied in syntheses of campesterol acetate $(\mathbf{1 5 1})^{100}$ and $\beta$-sitosterol (154) ${ }^{101}$ commenced from stigmaserol (149), see Scheme 13A. Similarly, a 19-phenylsulfonyl provitamin D analogue (159) was accomplished. Epoxidation of $\mathbf{1 5 5}$ afforded a mixture of epoxides $\mathbf{1 5 6} \alpha$ and $\mathbf{1 5 6} \beta$ in a ratio of 4.9:1. 156 $\beta$ was unreactive under the deoxygenation condition. Successive deoxygenation of 157 afforded 158 in 50\% yield (Scheme 13B). ${ }^{102}(S)-6$-Methylhept-5-en-2-ol (162), an aggregation hormone of gnathotrichus sulcatus, was accessed by deoxygenation of $\mathbf{1 6 0}$ followed by saponification of $\mathbf{1 6 1}$ in $90 \%$ yield over two steps (Scheme 13C). ${ }^{103}$ 

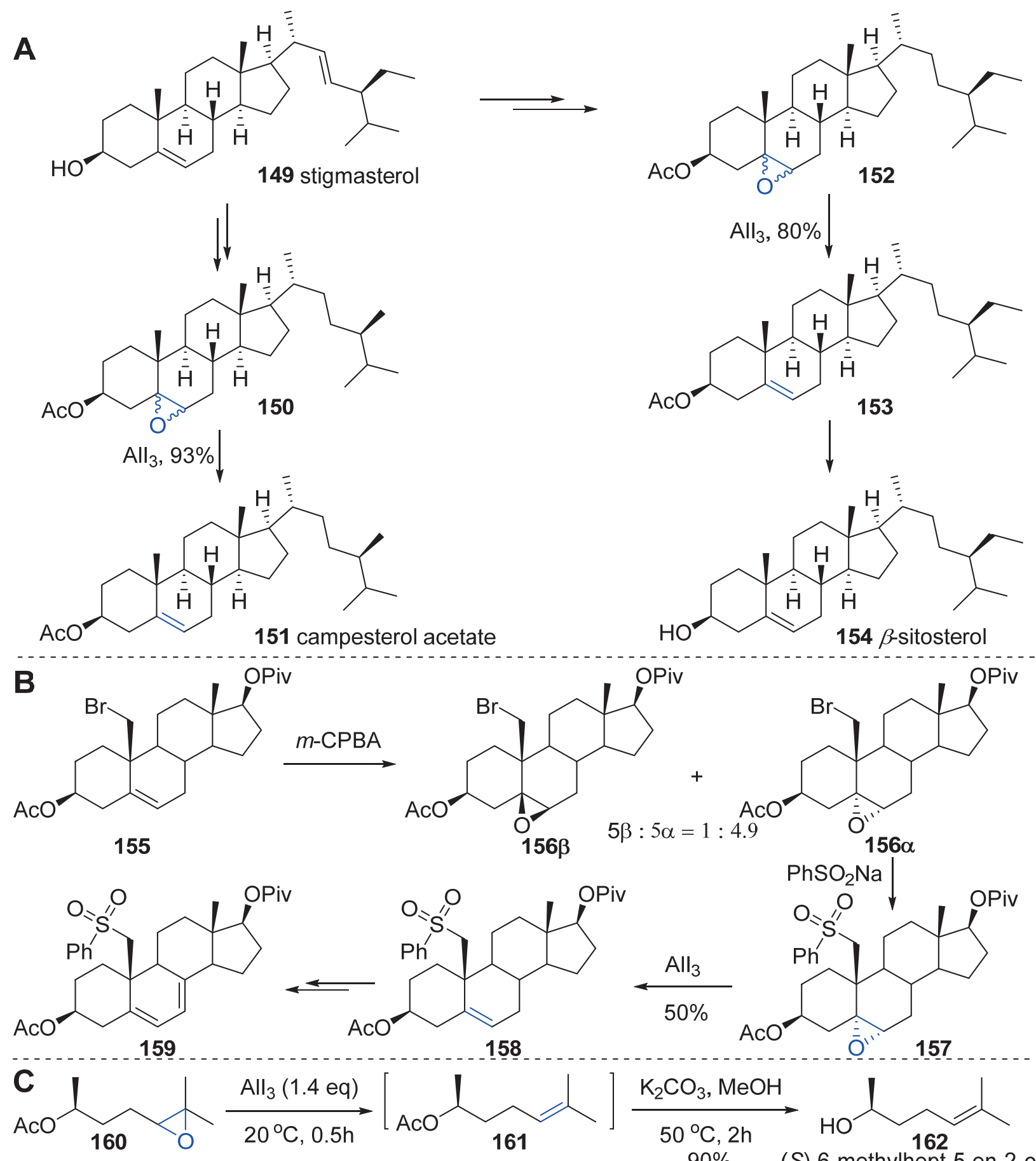

158

157
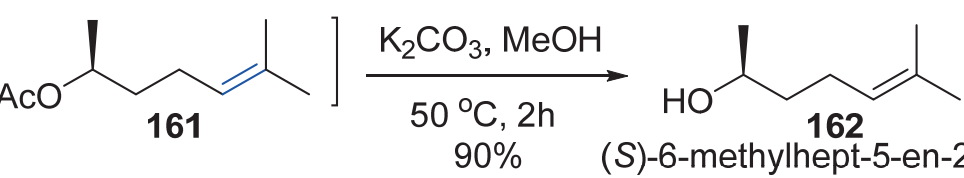

(S)-6-methylhept-5-en-2-ol

Scheme 13. Syntheses of natural products or intermediates via $\mathrm{AlI}_{3}$ induced deoxygenation of oxiranes. A: $\beta$-Sitosterol and campesterol acetate; B: 19-phenylsulfonyl provitamin D analogue; C: $(S)$-6-methylhept-5-en-2-ol.

\subsection{Deoxydehydration of diols}

Deoxydehydration (DODH) of diols involves the formation of iodohydrins as intermediates, and and affords olefins via $\mathrm{E}_{2}$ elimination. A plausible mechanism is depicted in Figure 6. Treatment of 
diol 163 with $\mathrm{AlI}_{3}$ afforded iodohydrin 165, 165 then undergone elimination to give olefin 168 . Several olefins (170 and 173) were prepared by this method (Scheme 14). ${ }^{104}$ It is noteworthy that both cis-diol (169) and trans-diol (17) afforded the same olefin (170), indicating that the conversion proceeded in a stepwise manner (Scheme 14).

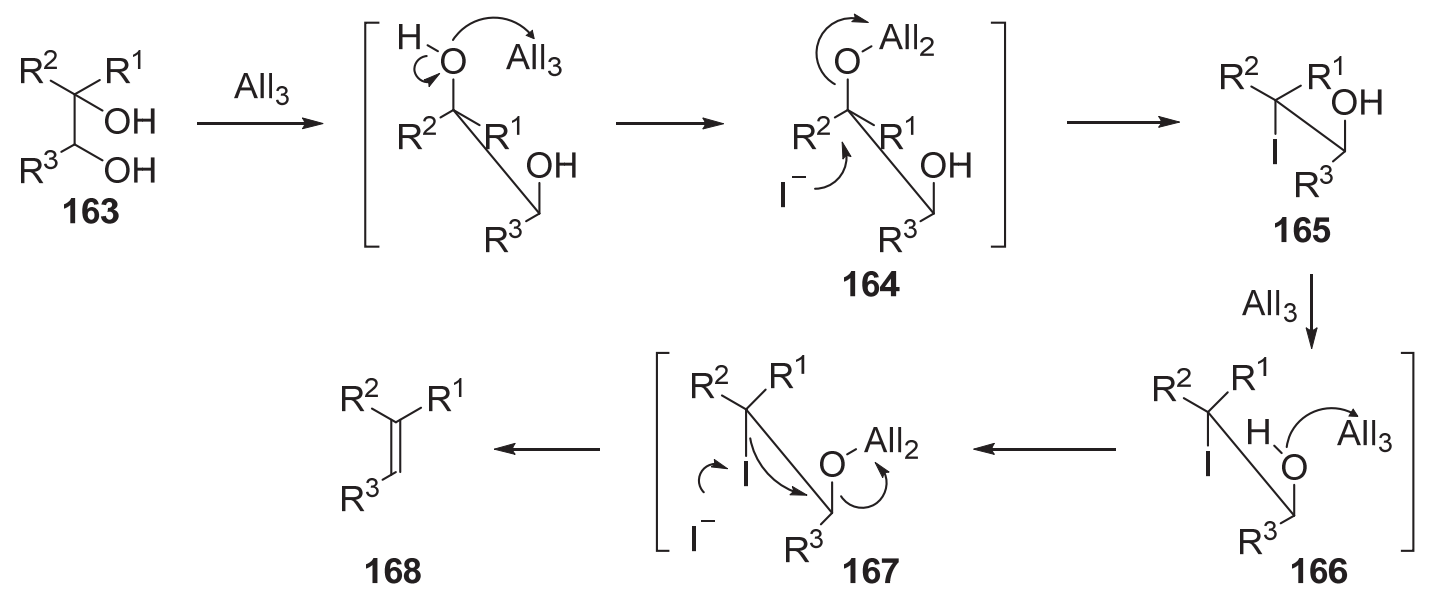

Figure 6. A plausible mechanism for the deoxydehydration of diols.

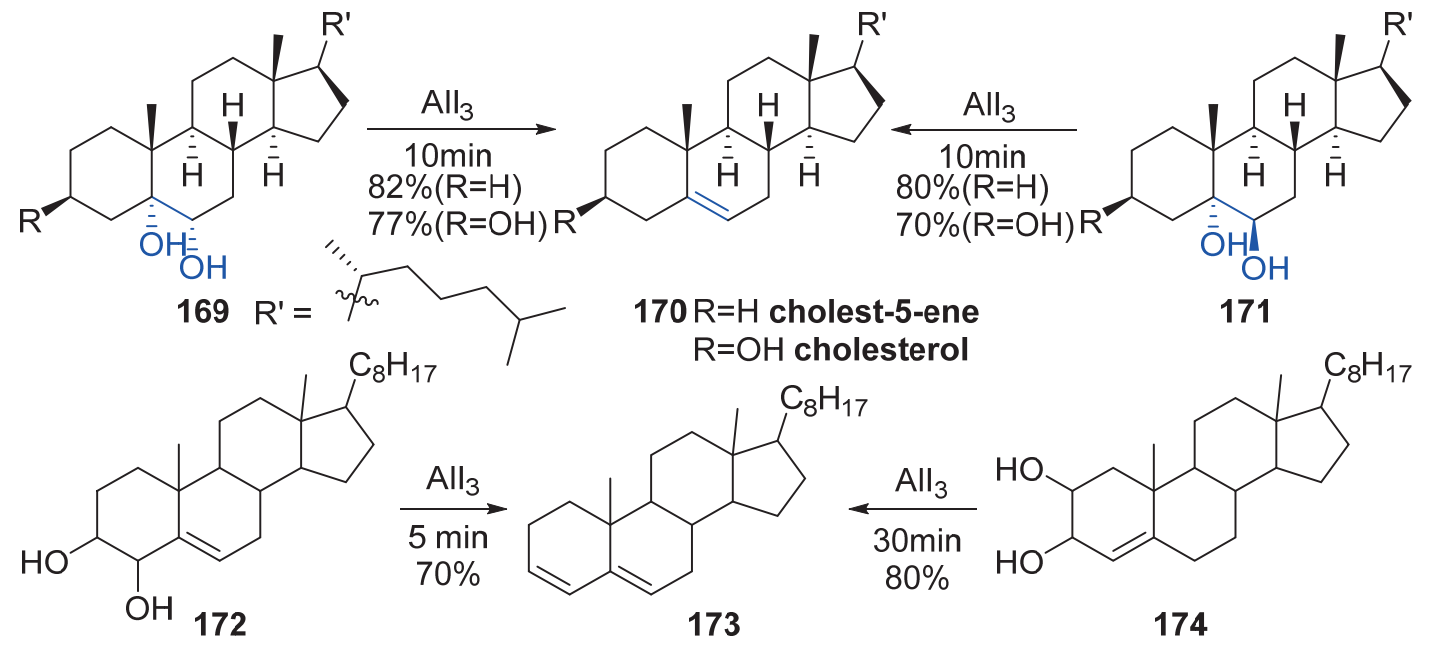

Scheme 14. Deoxydehydration of diols.

Recently, 5-hydroxymethylfurfural (HMF, 176), a biomass-derived precursor for biofuel, was accessed through deoxydehydration of $\alpha$-glucopyranose (175) with $\mathrm{All}_{3}$ in dimethylacetamide (DMAc). The conversion involved the $\alpha / \beta$ isomerization of glucopyranose (177), and the following dehydration of $\mathbf{1 7 8}$ furnished HMF in 54\% yield (Scheme 15). ${ }^{105}$ 

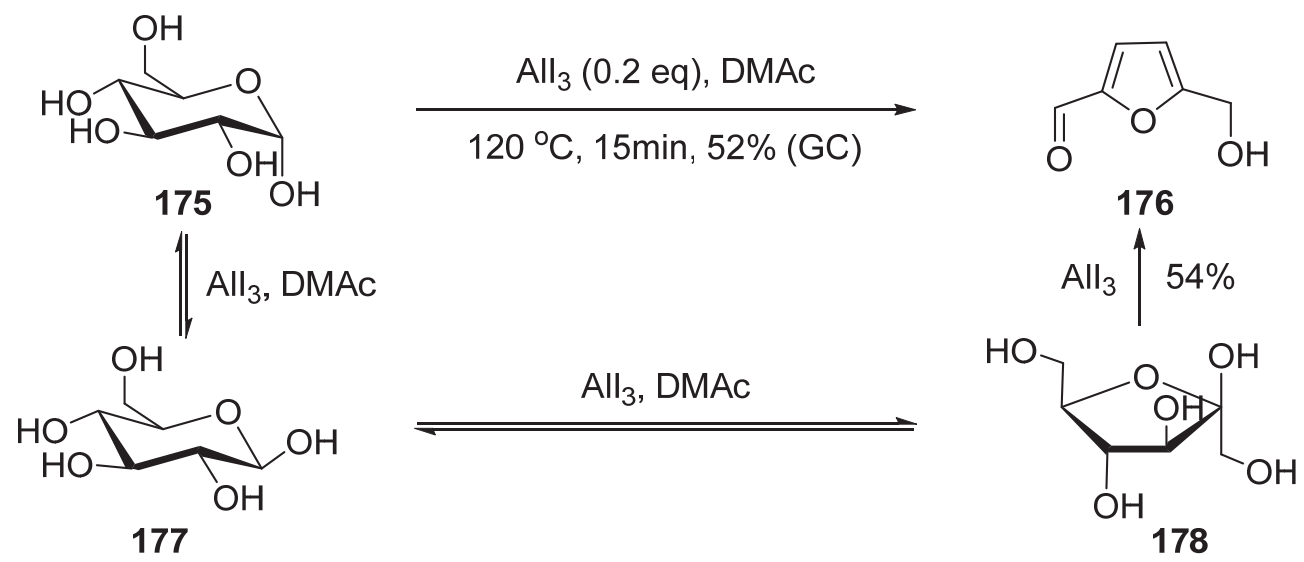

Scheme 15. Transformation of glucose to furfural via $\mathrm{AlI}_{3}$ catalyzed dehydrodeoxygenation.

\subsection{Deoxygenation of sulfoxides and sulfonyl chlorides}

Sulfoxides and sulfonyl chlorides can be converted into corresponding sulfides and disulfides by sodium iodide $(\mathrm{NaI}),{ }^{106}$ potassium iodide $(\mathrm{KI})^{107}$ or $\mathrm{TMSI}^{108} \mathrm{AlI}_{3}$ is also effective for these transformations. Alkyl and aryl sulfides such as dibutyl sulfide (180a), dibenzyl sulfide (180b), and diphenyl sulfide (180c) were prepared by reduction of sulfoxides (179a $\sim 189 c)$ with $\mathrm{AlI}_{3}$. The reduction was much slower for aryl sulfoxide (179c) compared to alkyl sulfoxide (179a). Similarly, reduction of phenoxathiine 10-oxide (179d) afforded phenoxathiine (180d), see Scheme $16 .{ }^{109}$

Reduction of sulfonyl chlorides (181) were complete typically in about 1 hour under reflux or 3 5 hours at room temperature, and afforded disulfides in high yields (Scheme 16). ${ }^{110}$ The method was applied in the synthesis of diferrocenyl disulfide from ferrocenesulfonyl chloride (171g). ${ }^{111,112}$

A plausible mechanism for the reduction is shown in figure $7 . \mathrm{AlI}_{3}$ served as an oxophilic agent as well as an I source during the transformations. The oxophilic character of $\mathrm{AlI}_{3}$ induced the formation of $\mathbf{1 8 4}$ and 186. Cleavage of the sulfinyl bond followed by intramolecular attack of S-I bond iodide via an envelope transition state furnished 180. Thiosulfonic S-ester $\left(\mathrm{RSO}_{2}-\mathrm{SR}, 190\right)$ was involved during the reduction of sulfonyl chlorides (181); 190 can be further reduced to disulfides $(\mathbf{1 8 2})$ by $\mathrm{AlI}_{3}{ }^{113} \mathrm{HCl}-\mathrm{KI}$ reagent system is also effective. ${ }^{114}$ 


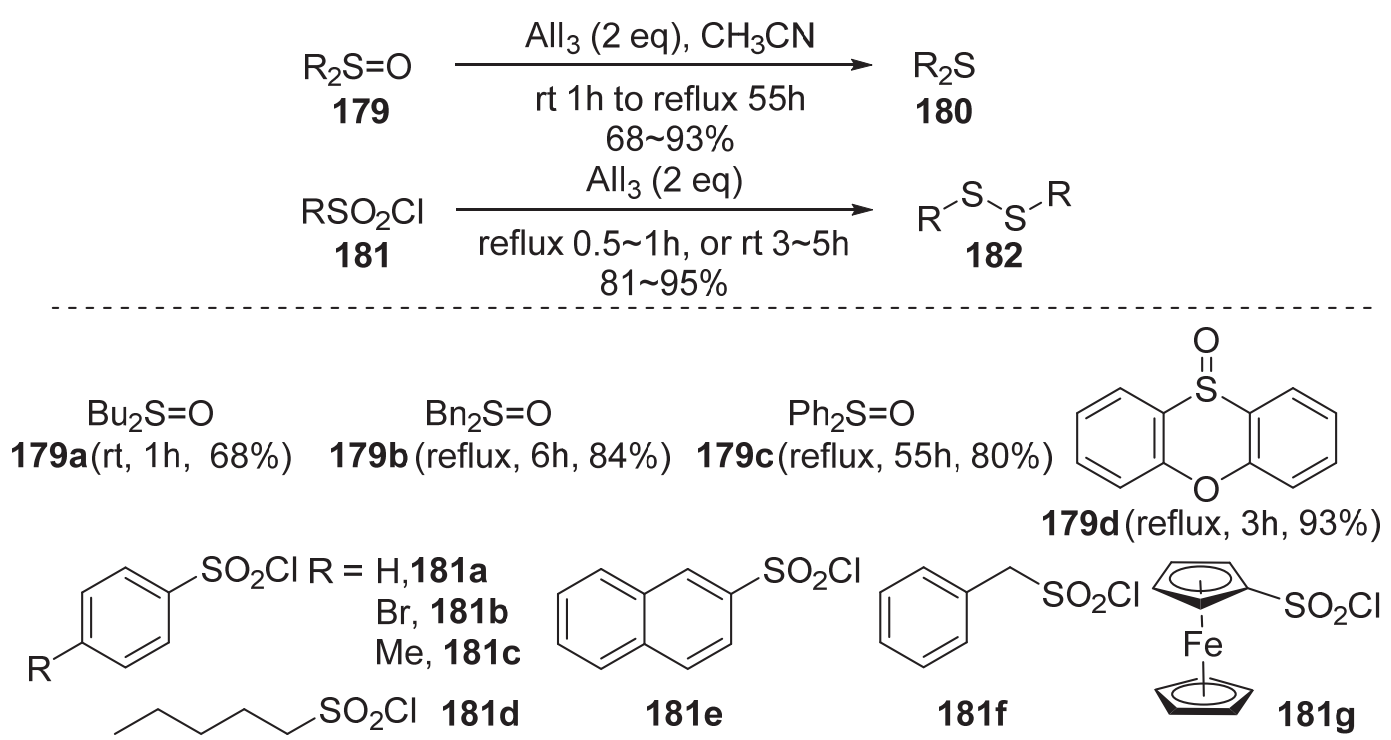

Scheme 16. Deoxygenation of sulfoxides and sulfonyl chlorides.

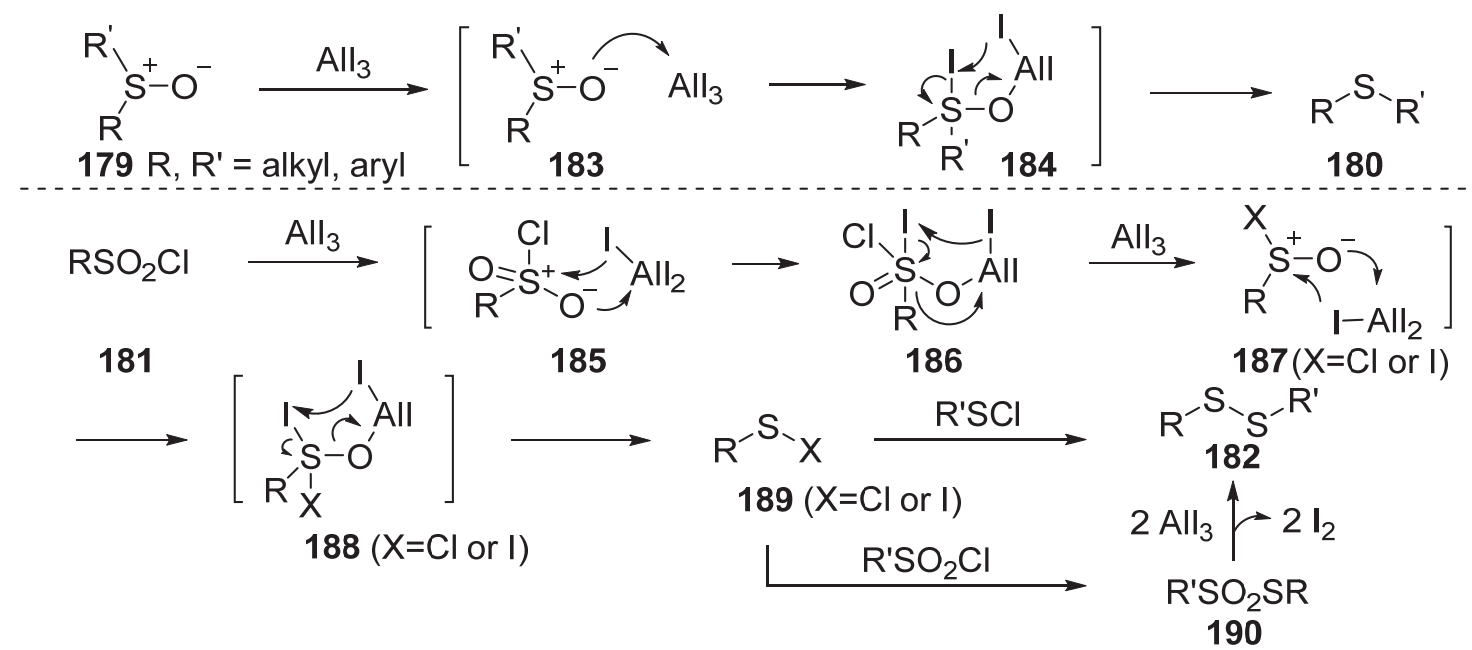

Figure 7. Plausible mechanisms for the deoxygenation of sulfoxides and sulfonyl chlorides.

\subsection{Deoxydehydration of oximes}

Oximes (191) can be reduced to nitriles (193) by $\mathrm{AlI}_{3}$ in moderate to high yields in acetonitrile under reflux for several hours (Figure 8A). The method was extended to substituted aliphatic oximes and arylaldoximes. ${ }^{115}$ Reduction of aryl ketoximes (194), such as benzophenone oxime and acetophenone oxime, afforded the corresponding anilides (198) in moderate yields via Beckmann rearrangement (conversions from 195 to 197), see Figure 8B. Aliphatic ketoximes remained unchanged under the condition. 
A
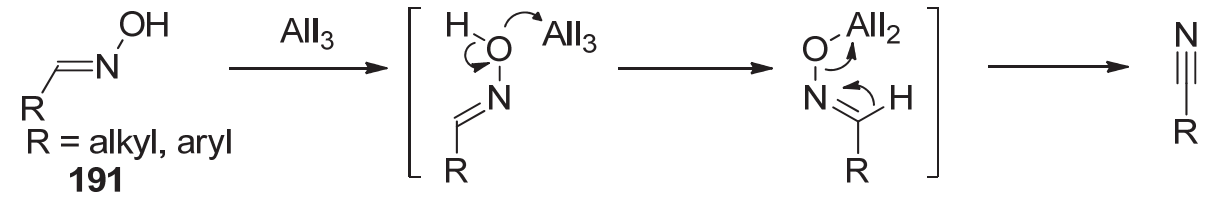

192

193

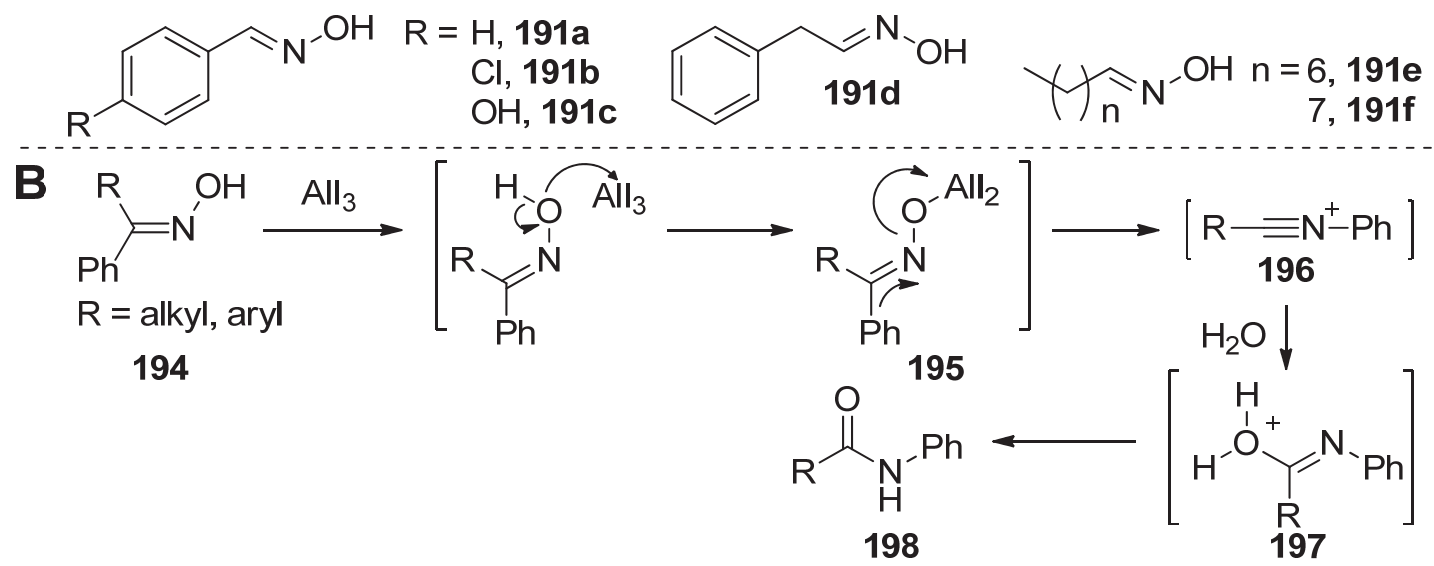

Figure 8. Deoxydehydration of $N$-oxides. A: Scope of substrates and mechanism of reaction; B: $\mathrm{AlI}_{3}$ induced Beckmann rearrangement of aryl ketoximes.

\subsection{Deoxygenation of $\mathrm{N}$-arylnitrones, azoxyarenes and $\mathrm{N}$-heteroarene $\mathrm{N}$-oxides}

Selective deoxygenation of $N$-arylnitrones (199) to $N$-arylimines (200) were achieved with $\mathrm{AlI}_{3}$ in moderate to high yields (Scheme 17A) ${ }^{116}$ The imine turned to be a by-product (203) when 201 was deoxygenated by the method (Scheme 17B). The conversion was complete after 4 hours of stirring at room temperature in acetonitrile. ${ }^{117}$ The major product $\mathbf{2 0 2}$ is a promising lead for selective $A_{2 B}$ adenosine receptor $\left(\mathrm{A}_{2 \mathrm{~B}} \mathrm{AR}\right)$ antagonist. ${ }^{118}$ Ruthenium trichloride is also suitable for deoxygenation of $N$-arylnitrones. ${ }^{119}$

$\mathrm{N}$-heteroarenes (205) can be achieved via deoxygenation of the corresponding $\mathrm{N}$-heteroarene $\mathrm{N}$ oxides (204) in high yields (Scheme 17C). ${ }^{116}$

Azobenzenes (207) are widely used as dyes in industry, and have potent applications in molecular devices. ${ }^{120-121}$ Commonly used reagents for preparation of 207 via deoxygenation of azoxybenzenes (206) include indium trichloride, zinc triflate, and copper(II) triflate. ${ }^{122} \mathrm{AlI}_{3}$ was developed as an efficient deoxygenation agent ${ }^{116}$ for syntheses of symmetrical azobenzenes in high yields (Scheme 17D). ${ }^{123}$

2-Aminobenzophenones (213), a class of synthetic intermediates for 1,4-benzodiazepines, ${ }^{124-125}$ were prepared by Lewis acid catalyzed ring opening of 2,1-benzisoxazoles (212). ${ }^{126}$ The conversions were complete within 1 hour in the presence of $\mathrm{AlI}_{3}$ and afforded 213 in high yields (Scheme 17E). ${ }^{127}$ The deoxygenationcan can be catalyzed more efficiently by TMSI $^{128}$ at room temperature in almost quantitative yields. ${ }^{129}$ 


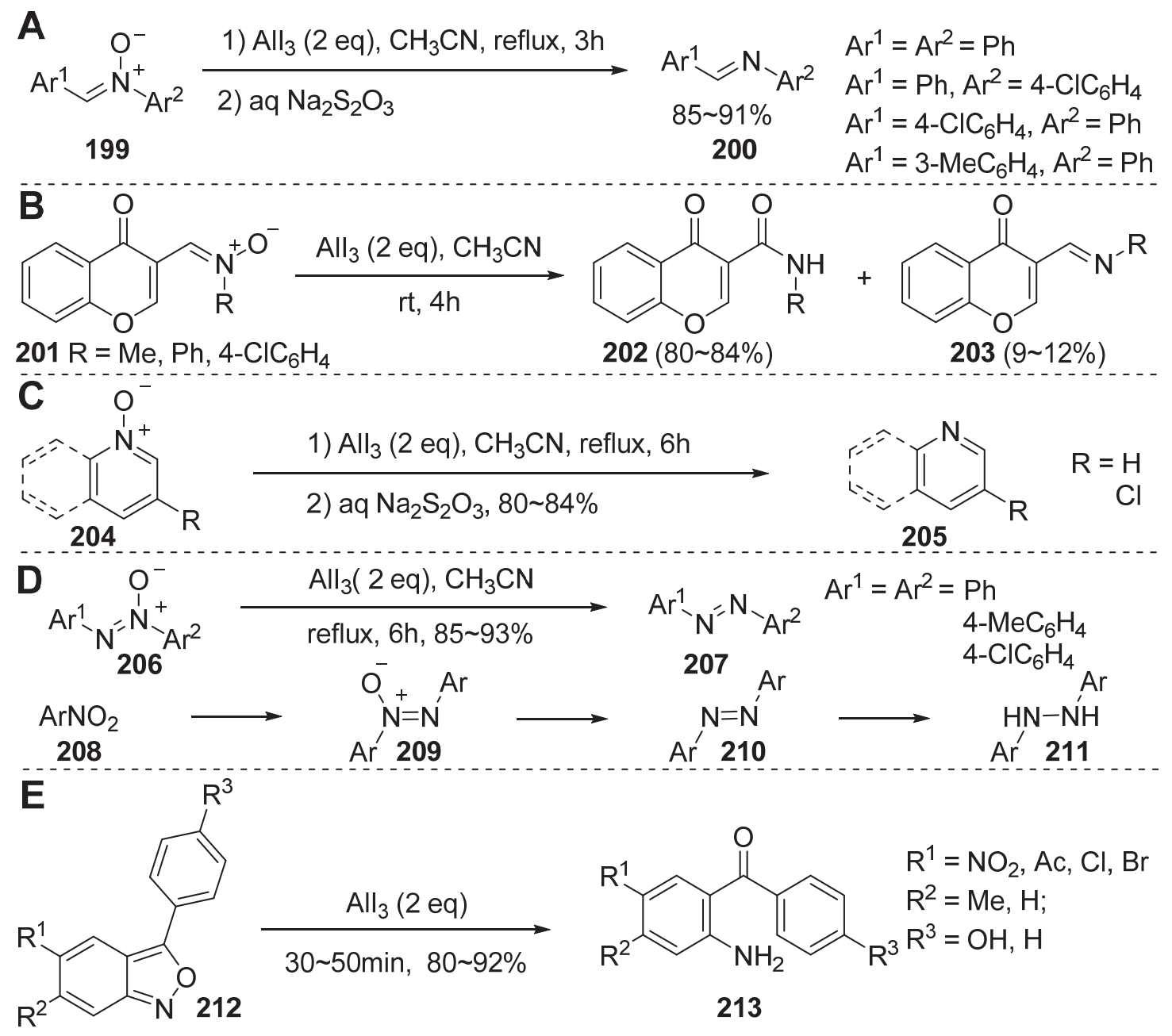

Scheme 17. $\mathrm{AlI}_{3}$ induced deoxygenation of $N$-oxides. A: $N$-arylnitrones; B: chromon-3-yl nitrone; $\mathrm{C}$ : $N$-heteroarene $N$-oxides; D: azoxybenzenes; E: preparation of 2-aminobenzophenone from 2,1benzisoxazole.

\section{Iodination}

\subsection{Halide exchange reaction}

The halide exchange between $\mathrm{AlI}_{3}$ and alkyl halides is known as the Gustavson method. ${ }^{130}$ For example, ethyl bromide underwent iodination within 5 minutes; ${ }^{6 \mathrm{~b}}$ and saturated $\mathrm{C}_{1-4}$ alkyl iodides were prepared from aliphatic chlorides. ${ }^{131}$ A more practical method for preparation of alkyl iodides is by the use of NaI or TBAI via Finkelstein reaction. ${ }^{68}$

Ethylidine diiodide (216), a reagent suitable for the preparation of methylpropane, was made in 30\% yield by iodination of Schiff base $\mathbf{2 1 5}$ (synthesized from acetaldehyde $\mathbf{2 1 4}$ and hydrazine). 216 was alternatively prepared through $\mathrm{AlCl}_{3}$ catalyzed halide exchange between ethylidine dichloride (217) and ethyl iodide in 60\% yield (Scheme 18). ${ }^{132}$ Deuterated ethylidine diiodide (220) was 
prepared in a similar manner by chlorination of deuterated acetaldehyde (218) with phosphorus pentachloride, followed by iodination with $\mathrm{AlI}_{3}$ (2 equivalents). The agent could be further transformed into $d^{1}\left(\mathrm{R}=\mathrm{CH}_{3}\right)$ and $d^{4}\left(\mathrm{R}=\mathrm{CD}_{3}\right)$ isotopologues of $\left(\mu_{2}-\mathrm{CHCH}_{3}\right)-\mathrm{Os}_{2}(\mathrm{CO})_{8}(\mathbf{2 2 1})$ for study of ethylidine surface species on metal surfaces. ${ }^{133}$

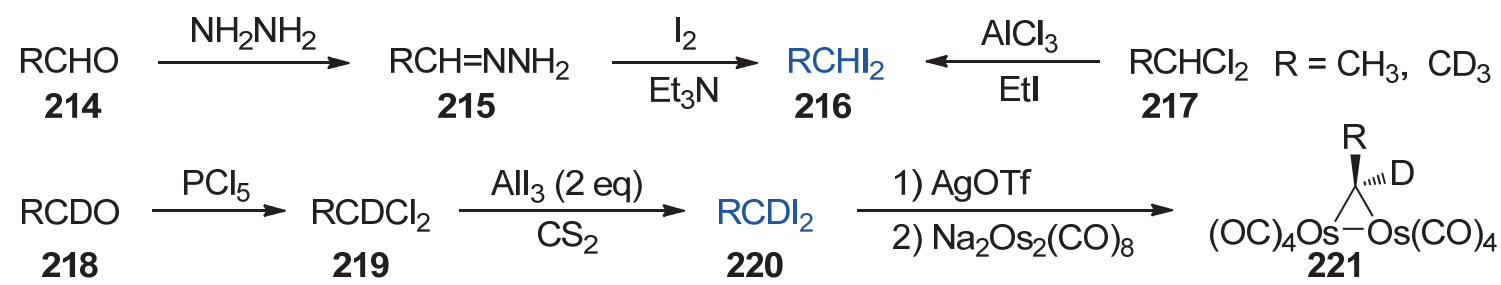

Scheme 18. Preparation of ethylidine diiodides via $\mathrm{AlI}_{3}$ catalyzed halogen exchange reactions.

Ethyl and phenyl groups attached to silicon atom can be replaced by iodine (Scheme 19). Triethyl iodosilane (225) and diethyldiiodosilane (226) can be prepared from tetraethylsilane (223) and iodine in the presence of catalytic $\mathrm{AlI}_{3}$ in moderate yields (Scheme 19A). $\mathrm{AlI}_{3}$ served as a catalyst in phenyl-iodine exchange reactions between iodine and silanes containing phenyl groups such as $\mathrm{Ph}_{2} \mathrm{SiMe}_{2}$ or $\mathrm{PhSiMe}_{3}$ (227), to give related iodosilanes (228), see Scheme 19B. ${ }^{134,135}$ This reaction is suitable for the synthesis of cyclic polydiiodosilanes $\left(\mathrm{I}_{2} \mathrm{Si}\right)_{\mathrm{n}}, \mathrm{n}=4 \sim 6 .{ }^{136,137}$

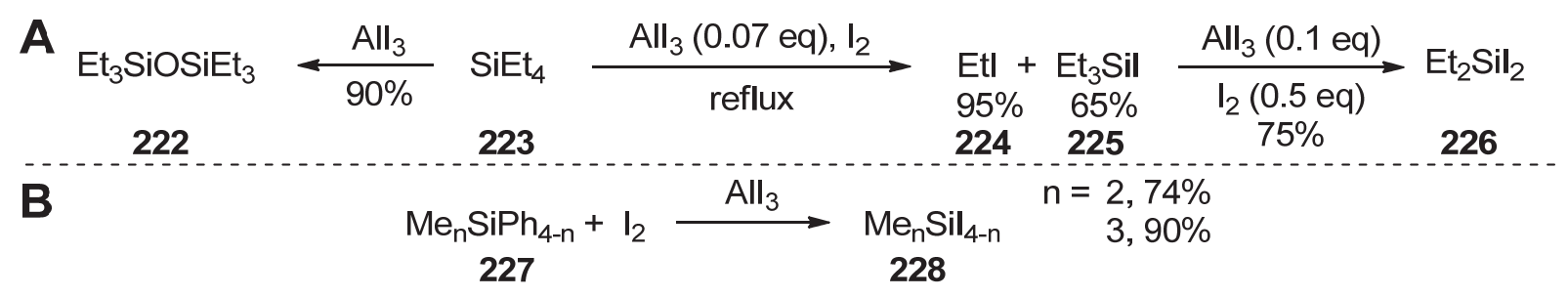

Scheme 19. $\mathrm{AlI}_{3}$ catalyzed Iodine-halogen/phenyl exchange reactions.

\subsection{Iodination of allylic, benzylic, and tertiary alcohols}

Allyl, benzyl and tert-alkyl alcohols (229) were transformed into corresponding iodides (230) by $\mathrm{AlI}_{3}$ in 5 10 minutes at room temperature in high yields (Scheme 20A). ${ }^{104}$ Intramolecular hemiacetal 231 was converted very quickly into iodoketone 233, whereas prolonged stirring led to olefin 232 (Scheme 20B). ${ }^{104}$ 


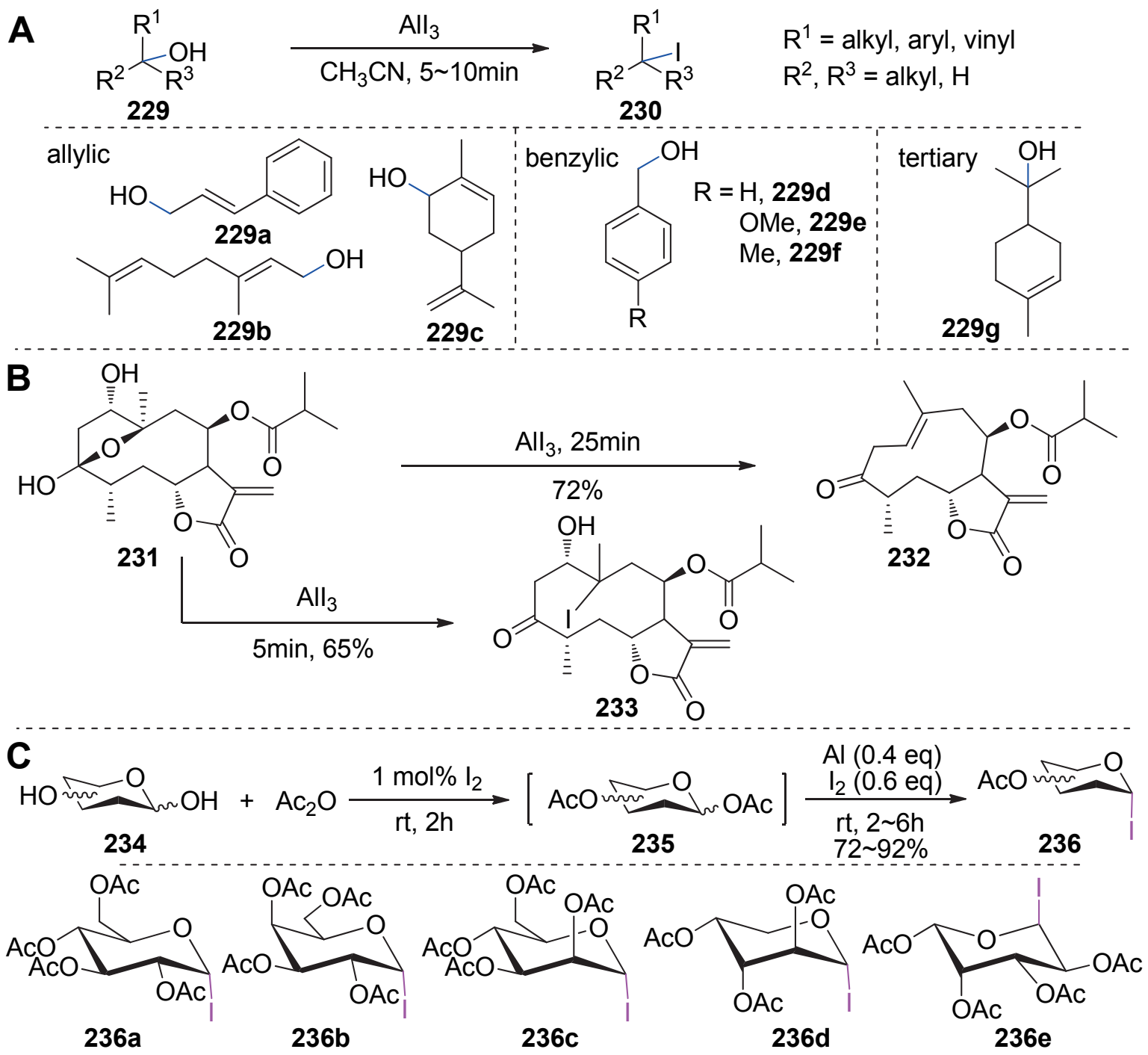

Scheme 20. Iodination of tertiary, benzoyl and allyl alcohols. A: Scope of substrates; B: iodination of an intramolecular hemiacetal; $\mathrm{C}$ : one-pot two-step preparation of O-peracetylated glycosol iodides.

Per- $O$-acetylated $\alpha$-glycosyl iodides (236), a class of anomeric intermediates useful for preparation of glycosides, ${ }^{138}$ were synthesized from unprotected reducing sugars (234) like $D$ glucose, $D$-galactose, $D$-mannose, $D$-arabinose, and $L$-fucose following a one-pot two-step sequence in moderate to high yields (Scheme 20C). ${ }^{139,140}$ Reducing sugars (234) were acetylated (235) by acetic anhydride in the presence of catalytic iodine at room temperature for 2 hours, and the resulting per- $O$-acetylated sugars were stirred with aluminum powder and iodine at ambient temperature to furnish per- $O$-acetylated glycosyl iodides (236). Other Lewis acids such as indium triiodide and cerium triiodide were also effective in preparation of such intermediates. ${ }^{141}$

\subsection{Hydroiodination of alkenes and alkynes}

Hydroiodination of alkenes or alkynes by HI afforded alkyl or alkenyl iodides. Although hydroiodic 
acid could be used directly, ${ }^{142} \mathrm{HI}$ is generally prepared in situ for yield consideration. HI generated by hydrolysis of $\mathrm{AlI}_{3}$ reacted smoothly with alkenes and alkynes, and furnished Markovnikov adducts (237 and 238) in moderate yields (Scheme 21A). ${ }^{143}$ Other reagents like KI-phosphoric acid $(95 \%)^{144}$, TMSI- $\mathrm{H}_{2} \mathrm{O}^{145}$, triphenylphosphine $\left(\mathrm{PPh}_{3}\right)-\mathrm{I}_{2}-\mathrm{H}_{2} \mathrm{O}^{146}$ and titanium(IV) iodide- $\mathrm{H}_{2} \mathrm{O}^{147}$ were also effective.

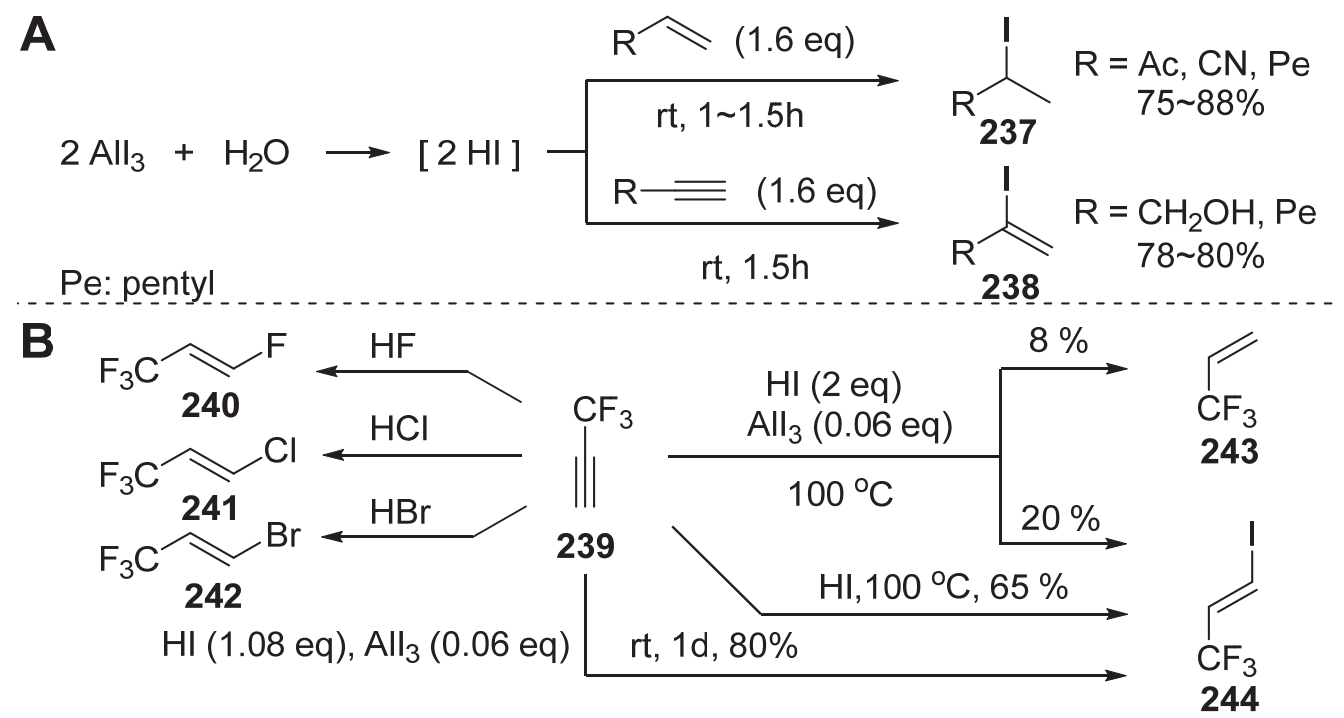

Scheme 21. $\mathrm{AlI}_{3}$ mediated hydroiodination. A: Alkenes or alkynes; B: 3,3,3-trifluoropropyne.

Anti-Markovnikov adducts (240 242, and 244) were observed during hydrohalogenations of propyne 239 with hydrohalic acids. Reactions between 239 and $\mathrm{HX}(\mathrm{X}=\mathrm{F}, \mathrm{Cl}, \mathrm{Br})$ were rapid even in the absence of catalysts such as boron trifluoride $\left(\mathrm{BF}_{3}\right), \mathrm{AlCl}_{3}$ and $\mathrm{AlBr}_{3}$. For hydroiodination, however, elevated temperature $\left(100{ }^{\circ} \mathrm{C}\right)$ was required. The conversion was improved by catalytic $\mathrm{AlI}_{3}$ and preceded at room temperature, whereas higher temperature resulted in lower yield $(20 \%)$ in concurrent with the formation of $\mathbf{2 4 3}$, see Scheme 21B. ${ }^{148}$

\subsection{Electrophilic iodination of secondary and tertiary alkanes}

$\mathrm{Cl}_{3} \mathrm{C}^{+}\left[\mathrm{Al}_{2} \mathrm{I}_{6} \mathrm{Cl}\right]^{-}$(246), a super electrophile in situ prepared by reaction of carbon tetrachloride $\left(\mathrm{CCl}_{4}\right)$ and $\mathrm{AlI}_{3}(2 \mathrm{eq})$, could abstract a hydrogen from secondary or tertiary alkanes (247) to form $\mathrm{R}^{+}\left[\mathrm{Al}_{2} \mathrm{I}_{6} \mathrm{Cl}\right]$ species (248), see Figure 9. Treating $\mathbf{2 4 8}$ with elementary iodine afforded alkyl iodides (249) in moderate to good yields. ${ }^{149}$ Another reagent combination useful for the conversion is sodium periodate-potassium iodide-sodium azide. ${ }^{150}$ 


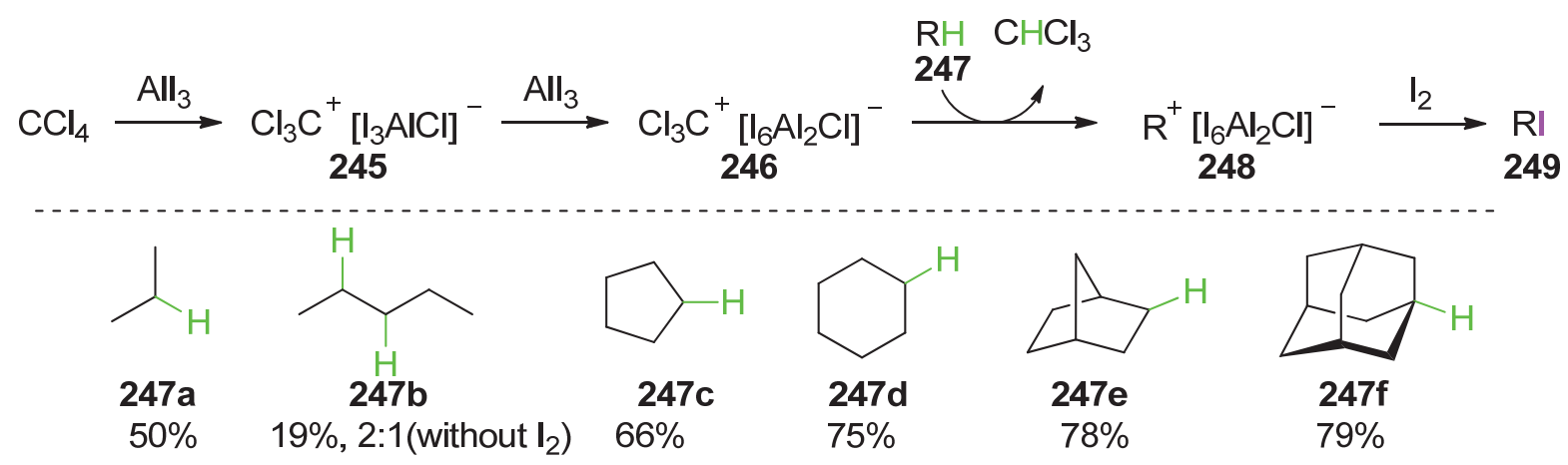

Figure 9. Scope of substrates for $\mathrm{AlI}_{3}$ catalyzed electrophilic iodination.

\section{Deprotection of Ketals}

The oxophilic nature of $\mathrm{AlI}_{3}$ was used in selective deprotection of ketals (250). Complete conversions could be achieved within 5 30 minutes in moderate to high yields (Figure 10). ${ }^{151}$

In a synthetic route to franosterol saponin (255) from diosgenin (252), a cascade transformations of spiral ketal deprotection followed by spontaneous iodination were accomplished by treating the spiral ketal 253 with $\mathrm{AlI}_{3}$ in $85 \%$ yield (Scheme 22). ${ }^{152}$

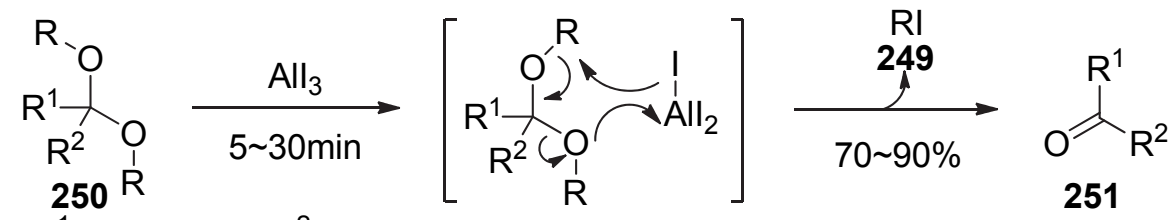

$\mathrm{R}^{1}=$ alkyl, aryl; $\mathrm{R}^{2}=\mathrm{H}$, alkyl, aryl; $\mathrm{R}=$ methyl, ethyl, or $\mathrm{R}, \mathrm{R}=$ ethylene

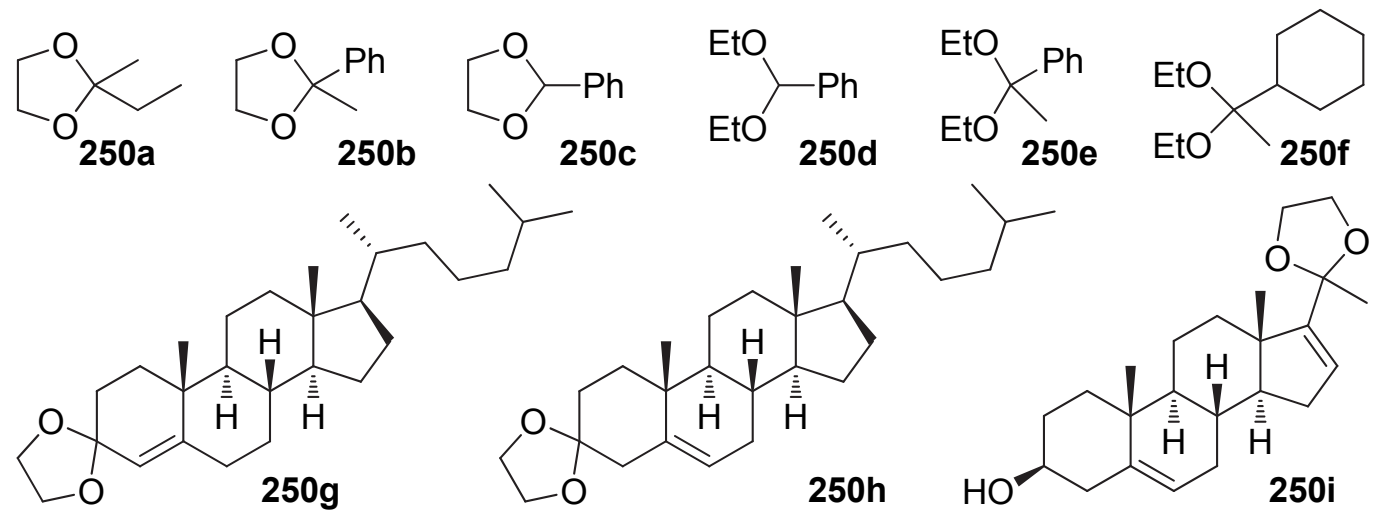

Figure 10. Scope of substrates for $\mathrm{AlI}_{3}$ catalyzed ketal deprotection. 


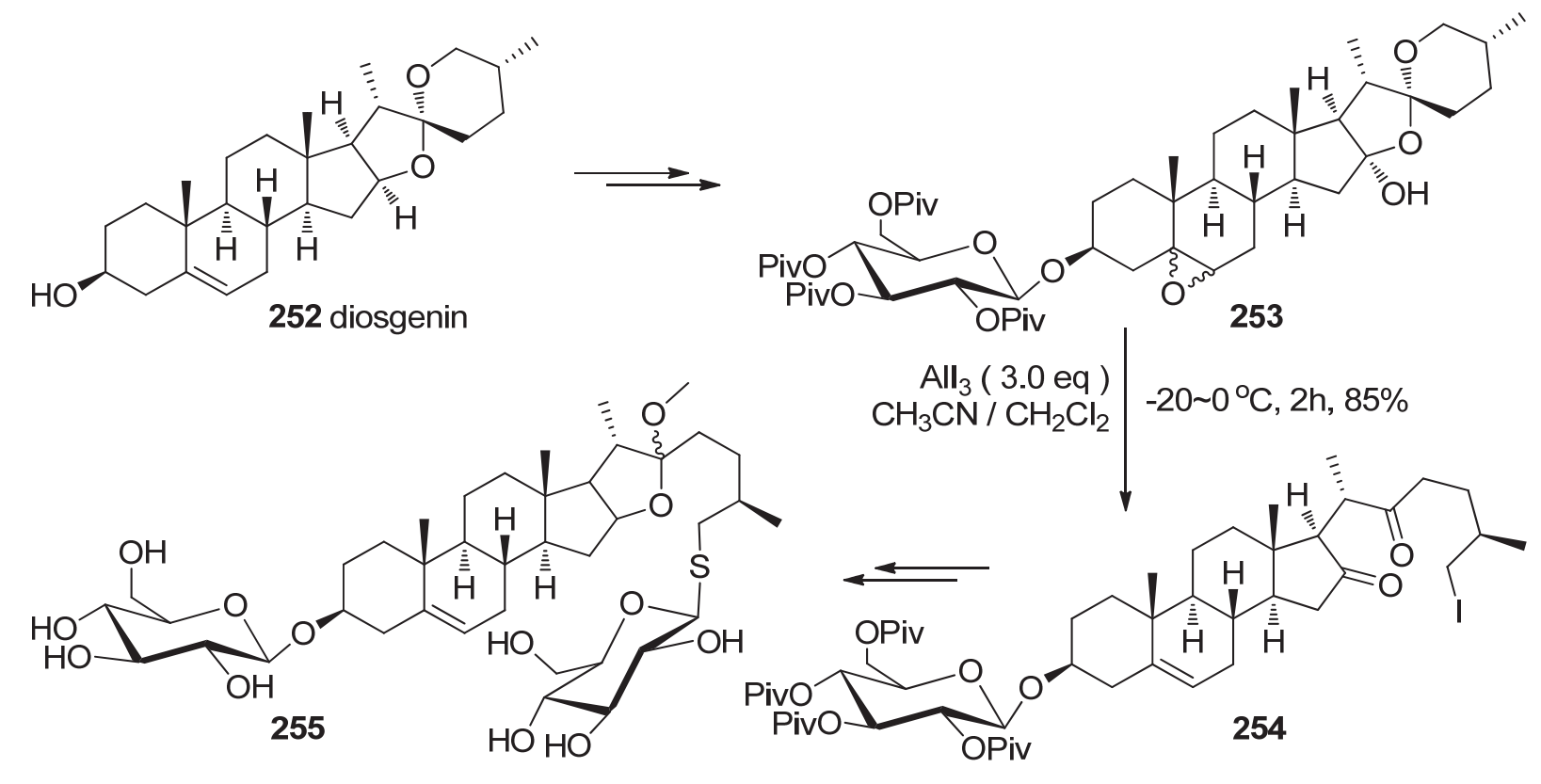

Scheme 22. Application of $\mathrm{AlI}_{3}$ in synthesis of a franosterol saponin.

\section{Reduction of Quinones}

Quinones (256) such as 1,4-benzoquinone, 1,2-benzoquinone, 1,4-naphthaquinone, and 9,10anthraquinone were reduced to corresponding hydroquinones (257) in moderate to high yields. $\mathrm{AlI}_{3}$ served as an oxophilic agent and iodide donor during the transformation (Figure 11A). Reactive species 260 could be trapped by dienophiles like $N$-methylmaleimide and fumaronitrile through Diels-Alder reaction (Figure 11B). ${ }^{153}$

\section{Reduction of Azides}

\subsection{Reduction of azides to primary amines}

Numerous methods have been developed for reduction of azides (263). Examples include reductions by $\mathrm{PPh}_{3}$ (Staudinger reaction), ${ }^{154}$ thiol, ${ }^{155} \mathrm{NaBH}_{4}-\mathrm{CoCl}_{2}-\mathrm{H}_{2} \mathrm{O}$, ${ }^{156}$ and palladium on carbon (catalytic hydrogenation). ${ }^{157,158}$ The electro-affinity character of $\mathrm{AlI}_{3}$ was used in reduction of azides (263) to afford corresponding primary amines (264) in moderate to high yields (Scheme 23A). ${ }^{159}$ Functional groups such as nitro (263c), methoxy (263e), ethoxycarbonyl (263k) and acetoxy groups (263f and 263p) remained unaffected. 
<smiles>O=C1c2ccccc2C(=O)c2ccccc21</smiles><smiles></smiles><smiles>Oc1c2ccccc2c(O)c2ccccc12</smiles>

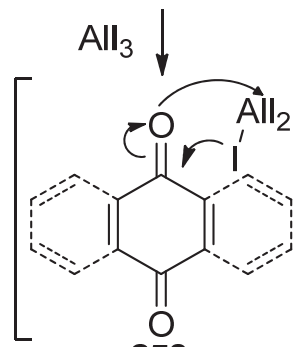
258

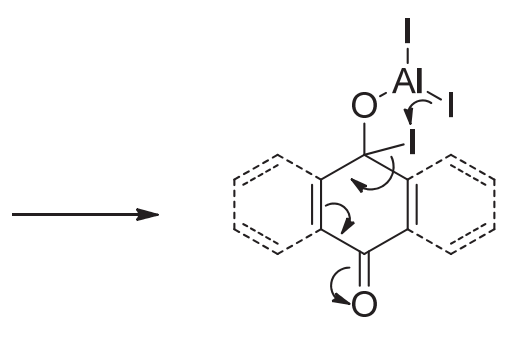

259

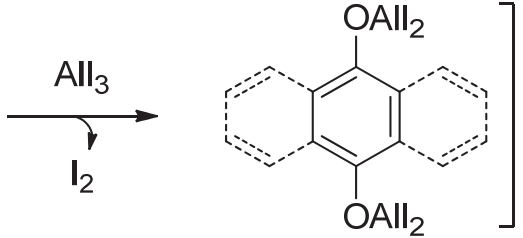

260

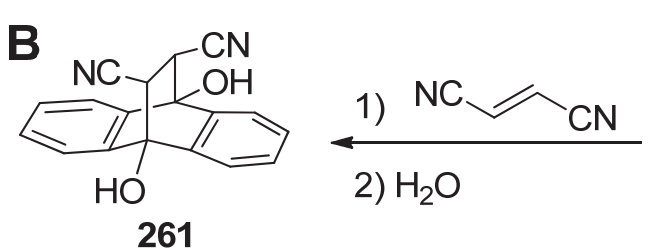

260

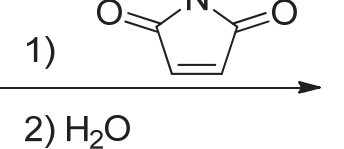

2) $\mathrm{H}_{2} \mathrm{O}$

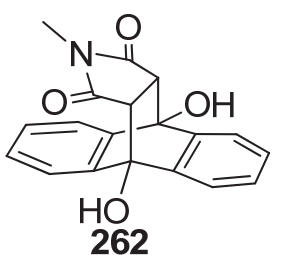

Figure 11. $\mathrm{AlI}_{3}$ catalyzed reduction of quinine. A:plausible reduction mechanism; B: trapping of reduction intermediate via Diels-Alder adduction by $N$-methylmaleimide and fumaronitrile.

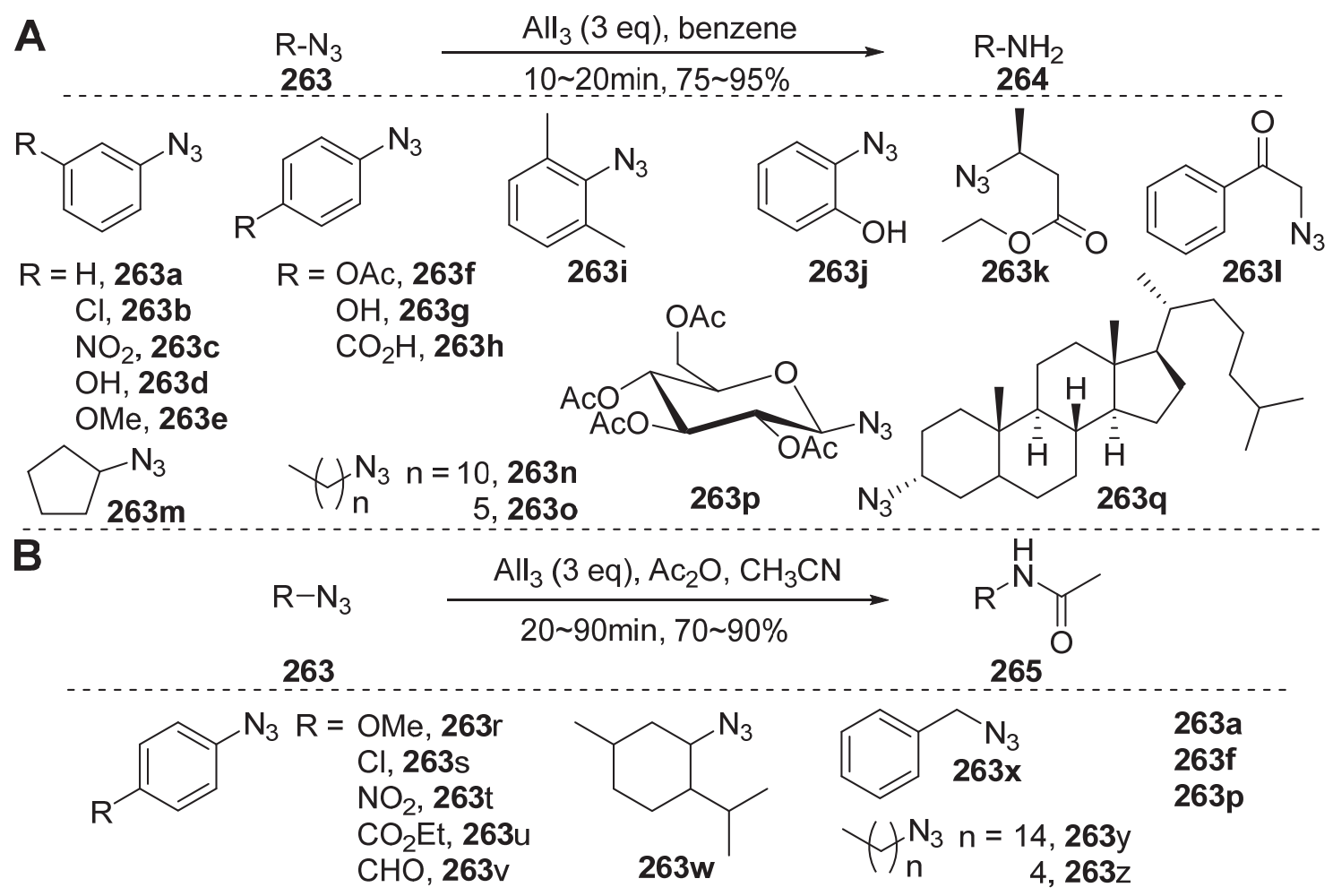

Scheme 23. $\mathrm{All}_{3}$ catalyzed reduction of azides. A: Scope of substrates for reducing to primary amine; B: Scope of substrate for reducing to secondary amine in anhydride. 


\subsection{Reduction of azides to secondary amines}

Azides (263) can also be transformed into substituted secondary amines (265). For example iminophosphorane, derived from reaction of azides and $\mathrm{PPh}_{3}$ via Staudinger reaction, could be trapped by intramolecular ester group to give a lactam, ${ }^{160}$ or a carboxylic acid activated by 2,2 'PySeSePy to give an amide. ${ }^{161}$ Capturing of iminophosphorane by MeI followed by hydrolysis led to methylamine, whereas reaction of the iminophosphorane with paraformaldehyde followed by reduction afforded mono-methylamine. ${ }^{162}$

In acetic anhydride, reduction of azides (263) by $\mathrm{AlI}_{3}$ afforded acetamide in moderate to high yields (Scheme 23B). ${ }^{163}$ It is noteworthy that methoxy (263r), acetoxy (263f, 263p), and ethoxycarbonyl (263u) groups tolerated the condition.

A plausible reaction mechanism is shown in Figure 12. The electro-affinity character of $\mathrm{AlI}_{3}$ enabled the formation of 266, concerted decomposition of $\mathbf{2 6 6}$ afforded iminoaluminane $\mathbf{2 6 7}$. Treatment of $\mathbf{2 6 7}$ with acetic anhydride led to $\mathbf{2 6 9}$. Hydrolysis of 267 and 269 afforded 264 and 265 , respectively.

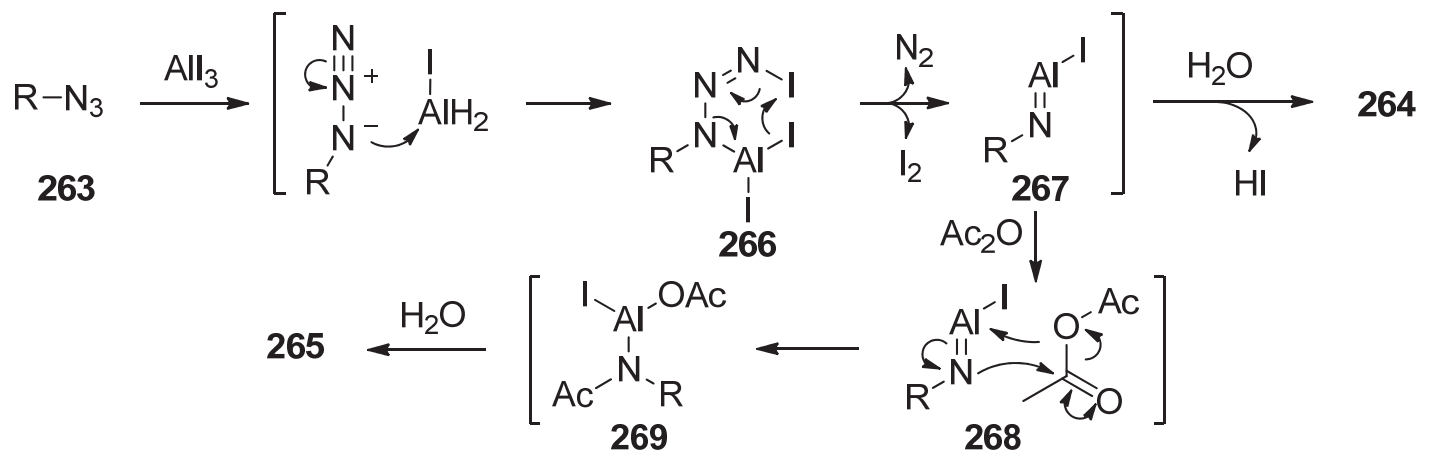

Figure 12. A plausible mechanism for $\mathrm{AlI}_{3}$ catalyzed reduction of azides.

\section{Aluminum Enolate Mediated Reactions}

\subsection{Generation of aluminum enolates}

Application of aluminum enolates in $\mathrm{C}-\mathrm{C}$ bond formation has garnered scant attention. The existence of aluminum enolate species (270), generated by $\alpha$-bromoacetophenone and $\mathrm{AlI}_{3}$, was confirmed by ${ }^{1} \mathrm{H}$ NMR spectrum; two doublet peaks ( $\delta 4.35$ and $\left.4.92 \mathrm{ppm}\right)$ were attributed to vinylic protons of $\mathbf{2 7 0}$ (Scheme 24A). Capturing of $\mathbf{2 7 0}$ by benzaldehyde via aldol condensation afforded 271. Similarly, $\alpha$-halocyclohexanone was transformed to $\mathbf{2 7 3}$ via $\mathbf{2 7 2}$. ${ }^{164}$

\subsection{Dehalogenation of $\alpha$-haloketones}

Aluminum enolates (275), prepared from $\alpha$-haloketone, were quenched by water to give corresponding ketones (276) deprived of the $\alpha$-halogen atoms, Scheme 24B. ${ }^{164}$ Alternatively, combinations of $\mathrm{NaI}$ and Lewis acids such as ferrous chloride, ferric chloride, titanium(IV) chloride, chromium(III) chloride and $\mathrm{AlCl}_{3}$ were applied in preparation of acetophenones from $\alpha$ - 
chloroacetophenones in $85 \sim 88 \%$ yields. ${ }^{165}$ It was discovered that sodium bromide, sodium chloride, sodium cyanate, sodium thiocyanate, sodium chlorite were also effective when used in combination with Lewis acids. ${ }^{166}$
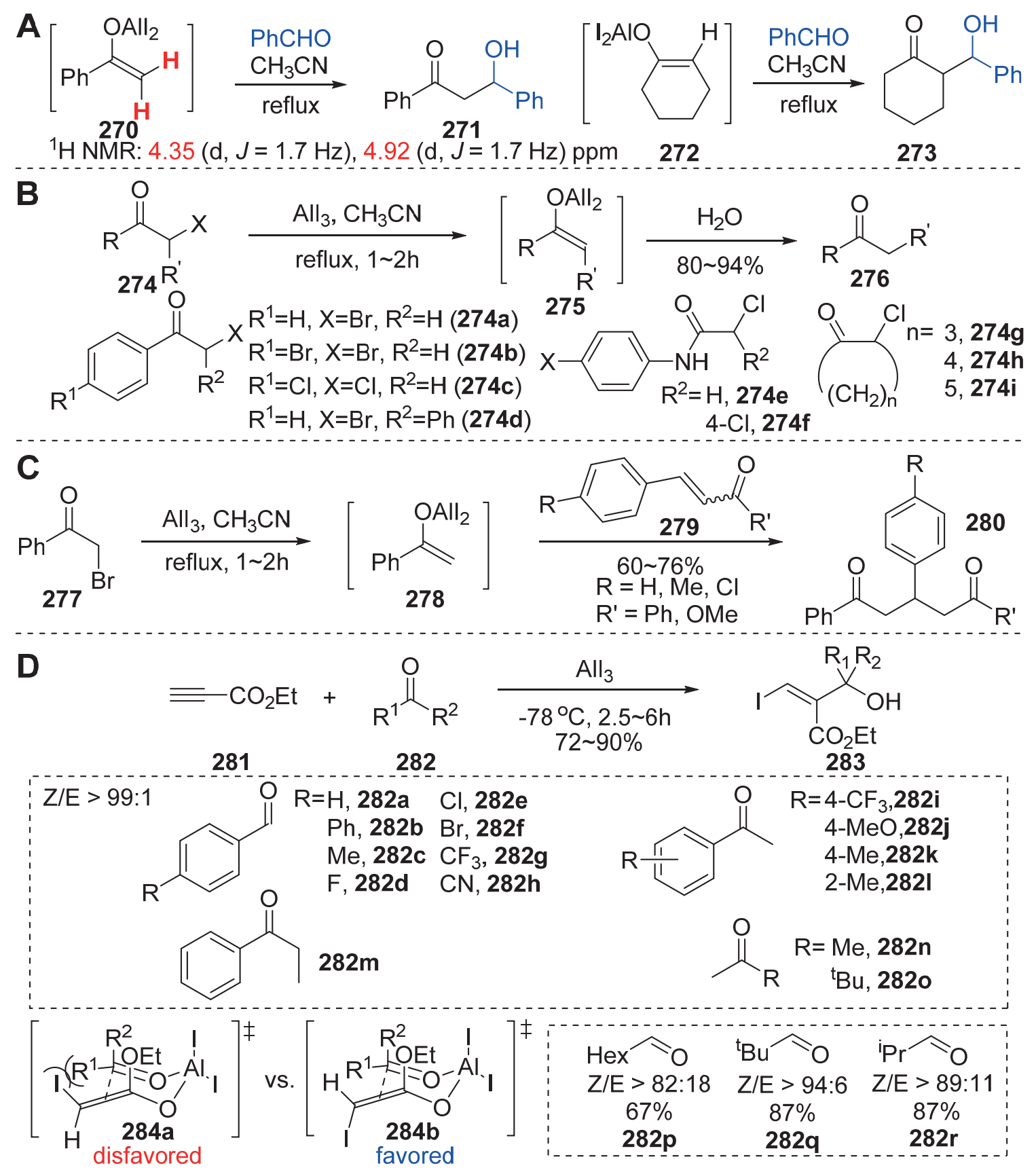

Scheme 24. Reactions of aluminum enolates. A: Existence of aluminum enolates; B: dehalogenation of $\alpha$-halocarbonyl compounds; $\mathrm{C}$ : Michael addition; D: preparation of Z- $\beta$-Iodo$\mathrm{MBH}$ esters and an explanation of the high $\mathrm{Z} / \mathrm{E}$ regioselectivity; 


\subsection{Michael addition}

Treating 277 with $\mathrm{AlI}_{3}$ afforded enolate 278 after refluxing in acetonitrile for $1 \sim 2$ hours. Capture of 278 with $\alpha, \beta$-unsaturated ketones or esters (279) via Mukaiyama-Michael addition afforded 1,4Michael adducts (280) in 60 76\% yields (Scheme 24C). ${ }^{167}$

\subsection{Preparation of Morita-Baylis-Hillman esters}

$\mathrm{AlI}_{3}$ induced Morita-Baylis-Hillman (MBH) reactions between aldehydes (282a $\left.\sim \mathbf{2 8 2} \mathbf{h}\right)$ or ketones (282i 2820) and ethyl propiolate (281) afforded $\beta$-Iodo esters (283) in high yields with high $Z$ stereoselectivity. The regioselectivity was low in the case of aliphatic aldehydes $(\mathbf{2 8 2} \mathbf{p} \sim \mathbf{2 8 2} \mathbf{r})$. The $Z / E$-stereoselectivity was attributed to steric hindrance between iodine and the substituents of carbonyl substrates. Thus transition state 284b was favored over 284a, as illustrated in Scheme 24D. ${ }^{168,169}$ Other Lewis acids effective in preparation of $\beta$-I-MBH esters include magnesium iodide, $\mathrm{TMSI}^{170}$ and $\mathrm{BF}_{3} \cdot \mathrm{Et}_{2} \mathrm{O}-\mathrm{TBAI}{ }^{171,172}$ Interestingly, $E$ - $\beta$-I-MBH esters could be achieved stereoselectively with $\mathrm{BF}_{3} \cdot \mathrm{Et}_{2} \mathrm{O}-\mathrm{TMSI}^{171}$

\subsection{Acetonitrile adduction}

In an attempted ring-opening iodination of a cylcoheptanone (285), an unexpected acetonitrile adduct (286) was obtained in 61\% yield (Figure 13a). Aluminum enolate species was possibly involved in the transformation. The tetrahydronfuran moiety remained unchanged probably due to the low reactivity of ring cleavage, whereas deficient Lewis acid $(0.95 \mathrm{eq})$ precluded further conversion. Extension of the condition to other substrates such as cyclohexanone (287) failed to give similar products except $\mathbf{2 8 8}$. $^{173}$

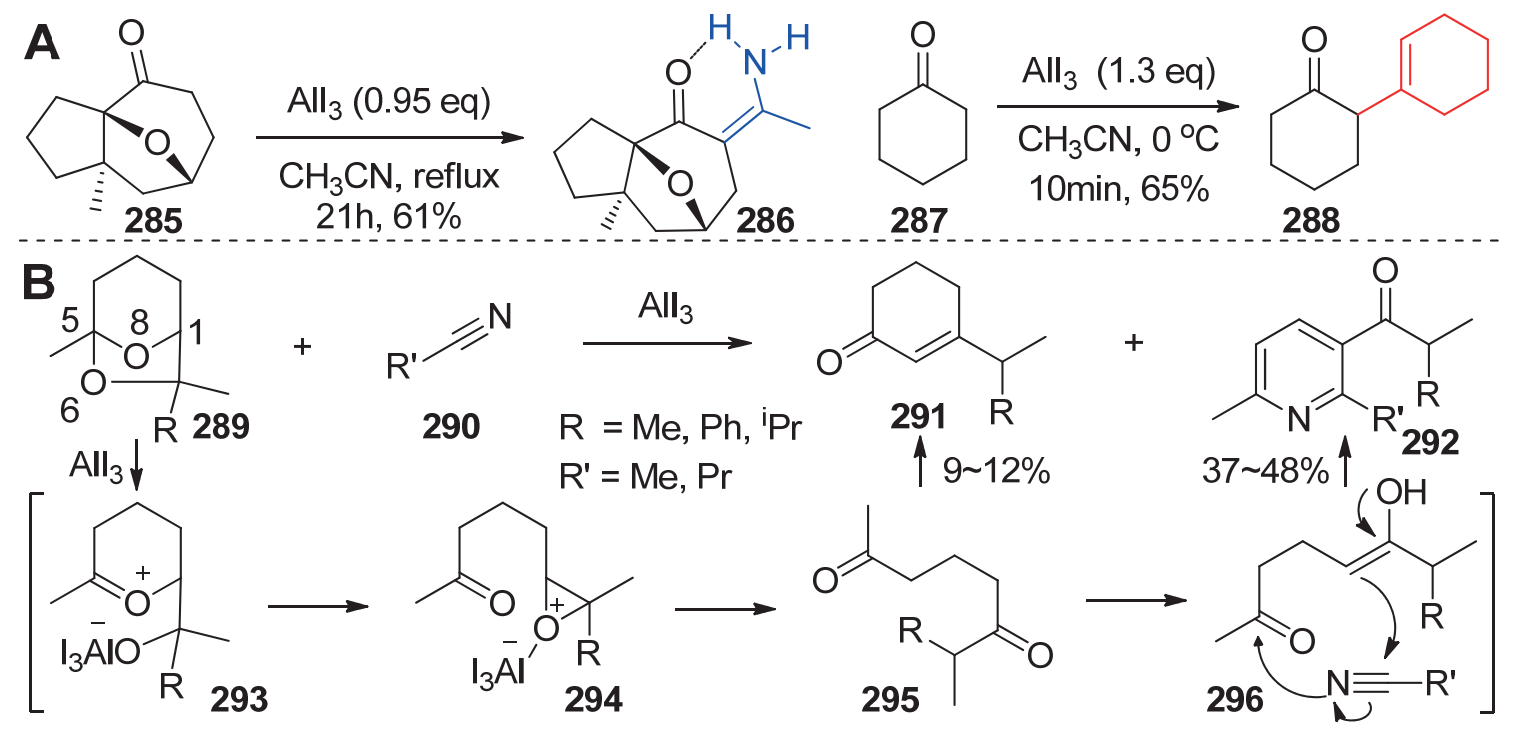

Figure 13. Unexpected adducts. A: Acetonitrile adduct; B: novel pyridine synthesis.

A similar adduct was observed during deprotection of 6,8-dioxobicyclo[3.2.1]octane 289, a bicyclic ketal, with $\mathrm{AlI}_{3}$ in acetonitrile. 2,3,6-Trisubstituted pyridine 292 was isolated as major 
product in about $40 \%$ yield along with cyclohexenone 291 in about 10\% yield. Apparently 1,5diketone $\mathbf{2 9 5}$ was the intermediate en route to the products. Aldol condensation of the 1,5-diketone afforded cyclohexenone 291. Addition of nitriles to enolate 296 of the 1,5-diketone gave pyridines (292), see Figure 13B. Other regioisomers, surprisingly, were not observed. ${ }^{174,175}$

\section{Friedel-Crafts Acylation and Alkylation}

Despite wide applications of $\mathrm{AlCl}_{3}$ and $\mathrm{BF}_{3} \cdot \mathrm{Et}_{2} \mathrm{O}$ in Friedel-Crafts acylation and alkylation, use of $\mathrm{AlI}_{3}$ usually resulted in complicated mixtures of products. For example, treatment of orcinol, resorcinol, and phlorogucinol (297) with 3-methylcrotonoyl chloride (298) in the presence of $\mathrm{AlCl}_{3}$ and oxyphosphorus chloride $\left(\mathrm{POCl}_{3}\right)$ led to related acylation product (299) or coumarins (300) in high yields even at room temperature. ${ }^{176}$ The reactions with $\mathrm{AlI}_{3}$ were sluggish, and the reaction mixtures were complex (299 302) and in low yields after refluxing in acetonitrile for $5 \mathrm{~h}$, (Scheme $25 \mathrm{~A}) .{ }^{177}$

A

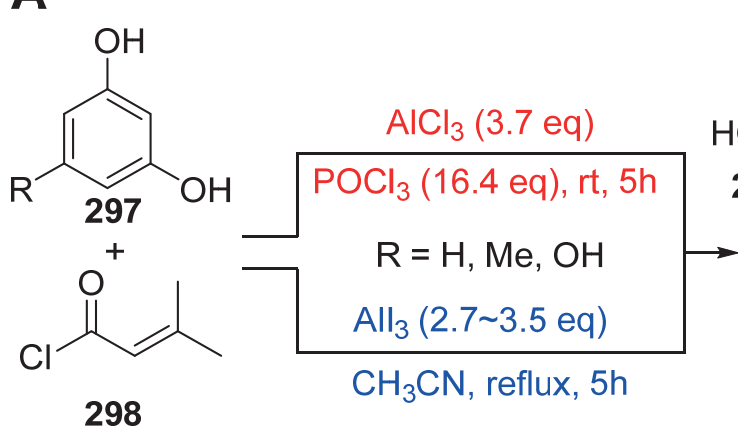<smiles>[R]c1cc(O)cc(O)c1C(=O)C=C(C)C</smiles>

$299 \mathrm{R}=\mathrm{H}, 92 \% ; 30 \%$ Me, $32 \%$

$\mathrm{HO}$<smiles>[R]c1cc(O)cc2c1C(=O)CC(C)(C)O2</smiles>

$300 \mathrm{R}=\mathrm{OH}, 86 \% ; 35 \%$

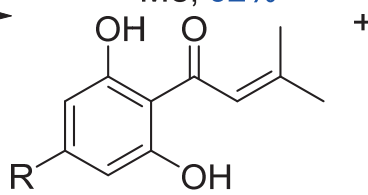

$301 \mathrm{R}=\mathrm{H}, 8 \%$
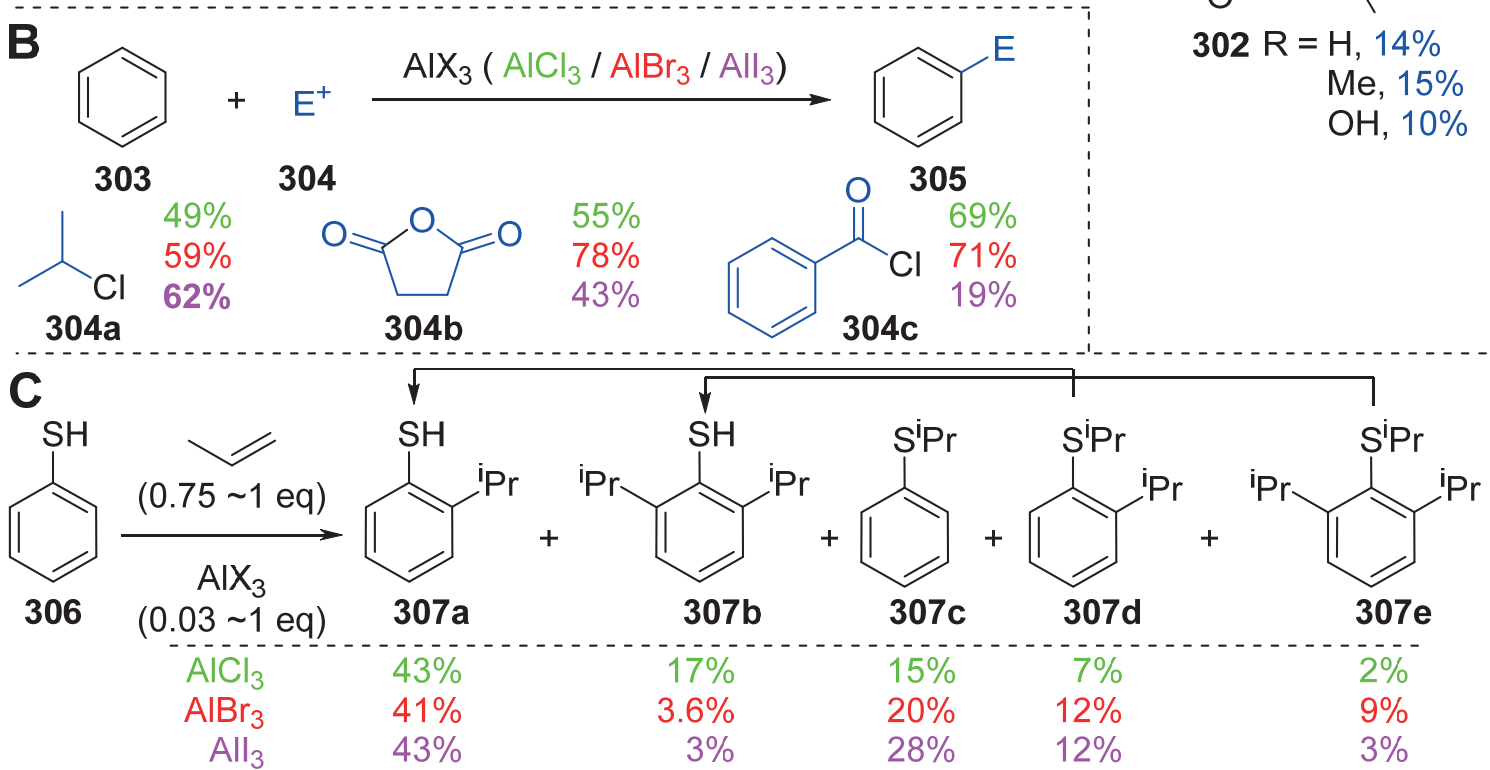

Scheme 25. $\mathrm{AlI}_{3}$ catalyzed Friedel-Crafts reactions. A: Acylation; B: comparison of catalytic efficiencies; C: syntheses of isopropylthiophenols. 
One potential use of $\mathrm{AlI}_{3}$ is the alkylation with bulky elecrophiles. Friedel-Crafts alkylation between benzene (303) and isopropyl chloride (304a) revealed a slightly higher yield when $\mathrm{AlI}_{3}$ was used as catalyst (Scheme 25B). ${ }^{178}$

In preparation of orthoalkyl thiophenols (307a and 307b) from thiophenol (306) and propene, $\mathrm{AlX}_{3}$ was selected as the alkylation catalyst. 2-Isopropylthiophenol (307a) and 2,6-dipropylthiophenol (307b) were the target products. Thiol ethers $(\mathbf{3 0 7} \sim \mathbf{3 0 7 e})$ were further transformed into the corresponding thiols. In alkylation catalyzed by $\mathrm{AlI}_{3}$, slightly higher portion of mono-alkylated products was obtained (Scheme 25C). ${ }^{179}$

\section{Miscellaneous}

\subsection{Preparation of selenocarbonyl fluorides}

Reactive selenocarbonyl fluorides (309) were prepared through $\mathrm{AlI}_{3}$ or diethylaluminum iodide $\left(\mathrm{Et}_{2} \mathrm{AlI}\right)$ induced the decomposition of $\mathrm{Hg}\left(\mathrm{SeR}_{\mathrm{F}}\right)_{2}(\mathbf{3 0 8})$ in octamethylcyclotetrasiloxan $\left(D_{4}\right)$. The products were collected by a $U$-trap cooled in liquid nitrogen in $35 \sim 45 \%$ yield. Selenocarbonyl fluoride polymerized at low temperature. Thermolysis of the colorless polymers (310) released selenocarbonyl fluoride monomers (309) and dimers (311 and 312), see Scheme 26A. ${ }^{180-182}$

\subsection{Triene electrocyclization}

Methylaluminum diiodide $\left(\mathrm{MeAlI}_{2}\right)$, prepared in situ with $\mathrm{AlI}_{3}$ and $\mathrm{AlMe}_{3}$, was used as an efficient catalyst in asymmetric carba-6 $\pi$ electrocyclization of triene 315 (Scheme 26B). ${ }^{183}$ The electrocyclization proceeded at $9{ }^{\circ} \mathrm{C}$ with an acceleration rate of $600\left(\mathrm{t}_{1 / 2}=7\right.$ minutes $)$ compared to thermocyclization that occurs at $52{ }^{\circ} \mathrm{C}$.

\subsection{Preparation of a perfluorophthalocyanine}

Perfluorophthalocyanine (318), a pigment of photoelectronic importance, was prepared by heating perfluorinated $o$-phthalonitrile (317) with catalytic $\mathrm{AlI}_{3}$ at elevated temperatures (Scheme 26C). ${ }^{184}$

\subsection{Formation of frustrated Lewis pairs with hindered Lewis bases}

Coordination of $\mathrm{AlI}_{3}$ to Lewis bases affords frustrated Lewis pairs (FLP) with hindered ligands such as $\left(\mathrm{Mes}_{3} \mathrm{P}\right) \mathrm{AlX}_{3}(\mathbf{3 2 2}, \mathrm{Mes}=2,4,6$-trimethylphenyl). The FLPs were found useful for activation of greenhouse gas carbon dioxide $\left(\mathrm{CO}_{2}\right)$, hydrogen gas $\left(\mathrm{H}_{2}\right)$, and olefins (Scheme 26D). ${ }^{185-188}$ Reaction of 322 with $\mathrm{CO}_{2}$ afforded 320 and carbon monoxide $(\mathrm{CO})$ via 323 and $\mathbf{3 2 4} . \mathrm{H}_{2}$ can be activated by 319 and $\mathrm{AlI}_{3}$ to give 325. Reaction of 325 with olefins afforded 326, and aqueous work-up of $\mathbf{3 2 6}$ gave the corresponding alkane (327). Reactions of ethylene and propene with $\mathbf{3 1 9}$ and $\mathrm{AlI}_{3}$ afforded 329 and 332, respectively. 

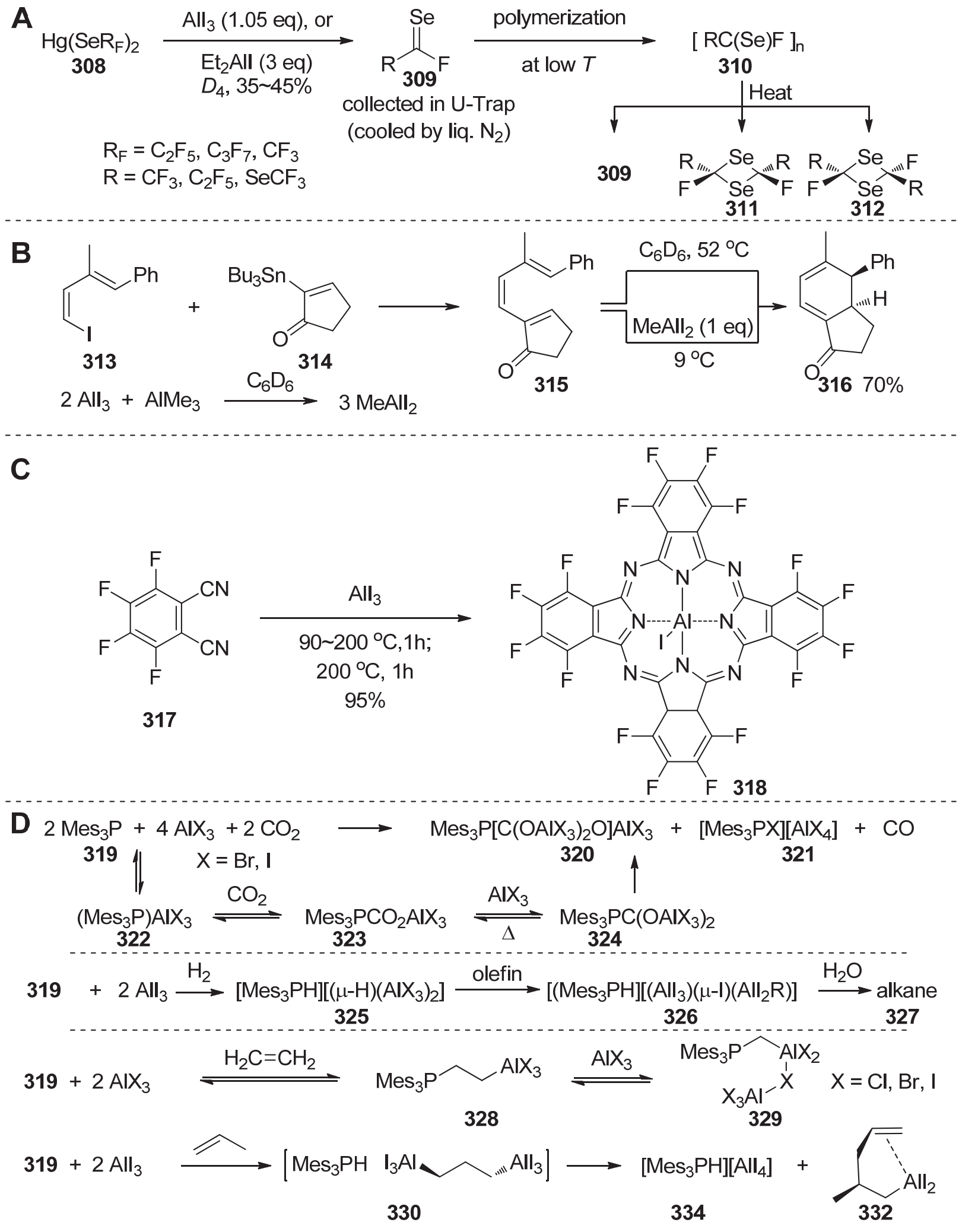

Scheme 26. Other applications of $\mathrm{AlI}_{3}$. A: Preparation of selenocarbonyl fluoride; B: triene electrocyclization; $\mathrm{C}$ : synthesis of perfluorophthalocyanine; $\mathrm{D}$ : potential of frustrated Lewis pair $\left(\mathrm{Mes}_{3} \mathrm{P}\right)\left(\mathrm{AlI}_{3}\right)$ in activation of $\mathrm{CO}_{2}, \mathrm{H}_{2}$, and olefins (ethylene and propylene). 


\section{Preparation of the Reagent}

For general application in organic synthesis, $\mathrm{AlI}_{3}$ can be prepared in situ. Colorless $\mathrm{AlI}_{3}$ crystal is available by reacting aluminum and iodine in hexane or by reacting aluminum with sublimed iodine in a vitreous pipe at $500 \sim 525^{\circ} \mathrm{C} .{ }^{189}$

\subsection{In situ preparation of $\mathrm{AlI}_{3}$}

A mixture of aluminum powder or foil $(250 \mathrm{mg}, 9.3 \mathrm{mmol})$ and elementary iodine (1.9 g, $15 \mathrm{mmol})$ were mixed in an inert solvent (benzene, toluene, acetonitrile, carbon disulfide, or cyclohexane, 8 $\mathrm{ml}$ ). The mixture was stirred under reflux for about $3 \mathrm{~h}$, till the purple color of iodine faded. The solution can be used directly without further purification. ${ }^{25}$

\subsection{Preparation of crystalline $\mathrm{AlI}_{3}$}

To a stirred mixture of aluminum foil $(3 \mathrm{mmol}, 0.1 \mathrm{~mm}$ thick) in hexane $(100 \mathrm{ml})$ was added elementary iodine $(4.5 \mathrm{mmol})$. Then the mixture was refluxed under slow argon flush for 1 hour until the purple color faded. Unreacted metal was filtered off while hot. After cooling to room temperature, colorless crystals precipitated and were collected, yield $96 \%$, mp $191{ }^{\circ} \mathrm{C} .{ }^{190}$

\section{Conclusions}

$\mathrm{AlI}_{3}$ is a strong Lewis acid and iodide source. Its unique oxophilicity has been widely and extensively applied in deoxygenation and deoxydehydration of a broad range of substrates such as oxiranes, diols, sulfoxides, sulfonyl chlorides, oximes, $N$-arylnitrones azoxyarenes, and $N$ heteroarene $N$-oxides. It can be used in generation of aluminum enolates from $\alpha$-haloketones which in turn can be quenched with water to afford dehalogenated products, or be captured by $\alpha, \beta-$ unsaturated ketone affording Michael addition products. $\mathrm{AlI}_{3}$ also serves as a precursor of $\mathrm{HI}$ in hydroiodination of alkenes or alkynes. Generally $\mathrm{AlI}_{3}$ is not suitable for application in FriedelCrafts reactions due to its unique oxophilicity and electroaffinity character. Among the broad range of other synthetic applications, ether cleavage and ester cleavage have been frequently applied in synthesis. Non-hydrolitic ester cleavage is suitable for substrates sensitive to strong acidic or basic conditions. Efficient demethylation of alkyl aryl ethers has made $\mathrm{AlI}_{3}$ an ideal alternative to $\mathrm{BBr}_{3}$.

\section{Acknowledgements}

The financial support from open project program of Hubei Key Laboratory of Drug Synthesis and Optimization, Jingchu University of Technology (No. OPP2015YB03) is acknowledged. 


\section{References}

1. Gugelchuk, M. In Encyclopedia of Reagents for Organic Synthesis; Paquette, L. A. Ed.; Wiley: Chichester, 1995; Vol. 1, P164. http://dx.doi.org/10.1002/047084289X.ra083

2. Hargittai, M.; Reffy, B.; Kolonits, M. J. Phy. Chem. A 2006, 110, 3770-3777. http://dx.doi.org/10.1021/jp056498e

3. Kumar, P. P.; Maiya, B. G. New J. Chem. 2003, 27, 619-625. http://dx.doi.org/10.1039/B208339F

4. Satchell, P. N.; Satchell, R. S. Chem. Rev. 1969, 69, 251-278. http://dx.doi.org/10.1021/cr60259a001

5. Ghadwal, R. S.; Roesky, H. W.; Herbst-Irmer, R.; Jones, P. G. Z. Anorg. Allg. Chem. 2009, 635, 431-433.

http://dx.doi.org/10.1002/zaac.200801350

6. Ogren, P. J.; Steenhoek, L.; Greve, K. S.; Hutton, W. C. J. Inorg. Nucl. Chem. 1975, 37, 293295.

http://dx.doi.org/10.1016/0022-1902(75)80176-X

7. Ogren, P. J.; Cannon, J. P.; Smith, C. F. J. Phys. Chem. 1971, 75, 282-284; http://dx.doi.org/10.1021/j100672a017

8. Arnáiz, F. J.; Bustillo, J. M.; Sanz, R. Synth. Reac. Inorg. Met.-Org. Chem. 1994, 24, 525-532. http://dx.doi.org/10.1080/00945719408000130

9. Mahajan, A. R.; Dutta, D. K.; Boruah, R. C.; Sandhu, J. S. Tetrahedron Lett. 1990, 31, 39433944.

http://dx.doi.org/10.1016/S0040-4039(00)97513-0

10. Nicolaou, K. C.; Estrada, A. A.; Zak, M.; Lee, S. H.; Safina, B. S. Angew. Chem. Int. Ed. 2005, 44, 1378-1382.

http://dx.doi.org/10.1002/anie.200462207

11. Giovanni, M. C. D.; Misiti, D.; Villani, C.; Zappia, G. Tetrahedron Asym. 1996, 7, 2277-2286. http://dx.doi.org/10.1016/0957-4166(96)00282-0

12. Bartlett, P. A.; Johnson, W. S. Tetrahedron Lett. 1970, 11, 4459-4462. http://dx.doi.org/10.1016/S0040-4039(01)83950-2

13. Mattsson, S.; Dahlstrom, M.; Karlsson, S. Tetrahedron Lett. 2007, 48, 2497-2499. http://dx.doi.org/10.1016/j.tetlet.2007.02.029

14. Olah, G. A.; Narang, S. C.; Gupta, B. G. B.; Malhotra, R. J. Org. Chem. 1979, 44, 1247-1251. http://dx.doi.org/10.1021/jo01322a012

15. Curotto, G.; Pellegatti, M.; Polinelli, S. U. S. Pat. 5733 867, 1998.

16. Curotto, G.; Pellegatti, M.; Polinelli, S. PCT Int. Appl. 03 284, 1995.

17. Ursini, A.; Capelli, A. M.; Carr, R. A. E.; Cassara, P.; Corsi, M.; Curcuruto,O.; Curotto, G.; Cin, M. D.; Davalli, S.; Donati, D.; Feriani, A.; Finch, H.; Finizia, G.; Gaviraghi, G.; Marien, M.; Pentassuglia, G.; Polinelli, S.; Ratti, E.; Reggiani, A.; Tarzia, G.; Tedesco, G.; Tranquillini, M. E.; Trist, D. G.; Van Amsterdam, F. T. M. J. Med. Chem. 2000, 43, 3596-3613. 


\section{http://dx.doi.org/10.1021/jm990967h}

18. Chu, X. J.; Ding, Q. J.; Jiang, N.; Liu, J. J.; Ross, T. M.; Zhang, Z. M. U. S. Pat. 65 210, 2012

19. Arrachart, G.; Karatchevtseva, I.; Cassidy, D. J.; Triani, G.; Bartlett, J. R.; Wong, M. C. M. J. Mat. Chem. 2008, 18, 3643-3649.

http://dx.doi.org/10.1039/B803100B

20. Mincione, E. Ric. Sci. 1969, 39, 424-427.

21. Cabiddu, S.; Gelli, G.; Maccioni, A.; Secci, M. Ann. Chim. 1972, 62, 505-512.

22. Robertson, A.; Waters, R. B. J. Chem. Soc. 1933, 83-86. http://dx.doi.org/10.1039/JR9330000083

23. Grethe, G.; Toome, V.; Lee, H. L.; Uskokovic, M.; Brossi, A. J. Org. Chem. 1968, 33, 504508.

http://dx.doi.org/10.1021/jo01266a005

24. Buu-Hoi, N. P.; Lavit, D. J. Org. Chem. 1956, 21, 21-23.

http://dx.doi.org/10.1021/jo01107a003

25. Bhatt, M. V.; Babu, J. R. Tetrahedron Lett. 1984, 25, 3497-3500.

http://dx.doi.org/10.1016/S0040-4039(01)91058-5

26. Bhatt, M. V.; Kulkarni, S. U. Synthesis 1983, 249-282.

http://dx.doi.org/10.1055/s-1983-30301

27. Suehiro, I. R.; Ueno, H. Jpn. Pat. 9059 202, 1997.

28. Tan, L. S.; Venkatasubramanian, N. Synth. Commun. 1995, 25, 2189-2195. http://dx.doi.org/10.1080/00397919508015900

29. Tan, L. S.; Venkatasubramanian, N. U. S. Pat. 5616 765, 1997.

30. Goldman, A. S.; Brookhart, M.; Roy, A. H.; Ahuja, R.; Huang, Z. U. S. Pat. 7902 417, 2011.

31. Jarman, M.; Barrie, S. E.; Deadman, J. J.; Houghton, J.; McCague, R.; Rowlands, M. G. J. Med. Chem. 1990, 33, 2452-2455.

http://dx.doi.org/10.1021/jm00171a019

32. Roberts, K.; Ursini, A.; Barnaby, R.; Cassarà, P. G.; Corsi, M.; Curotto, G.; Donati, D.; Feriani, A.; Finizia, G.; Marchioro, C.; Niccolai, D.; Oliosi, B.; Polinelli, S.; Ratti, E.; Reggiani, A.; Tedesco, G.; Tranquillini, M. E.; Trist, D. G.; van Amsterdam, F. T. M. Bioorg. Med. Chem. 2011, 19, 4257-4273.

http://dx.doi.org/10.1016/j.bmc.2011.05.057

33. Swanson, S. A.; Wallraff, G. M. U. S. Pat. 12 748, 2002.

34. Zehnter, R.; Gerlach, H. Liebigs Ann. 1995, 2209-2220. http://dx.doi.org/10.1002/jlac.1995199512307

35. Wang, D. X.; Liang, X. T. Acta Chim. Sin. 1986, 44, 692-694.

36. Wang, X. C.; Pan, X. F.; Ge, X. M.; Zhang, G. C. Chin. J. Org. Chem. 1993, 13, 149-152.

37. Ogata, T.; Okamoto, I.; Doi, H.; Kotani, E.; Takeya, T. Tetrahedron Lett. 2003, 44, 2041-2044. http://dx.doi.org/10.1016/S0040-4039(03)00213-2

38. Owton, W. M. J. Chem. Soc. Perkin Trans. 1 1999, 2409-2420. http://dx.doi.org/10.1039/A707426C

39. Praly, J. P.; He, L.; Qin, B. B.; Tanoh, M.; Chen, G. R. Tetrahedron Lett. 2005, 46, 7081-7085. 
http://dx.doi.org/10.1016/j.tetlet.2005.07.125

40. Takeya, T.; Kajiyama, M.; Nakamura, C.; Tobinaga, S. Chem. Pharm. Bull. 1998, 46, 16601661.

41. Li, G. X.; Zou, Y.; Zhang, X. J. J. Chem. Res. 2007, 657-659.

http://dx.doi.org/10.3184/030823407X266234

42. Sun, H. Y.; Xiao, C. F.; Cai, Y. C.; Chen, Y.; Wei, W.; Liu, X. K.; Lv, Z. L.; Zou, Y. Chem. Pharm. Bull. 2010, 58, 1492-1496.

43. Zou, Y.; Li, G. X.; Zhang, X. J.; Wei, W.; Lin, H. Z. Chin. Pat. 101066 912, 2010.

44. Feng, Y. B.; Wang, L.; Zhao, Z. Z. Chin. Chem. Lett. 1998, 9, 1003-1004.

45. Ding, L. G. Master thesis, Jinan Univ. 2007, Ch6, P38.

46. Yan, R. A.; Ding, L. G.; Feng, J. L.; Fu, Y. P. Chin. Pat. 100360 489, 2006.

47. Yan, R. A.; Ding, L. G.; Feng, J. L.; Fu, Y. P. Chin. Pat. 1907 931, 2007.

48. Wang, H. J. Ph. D. Thesis, Peking Union Med. Col. 1989, Ch2, P14.

49. Illuminati, G.; Gilman, H. J. Am. Chem. Soc. 1949, 71, 3349-3351. http://dx.doi.org/10.1021/ja01178a021

50. Node, M.; Kumar, K.; Nishide, K.; Ohsugi, S.; Miyamoto, T. Tetrahedron Lett. 2001, 42, 9207-9210. http://dx.doi.org/10.1016/S0040-4039(01)02024-X

51. Zeng, Y. J.; Chen, Y. C.; Pu, G.; Yang, M.; Li, P.; Hu, L. Chin. Pat. 102863 394, 2013.

52. Cai, M. S.; Cao, X. D. Acta. Chim. Sin. 1988, 46, 887-894.

53. van Strijdonck, G. P. F.; van Haare, J. A. E. H.; Hönen, P. J. M.; van den Schoor, R. C. G. M.; Feiters, M. C.; van der Linden, J. G. M.; Steggerda, J. J.; Nolte, R. J. M. J. Chem. Soc. Dalton Trans. 1997, 449-461. http://dx.doi.org/10.1039/A602587K

54. Jones, M. F.; Myers, P. L.; Robertson, C. A.; Storer, R. Williamson, C. J. Chem. Soc. Perkin Trans. 1 1991, 2479-2484.

http://dx.doi.org/10.1039/P19910002479

55. Sicinski, R. R.; Glebocka, A.; Plum, L. A.; DeLuca, H. F. J. Med. Chem. 2007, 50, 6154-6164.

56. Sicinski, R. R.; Glebocka, A.; Plum, L. A.; DeLuca, H. F. J. Steroid Biochem. Mol. Bio. 2007, 103, 293-297.

57. DeLuca, H. F.; Sicinski, R. R.; Glebocka, A.; Plum, L. A.; Clagett-Dame, M. U. S. Pat. 238 $712,2007$.

58. Wilkinson, J. A.; Rossington, S. B.; Leonard, J.; Hussain, N. Tetrahedron Lett. 2004, 45, 5481-5483.

http://dx.doi.org/10.1016/j.tetlet.2004.05.058

59. Liu, C. J.; Lin, J.; Delucca, G. V.; Batt, D. G.; Liu, Q. J. PCT Int. Appl. 159 857, 2011.

60. Weng, W.; Zhang, Z. C.; Schlueter, J. A.; Redfern, P. C.; Curtiss, L. A.; Amine, K. J. Power Sources 2011, 196, 2171-2178.

http://dx.doi.org/10.1016/j.jpowsour.2010.09.110

61. Ramanathan, S.; Sang, D. Y.; Kumar, V.; Lemal, D. M. In Efficient Preparations of Fluorine Compounds; Roesky, H. W. Ed.; Wiley: New Jersey, 2013; Ch41, P252-255. 
http://dx.doi.org/10.1002/9781118409466.ch41

62. Ma, H. W.; Cheng, Y. J. Chromat. A 2010, 1217, 7914-7920.

http://dx.doi.org/10.1016/j.chroma.2010.10.063

63. Ma, H. W.; Zhang, L. Anal. Lett. 2011, 44, 2423-2437.

http://dx.doi.org/10.1080/00032719.2011.551853

64. Ma, H. W.; Zhao, L. G.; Hong, X. Q. Huang, X. X. Chin. Leather 2011, 40, 50-55.

65. Ma, H. W.; Zhang, D. Y.; Huang, X. X.; Li, X. W. Leather Sci. Eng. 2009, 19, 71-75.

66. Ma, H. W.; Huang, X. X. Chin. Pat. 101650 349, 2012.

67. Ma, H. W. Chin. Pat. 101655 481, 2009.

68. Finkelstein, H. Chem. Ber. 1910, 43, 1528-1532.

http://dx.doi.org/10.1002/cber.19100430257

69. Anderson, S. G. B. Synthesis 1985, 437-439.

http://dx.doi.org/10.1055/s-1985-31235

70. Anderson, S. G. B. U. S. Pat. 4695 659, 1987.

71. Cassis, R.; Fernandez, M.; Tapia, R.; Valderrama, J. A. Synth. Commun. 1987, 17, 1077-1088. http://dx.doi.org/10.1080/00397918708078789

72. Druzgala, P. U. S. Pat. 5849 788, 1998.

73. Druzgala, P.; Milner, P. G. U. S. Pat. 193 428, 2002.

74. Druzgala, P.; Milner, P. G. PCT Int. Appl. 029 018, 2001.

75. Geyer, A. G.; McClellan, W. J.; Stewart, K. D.; Weitzberg, M.; Wendt, M. D. U. S. Pat. 6258 822, 2001.

76. Deffieux, D.; Gossart, P.; Quideau, S. Tetrahedron Lett. 2014, 55, 2455-2458. http://dx.doi.org/10.1016/j.tetlet.2014.02.134

77. Kreipl, A. T.; Reid, C.; Steglich, W. Org. Lett. 2002, 4, 3287-3288. http://dx.doi.org/10.1021/o1026555b

78. Reddy, B. V. S.; Rao, R. N.; Reddy, N. S. S.; Somaiah, R.; Yadav, J. S.; Subramanyam, R. Tetrahedron Lett. 2014, 55, 1049-1051.

http://dx.doi.org/10.1016/j.tetlet.2013.12.079

79. Fukuda, T.; Fukushima, K.; Sanai, S.; Iwao, M. Bull. Chem. Soc. Jpn. 2012, 85, 133-135. http://dx.doi.org/10.1246/bcsj.20110243

80. Reddy, B. V. S.; Reddy, P. J.; Reddy, C. S. Tetrahedron Lett. 2013, 54, 5185-5187. http://dx.doi.org/10.1016/j.tetlet.2013.07.055

81. Yadav, J. S.; Thrimurtulu, N.; Gayathri, K. U.; Reddy, B. V. S.; Prasad, A. R. Synlett 2009, 790-792. http://dx.doi.org/10.1055/s-0028-1087956

82. Liang, Q. R.; Sun, Y. Q.; Yu, B. X.; She, X. G.; Pan, X. F. J. Org. Chem. 2007, 72, 9846-9849. http://dx.doi.org/10.1021/jo701885n

83. Yadav, J. S.; Vani, C. D.; Bhasker, N.; Reddy, B. V. S. ARKIVOC 2014, (v), 291-300. http://www.arkat-usa.org/get-file/51170/

84. Joarder, D. D.; Jennings, M. P. Tetrahedron Lett. 2013, 54, 3990-3992. http://dx.doi.org/10.1016/j.tetlet.2013.05.068 
85. Liang, Q. R.; Zhang, J. Y.; Quan, W. G.; Sun, Y. Q.; She, X. G.; Pan, X. F. J. Org. Chem. 2007, 72, 2694-2697.

http://dx.doi.org/10.1021/jo070159v

86. Yadav, J. S.; Thrimurtulu, N.; Gayathri, K. U.; Reddy, B. V. S.; Prasad, A. R. Tetrahedron Lett. 2008, 49, 6617-6620.

http://dx.doi.org/10.1016/j.tetlet.2008.08.096

87. Baggelaar, M. P.; Huang, Y.; Feringa, B. L.; Dekker, F. J.; Minnaard, A. J. Bioorg. Med. Chem. 2013, 21, 5271-5274.

http://dx.doi.org/10.1016/j.bmc.2013.06.024

88. Murthy, P. V.; Reddy, N. Int. Arch. Sci. Technol. 2015, 15, 1-5.

89. Yadav, J. S.; Murthy, P. V. Synthesis 2011, 2117-2124.

http://dx.doi.org/10.1055/s-0030-1260054

90. Keinan, E.; Sinha, S. C.; Sinha-Bagchi, A. J. Chem. Soc. Perkin Trans. 1 1991, 3333-3339.

http://dx.doi.org/10.1039/P19910003333

91. Taub, D.; Girotra, N. N.; Hoffsommer, R. D.; Kuo, C. H.; Slates, H. L.; Weber, S.; Wendler, N. L. Tetrahedron 1968, 24, 2443-2461. http://dx.doi.org/10.1016/S0040-4020(01)82517-5

92. Ugele, M.; Sasse, F.; Knapp, S.; Fedorov, O.; Zubriene, A.; Matulis, D.; Maier, M. E. ChemBioChem 2009, 10, 2203-2212.

http://dx.doi.org/10.1002/cbic.200900109

93. Zimmermann, T. J.; Niesen, F. H.; Pilka, E. S.; Knapp, S.; Oppermann, U.; Maier, M. E. Bioorg. Med. Chem. 2009, 17, 530-536.

http://dx.doi.org/10.1016/j.bmc.2008.11.076

94. Rink, C.; Sasse, F.; Zubriene, A.; Matulis, D.; Maier, M. E. Chem. Eur. J. 2010, 16, 1446914478.

http://dx.doi.org/10.1002/chem.201001752

95. Umbreit, M. A.; Sharpless, K. B. Org. Synth. 1981, 60, 29-31.

http://dx.doi.org/10.15227/orgsyn.060.0029

96. Sarmah, P.; Barua, N. C. Tetrahedron Lett. 1988, 29, 5815-5816.

http://dx.doi.org/10.1016/S0040-4039(00)82200-5

97. Halton, B.; Russell, S. G. G. J. Org. Chem. 1991, 56, 5553-5556.

http://dx.doi.org/10.1021/jo00019a015

98. Abdel-Sayed, A. N.; Bauer, L. Tetrahedron 1988, 44, 1873-1882.

http://dx.doi.org/10.1016/S0040-4020(01)90330-8

99. Eisch, J. J.; Liu, Z. R.; Ma, X.; Zheng G. X. J. Org. Chem. 1992, 57, 5140-5144. http://dx.doi.org/10.1021/jo00045a026

100. Hang, J. L.; Dussault, P. Steroids 2010, 75, 879-883. http://dx.doi.org/10.1016/j.steroids.2010.05.016

101. Hang, J. L. Ph. D. Thesis, 2012, UNebraska, Ch1, P16.

102. Rzegorzewski, P. G.; Oladkiewicz, I. K.; Orzycki, J. W. M.; Icinski, R. R. S. Collect. Czech. Chem. Commun. 1998, 63, 1597-1612. 
http://dx.doi.org/10.1135/cccc19981597

103. Ishmttratov, G. Y.; Kharisov, R. Y.; Yakovleva, M. P.; Muslukhov, R. R.; Galkin, E. G.; Shmakov, V. S.; Khakimova, T. V.; Tolstikov, G. A. Rus. Chem. Bull. 2000, 49, 717-721. http://dx.doi.org/10.1007/BF02495488

104. Sarmah, P.; Barua, N. C. Tetrahedron 1989, 45, 3569-3574. http://dx.doi.org/10.1016/S0040-4020(01)81035-8

105. Ren, Q. H.; Huang, Y. Z.; Ma, H.; Wang, F.; Gao, J.; Xu, J. BioResources 2013, 8, 1563-1572. http://www.ncsu.edu/bioresources/BioRes_08/BioRes_08_2_1563_Ren_HMWGW_Convers Glucose HMF Catal DMA 3407.pdf

106. Kudzin, Z. H.; kudzin, M. H.; Drabowicz, J.; Kotynski, A. ARKIVOC 2007, (vi), 112-171. http://www.arkat-usa.org/get-file/18865/

107. Palumbo, G.; Caputo, R. Synthesis 1981, 888-890. http://dx.doi.org/10.1055/s-1981-29634

108. Palumbo, G.; Parrilli, M.; Neri, O.; Ferreri. C.; Caputo, R. Tetrahedron Lett. 1982, 23, 23912394.

http://dx.doi.org/10.1016/S0040-4039(00)87350-5

109. Bhatt, M. V.; Babu, J. R. Indian J. Chem. 1988, 27B, 259-260.

110. Babu J. R. and Bhatt, M.V. Tetrahedron Lett. 1986, 27, 1073-1074. http://dx.doi.org/10.1016/S0040-4039(86)80051-X

111. Lu, J.; Li, M.; Bai, Y. J.; Hu, H. M. Chin. J. Org. Chem. 2003, 23, 277-280.

112. Lu, J.; Li, M.; Bai, Y. J.; Hu, H. M.; Ma, H. R. Synth. Reac. Inorg. Met.-Org. Chem. 2003, 33, 999-1009.

http://dx.doi.org/10.1081/SIM-120021933

113. Caputo, R.; Ferreri, C.; Palumbo, G. Tetrahedron Lett. 1986, 42, 5377-5383. http://dx.doi.org/10.1016/S0040-4039(01)01044-9

114. Chasar, D. W.; Shockcor, J. P. Phosp. Sul.1980, 8, 187-188. http://dx.doi.org/10.1080/03086648008078186

115. Konwar, D.; Eoruah, R. C.; Sandhu, J. S. Tetrahedron Lett. 1990, 31, 1063-1064. http://dx.doi.org/10.1016/S0040-4039(00)94431-9

116. Konwar, D.; Boruah, R. C.; and Sandhu, J. S. Synthesis 1990, 337-339. http://dx.doi.org/10.1055/s-1990-26871

117. Mahajan, A. R.; Boruah, R. C.; Sandhu, J. S. Chem. Ind.(London) 1990, 261-262.

118. Gaspar, A.; Reis, J.; Matos, M. J.; Uriarte, E.; Borges, F. Eur. J. Med. Chem. 2012, 54, 914918.

http://dx.doi.org/10.1016/j.ejmech.2012.05.033

119. Kumar, S.; Sain,i A.; Sandhu, J. S. Tetrahedron Lett. 2005, 46, 8737-8739. http://dx.doi.org/10.1016/j.tetlet.2005.10.047

120. Qin, C. G.; Li, Y.; Li, H. L.; Li, D. W.; Niu, W. N.; Shang, X. Y.; Xu, C. L. Chin. J. Org. Chem. 2013, 33, 444-457. http://dx.doi.org/10.6023/cjoc201209042

121. Merino, E. Chem. Soc. Rev. 2011, 40, 3835-3853. 
http://dx.doi.org/10.1039/C0CS00183J

122. Saini, A.; Kumar, S.; Sandhu, J. S. Synlett 2006, 395-398.

http://dx.doi.org/10.1055/s-2006-926269

123. Kabalka, G. W.; Varma, R. In Comprehensive Organic Synthesis; Trost, B. M.; Fleming, I. Eds.; Pergamon: Oxford, 1991; Vol. 8, P363-366.

124. Sternbach, L. H. In The Benzodiazepines; Garattini, S.; Mussini, G.; Randall, L. O. Eds.; Raven: New York, 1973; P9.

125. Coombs, R. V.; Danna, R. P.; Denzer, M.; Hardtmann, G. E.; Huegi, B.; Koletar, G.; Koleter, J.; Ott, H.; Jukiniewicz, E.; Perrine, J. W.; Takesue, E. I.; Trapold, J. H. J. Med.Chem. 1973, 16, 1237-1245.

http://dx.doi.org/10.1021/jm00269a006

126. Fan, X. S.; Zhang, Y. M. Tetrahedron Lett. 2002, 43, 7001-7003.

http://dx.doi.org/10.1016/S0040-4039(02)01583-6

127. Konwar, D.; Boruah, R. C.; Sandhu, J. S. Chem. Ind. 1989, 191-191.

128. Konwar, D.; Boruah, R. C.; Sandhu, J. S.; Baruah, J. N. Synth. Commun. 1984, 14, 1053-1058. http://dx.doi.org/10.1080/00397918408059633

129. Boruah, M.; Konwar, D. J. Chem. Res. (S) 2002, 601-603.

http://dx.doi.org/10.3184/030823402103171186

130. Gustavson, G. Compt. Rendus 1874, 78, 1126-1129.

131. Arnaiz, F. J.; Bustillo, J. M. Anal. Quim. 1986, 82C, 270-271.

132. Friederich, E. C; Falling, S. N.; Lyons, D. E. Synth. Commun. 1975, 5, 33-36. http://dx.doi.org/10.1080/00397917508063512

133. Anson, C. E.; Sheppard, N.; Powell, D. B.; Norton, J. R.; Fischer, W.; Keiter, R. L.; Johnson, B. F. G.; Lewis, J.; Bhattacharrya, A. K.; Knox, S. A. R.; Turner, M. L. J. Am. Chem. Soc.1994, 116, 3058-3062.

http://dx.doi.org/10.1021/ja00086a039

134. Eaborn, C. J. Chem. Soc. 1949, 2755-2764.

http://dx.doi.org/10.1039/JR9490002755

135. Eaborn, C. J. Chem. Soc. 1950, 3077-3089.

http://dx.doi.org/10.1039/JR9500003077

136. Hengge, E.; Kovar, D. Angew. Chem. 1981, 93, 698-701.

http://dx.doi.org/10.1002/ange.19810930822

137. Hassler, K.; Kovar, D.; Soellradl, H.; Hengge, E. Z. Anorg. Allg. Chem. 1982, 488, 27-37. http://dx.doi.org/10.1002/zaac.19824880103

138. Meloncelli, P. J.; Martin, A. D.; Lowary, T. L. Carbohydrate Res. 2009, 344, 1110-1122. http://dx.doi.org/10.1016/j.carres.2009.02.032

139. Meloncelli, P. J.; Martin, A. D.; Lowary, T. L. Carbohyd. Res. 2009, 344, 1110-1122. http://dx.doi.org/10.1016/j.carres.2009.02.032

140. Hadd, M. J.; Gervay, J. Carbohyd. Res. 1999, 320, 61-69. http://dx.doi.org/10.1016/S0008-6215(99)00146-9

141. Weng, S. S.; Li, C. L.; Liao, C. S.; Chen, T. A.; Huang, C. C.; Hung, K. T. J. Carbohyd. Chem. 
2010, 29, 429-440.

http://dx.doi.org/10.1080/07328303.2011.565894

142. Zoller, T.; Uguen, D. Tetrahedron Lett. 1998, 39, 6719-6720.

http://dx.doi.org/10.1016/S0040-4039(98)01434-8

143. Dutta, D. K.; Lekhok, K. C.; Boruah, R. C.; Sandhu, J. S. Chem. Ind. 1991, 175-175.

144. Stone, H.; Shechter, H. Org. Synth. 1951, 31, 66-67.

http://dx.doi.org/10.15227/orgsyn.031.0066

145. Irifune, S.; Kibayashi, T.; Ishii, Y.; Ogawa, M. Synthesis 1988, 366-369.

http://dx.doi.org/10.1055/s-1988-27575

146. Kawaguchi, S.; Gonda, Y.; Masuno, H.; Vu, H. T.; Yamaguchi, K.; Shinohara, H.; Sonoda, M.; Ogawa, A. Tetrahedron Lett. 2014, 55, 6779-6783 .

http://dx.doi.org/10.1016/j.tetlet.2014.10.039

147. Shimizu, M.; Toyoda, T.; Baba, T. Synlett 2005, 2516-2518.

http://dx.doi.org/10.1055/s-2005-872679

148. Haszeldine, R. N. J. Chem. Soc. 1952, 3490-3498.

http://dx.doi.org/10.1039/JR9520003490

149. Akhrem, I.; Orlinkov, A.; Vitt, S. Chistyakov, A. Tetrahedron Lett. 2002, 43, 1333-1335. http://dx.doi.org/10.1016/S0040-4039(01)02371-1

150. Chouthaiwale, P. V.; Suryavanshi, G.; Sudalai, A. Tetrahedron Lett. 2008, 49, 6401-6403. http://dx.doi.org/10.1016/j.tetlet.2008.08.071

151. Sarrnah, P.; Barua, N. C. Tetrahedron Lett. 1989, 30, 4703-4704.

http://dx.doi.org/10.1016/S0040-4039(01)80779-6

152. Li, M.; Yu, B. Chin. Pat. 133 187, 2007.

153. Dutta, D. K.; Boruah, R. C.; Sandhu, J. S. Ind. J. Chem. 1992, 31B, 780-781.

154. Ayesa, S.; Samuelsson, B.; Classon, B. Synlett 2008, 97-99. http://dx.doi.org/10.1055/s-2007-990927

155. Cartwright, I. L.; Hutchinson, D. W.; Armstrong, V. W. Nucleic Acids Res. 1976, 3, 23312339.

http://dx.doi.org/10.1093/nar/3.9.2331

156. Fringuelli, F.; Pizzo, F.; Vaccaro, L. Synthesis 2000, 646-650.

http://dx.doi.org/10.1055/s-2000-6389

157. Gartizer, T.; Selve, C.; Delpuech, J. J. Tetrahedron Lett. 1983, 24, 1609-1610. http://dx.doi.org/10.1016/S0040-4039(00)81722-0

158. Sugandhi, E. W. Ph. D. Thesis, VirginiaTech, 2007, Ch2, P54.

159. Barua, A.; Bez, G.; Harua, N. Indian J. Chem. 1999, 38B, 128-129.

160. Saxon, E.; Bertozzi, C. R. Science 2000, 287, 2007-2010. http://dx.doi.org/10.1126/science.287.5460.2007

161. Burés, J.; Martín, M.; Urpí, F.; Vilarrasa, J. J. Org. Chem. 2009, 74, 2203-2206. http://dx.doi.org/10.1021/jo802825e

162. Kato, H.; Ohmori, K.; Suzuki, K. Synlett 2001, 1003-1005.

http://dx.doi.org/10.1055/s-2001-14646 
163. Bez, G. Synth. Commun. 2002, 32, 3625-3628.

http://dx.doi.org/10.1081/SCC-120014976

164. Borah, H. N.; Boruah, R. C.; Sandhu, J. S. J. Chem. Soc. Chem. Commun. 1991, 154-155. http://dx.doi.org/10.1039/C39910000154

165. Ono, A.; Fujimoto, E.; Ueno, M. Synthesis 1986, 570-571.

http://dx.doi.org/10.1055/s-1986-31709

166. Ono, A.; Kamimura, J.; Suzuki, N. Synthesis 1987, 406-407.

http://dx.doi.org/10.1055/s-1987-27965

167. Borah, H. N.; Boruah, R. C.; Sandhu, J. S. Indian J. Chem. 1997, 36B, 384-385.

168. Lee, S. I.; Hwang, G.; Ryu, D. H. Synlett 2007, 59-62.

http://dx.doi.org/10.1055/s-2006-958421

169. Chen, Z. H. Ph. D. Thesis, UAlberta, 2011, Ch3, P216.

170. Senapati, B. K.; Hwang, G. S.; Lee, S.; Ryu, D. H. Angew. Chem. Int. Ed. 2009, 48, 43984401.

http://dx.doi.org/10.1002/anie.200900351

171. Lee, S. I.; Hwang, G. S.; Shin, S. C.; Lee, T. G.; Jo, R. H.; Ryu, D. H. Org. Lett. 2007, 9, 50875089.

http://dx.doi.org/10.1021/o1702134w

172. Ryu, D. H.; Hwang, G. S.; Kim, K. H.; Park, J. H.; Kim, H. J. PCT Int. Appl. 110 655, 2009.

173. Sammes, P. G.; Swanson, A. G.; Whitby, R. J. J. Chem. Res. (S) 1988, 162-163.

174. Jun, J. G.; Ha, T. H.; Mundy, B. P.; Cardellina II, J. H. Bull. Korean Chem. Soc. 1994, 15, 614615.

175. Jun, J. G.; Ha, T. H.; Mundy, B. P.; Bartelt, K. E.; Bain, R. S.; Cardellina II, J. H. J. Chem. Soc. Perkin Trans. 1 1994, 2643-2645.

http://dx.doi.org/10.1039/P19940002643

176. Sowmihran, D.; Prasad, K. J. R. Synthesis 1985, 545-546.

http://dx.doi.org/10.1055/s-1985-31270

177. Vijayalakshmi, C. S.; Subramanian, M.; Prasad, K. J. R. Indian J. Chem. 1990, 29B, 661-663.

178. Kline, E. R.; Campbell, B. N.; Spaeth, E. C. J. Org. Chem. 1959, 24, 1781-1783.

http://dx.doi.org/10.1021/jo01093a600

179. Lsugrt, R. J.; Pa, P. U. S. Pat. 3076 848, 1963.

180. Boese, R.; Haas, A.; Spehr, M. Chem. Ber. 1991, 124, 51-61.

http://dx.doi.org/10.1002/cber.19911240109

181. Haas, A.; Spehr, M. Chimia 1988, 42, 265-267.

182. Dunn, P. J. In Comprehensive Organic Functional Group Transformations II; Ray, J. Ed.; Elsevier, 2004; Vol. 5, Ch5.11.9, P448-450.

183. Bishop, L. M.; Roberson, R. E.; Bergman, R. G.; Trauner, D. Synthesis 2010, 2233-2244. http://dx.doi.org/10.1055/s-0029-1218812

184. Isao, O.; Hideki, I.; Osamu, K. Jpn. Pat. 63141 982, 1988.

185. Ménard, G.; Tran,L.; Stephan, D. W. Dalton Trans. 2013, 42, 13685-13691. http://dx.doi.org/10.1039/C3DT51739J 
186. Ménard, G.; Tran,L.; Stephan, D. W. Angew. Chem. Int. Ed. 2011, 50, 8396-8399; http://dx.doi.org/10.1002/anie.201103600

187. Ménard, G.; Gilbert, T. M.; Hatnean, J. A.; Kraft, A.; Krossing, I.; Stephan, D. W. Organometallics 2013, 32, 4416-4422;

http://dx.doi.org/10.1021/om400619y

188. Ménard, G.; Tran, L.; McCahill, J. S. J.; Lough, A. J.; Stephan, D. W. Organometallics 2013, 32, 6759-6763.

http://dx.doi.org/10.1021/om400222w

189. Watt, G. W.; Hall, J. L. Inorg. Syn. 1953, 4, 117-119.

http://dx.doi.org/10.1002/9780470132357.ch39

190. Gil, F. J. M.; Salgado, M. A.; Gil, J. M. Synth. React. Inorg. Met.-Org. Chem. 1986, 16, 663666.

http://dx.doi.org/10.1080/00945718608057539

\section{Authors' Biographies}

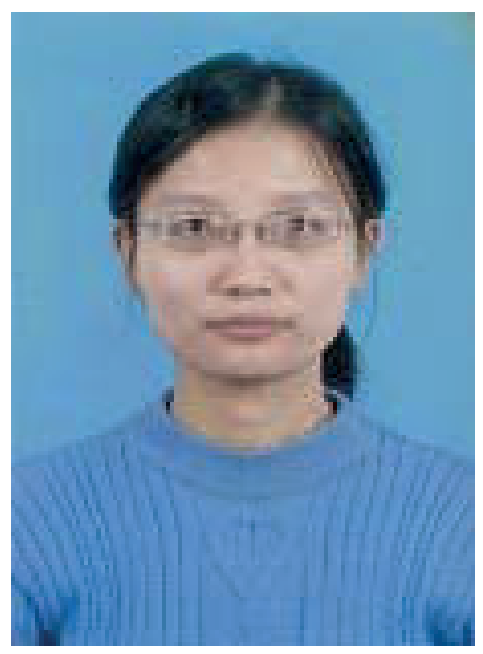

Juan Tian was born in Wuhan, China. She is presently a lecturer of Medicinal Chemistry at Jingchu University of Technology. She graduated from Jianghan University in 2000 with a B. Sc. degree, and from Hubei University in 2003 with a M. Sc. degree. She received her Ph. D. degree in 2006 from Shanghai Institute of Organic Chemistry. During 2010 and 2012 she worked as a post doctor in Shanghai Institute of Materia Medica. She has occupied teaching and research positions in Donghua University and Wuhan Institute of Bioengeering. Her research interests include the study of synthesis and reactivity of biologically important compounds and fluorinated materials, and fluorescence. 


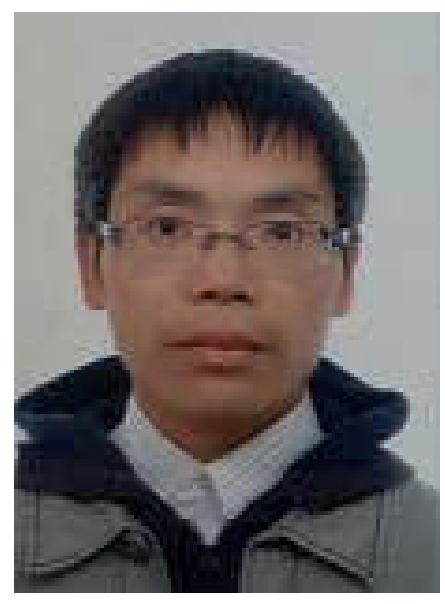

Dayong Sang was born in Anhui province, China. He received a B. Sc. in applied chemistry from Wuhan University in 2001, and a Ph. D. degree from Shanghai Institute of Organic Chemistry in 2006. He is currently a lecturer at Jingchu University of Technology. His research interests are organic synthesis and organofluorine chemistry. 